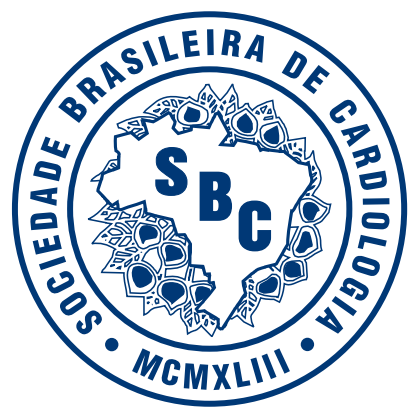

\title{
DIRETRIZES SBC RESSONÂNCIA E TOMOGRAFIA CARDIOVASCULAR
}

\section{GRUPO DE ESTUDO EM RESSONÂNCIA E TOMOGRAFIA CARDIOVASCULAR (GERT)}

\section{EDITOR}

Carlos Eduardo Rochitte

\section{Co-Editor}

Ibraim Masciarelli Francisco Pinto

\section{Editores Associados}

Juliano Lara Fernandes, Clério Francisco Azevedo Filho, Adib Jatene, Antonio Carlos de Camargo Carvalho, Jorge Pinto Ribeiro, José Antonio Franchini Ramires, Sergio Almeida Oliveira.

\section{Colaboradores}

César Augusto Mastrofrancisco Cattani, Dany Jasinowodolinsk, Fabiano Lucchesi, Fábio Berezowsky Rocha, Fátima Cristina Pedroti, Gilberto Szarf, Guilherme Urpia Monte, lugiro Roberto Kuroki , Joalbo Andrade, José Rodrigues Parga Filho, Luis Cláudio Correia, Luiz Francisco Ávila,

Marcelo Hadlich, Marcelo Zapparoli, Marcia Barbosa, Márcia Lima Mugnaini, Maria Helena Albernaz Siqueira, Marly Maria Uellendhal, Miguel Abraão Rosário Neto, Paulo R. Schwarzman,

Raul Dias dos Santos Filho, Ricardo Loureiro, Roberto Kalil Filho, Robson de Macedo Vieira.

\section{Coordenador de Normatizações e Diretrizes da SBC}

\section{Anis Rassi Jr.}

\section{REALIZAÇÃo}

Grupo de Estudos de Ressonância e Tomografia Cardiovascular (GERT) do Departamento de Cardiologia Clínica da Sociedade Brasileira de Cardiologia

Correspondência: Carlos Eduardo Rochitte - INCOR - Av. Dr. Enéas de Carvalho Aguiar, 44 - 05403-000 - São Paulo, SP E-mail: rochitte@incor.usp.br 


\section{SUMÁRıO}

A ressonância magnética cardiovascular (RMC) e a tomografia computadorizada cardiovascular (TCC) vêm tendo grande utilidade na prática clínica da cardiologia no Brasil nos últimos anos. Este documento vem consolidar o uso clínico de ambos os métodos, organizando suas principais indicações e trazendo o que há de mais atual na literatura mundial sobre o tema.

A RMC, técnica baseada no uso da radiofreqüência em tecidos submetidos a um campo magnético, não utiliza radiação ionizante ou contrastes nefrotóxicos, sendo um dos métodos de maior segurança no diagnóstico cardiovascular. Através da análise da anatomia e morfologia, função ventricular, perfusão e detecção de áreas de infarto e fibrose, o método é aplicável clinicamente num amplo espectro de doenças cardíacas. Também através de técnicas de angiografia, o método é hoje um dos mais acurados na avaliação vascular, sendo de grande valia na avaliação das doenças aórticas, de carótidas, das artérias e veias pulmonares.

Suas aplicações nas doenças cardiovasculares incluem a utilização da RMC no diagnóstico das doenças congênitas, onde a técnica se destaca sobretudo pela sua aplicação nas anomalias arteriais e venosas. Também dentro das cardiopatias congênitas a ressonância tem grande utilidade na avaliação das alterações ventriculares, além do seguimento pós-operatório de adultos com estas doenças.

A RMC também vem apresentando grande utilidade na avaliação de forma completa da doença arterial coronária, tanto em sua fase aguda como crônica. Devido sua alta resolução espacial, o método hoje pode ser considerado como um padrão de referência para avaliação da função global e regional e na detecção e quantificação de áreas de infarto do miocárdio. Isto permite à RMC grande acurácia na determinação da viabilidade miocárdica, além de permitir também uma completa avaliação de isquemia através de técnicas de perfusão em estresse, trazendo ao mesmo tempo informações diagnósticas e prognósticas.

Nas cardiomiopatias, a RMC é hoje considerada como um exame de primeira escolha para algumas doenças específicas, mas sua grande aplicabilidade está na possibilidade de realizar o diagnóstico diferencial entre as diversas etiologias que envolvem alterações do músculo cardíaco. Assim, permite a diferenciação de forma específica das cardiomiopatias isquêmicas versus não isquêmicas, além de identificar também padrões característicos de fibrose miocárdica com determinação prognóstica associada. Também consegue atualmente fazer a caracterização diagnóstica de miocardites agudas ou crônicas, permitindo o seguimento desta doença ao longo do tempo, além de caracterizar de forma muito precisa as doenças pericárdicas.
Finalmente, a RMC também já é bastante utilizada para a diferenciação das diversas massas ventriculares, permitindo a diferenciação entre diversos tipos de neoplasias e, especialmente, com a detecção de trombos ventriculares.

Por todas as aplicações principais da RMC descritas acima, o método já está disponibilizado em um grande número de centros do país, com custo similar à outras tecnologias mas permitindo a integração num único exame de diversas informações de grande valia para o cardiologista clínico.

Já a TCC é um método mais recente, mas que vem rapidamente ganhando aplicação clínica dado o seu acelerado ritmo de desenvolvimento tecnológico. A TCC é hoje realizada em tomógrafos denominados de multi-detectores (TCMD), com pelo menos 16 cortes por rotação. Este método utiliza radiação ionizante e contrastes iodados e tem sua principal aplicação clínica centrada no diagnóstico da doença coronária.

Uma de suas aplicações (que não utiliza contraste) envolve a determinação do escore de cálcio coronário (CAC). O escore de cálcio representa a extensão de doença coronária em um determinado indivíduo e deve ser utilizado em pacientes assintomáticos com risco intermediário de eventos cardiovasculares pelos fatores de risco tradicionais ou com histórico familiar de doença coronária precoce na família.

A segunda grande aplicação da TCC é sua utilização na realização de angiografias coronárias de forma não invasiva. Através da aquisição de toda árvore coronária em apenas uma pausa respiratória e com alta resolução espacial, a angiografia coronária não invasiva pela TCC vem sendo um dos principais focos de pesquisa na área de imagem cardiológica nos últimos anos. Embora ainda não possa ser rotulado como um substituto do cateterismo invasivo, o método tem aplicação clínica validada em situações de pacientes específicos onde seu alto valor preditivo negativo tem maior utilidade. Assim, as recomendações nestas diretrizes citam sua utilização em pacientes com risco intermediário de doença coronária e testes de isquemia duvidosos ou em pacientes com baixa probabilidade clínica de doença coronária mas com um teste de isquemia positivo. Além disso, também pode-se utilizar o método para avaliação da patência de enxertos cirúrgicos ou para diferenciação entre a cardiomiopatia isquêmica versus não isquêmica. 0 método ainda não deve ser utilizado indiscriminadamente em todos pacientes, especialmente em indivíduos com baixa probabilidade de doença coronária, assintomáticos ou com testes negativos ou ainda para seguimento de lesões obstrutivas encontradas em angiografias invasivas prévias.

\section{Palavras-Chave}

Imagem por ressonância magnética, tomografia, técnicas de diagnóstico cardiovascular. 


\section{INTRODUÇÃO}

Recentemente o uso da ressonância magnética e da tomografia computadorizada no diagnóstico das doenças cardiovasculares tem demonstrado um crescimento tecnológico e clínico expressivo, e, conseqüentemente, despertado um grande interesse entre cardiologistas e médicos que lidam com pacientes cardiopatas. Estes fatos, aliados à escassez de diretrizes específicas sobre o tema, tornam urgente a criação de Diretrizes da Sociedade Brasileira de Cardiologia orientando o emprego destes exames na prática clínica.

Ainda não existem diretrizes de tomografia computadorizada na literatura após a emergência da tomografia computadorizada por múltiplos detectores (TCMD) que permitiu a visualização das coronárias de forma não invasiva, acurada e com aplicabilidade clínica. A única fonte de orientação para o clínico é a Task Force American Heart Association (AHA) e American College of Cardiology (ACC) sobre a tomografia computadorizada por feixe de elétrons na abordagem do escore de cálcio ${ }^{1}$. Com relação à ressonância magnética cardiovascular (RMC), existe um Task Force europeu publicado em 1998², que foi recentemente atualizado por um Consensus Panel Report envolvendo especialistas europeus ${ }^{3}$. Contudo, diretrizes formais da ACC ou AHA ainda não foram publicadas para nenhuma das duas modalidades.

Conseqüentemente, este documento visa estabelecer normas que orientem o uso racional da TCMD e da RMC. Foi elaborado por cardiologistas e radiologistas com área de interesse nestas modalidades, e, posteriormente, analisado criticamente por clínicos e cirurgiões que já incorporaram estes exames em suas práticas clínicocirúrgicas. Assim, o documento final expressa não apenas a visão do especialista na área, mas sobretudo a sua aplicabilidade clínica.

Estas diretrizes foram elaboradas baseadas em estudos da literatura, assim como a partir da experiência de especialistas, sendo o uso diagnóstico da RMC e da TCMD descrito no contexto de outras modalidades de imagens, levando-se em conta, inclusive, a sua relação custo-benefício com as mesmas.

\section{Classificação}

O uso mais eficiente e apropriado de métodos de imagem em cardiologia é o desejo de todos profissionais que utilizam o exame, sejam especialistas ou não. Porém, apesar da forma de se indicar a adequação de métodos de imagem em comparação com outras terapias clínicas ainda ser controversa ${ }^{4}$, ainda assim sua classificação deve levar em conta os atuais conceitos de medicina baseada em evidência ${ }^{5}$. Baseado nestes aspectos e como não existe, ainda, uma classificação dos níveis de indicação para a RMC e TCMD ou grandes estudos multicêntricos e randomizados na área de imagens ${ }^{5}$, optou-se por utilizar a seguinte classificação abaixo:
Classe I: fornece informações relevantes e, geralmente, é apropriada; pode ser usada como técnica de imagem de primeira linha; geralmente substanciada por estudos que avaliam sensibilidade, especificidade, valores preditivos positivo e negativo e acurácia do método em relação a métodos diagnósticos de referência com literatura consistente e abundante e/ou opiniões concordantes.

Classe II: condições nas quais há evidência conflitante e/ou divergência de opiniões sobre a utilidade/eficácia de determinado procedimento:

Ila: O nível de evidência/opinião é a favor de sua utilização/eficácia.

Ilb: A utilização/eficácia é menos estabelecida por evidência/opinião.

Classe III: Situações onde há consenso de que o procedimento não é útil/eficaz e, em alguns casos, os riscos são maiores que os benefícios.

Deve ser notado que estas diretrizes refletem o estado da arte em 2006 e os avanços tecnológicos e experiência clínica com a RMC e a TCMD evoluem de forma bastante rápida, sendo atualizações periódicas do texto certamente necessárias.

\section{Ressonância Magnética Cardiovascular}

\section{1- Técnicas de ressonância magnética}

A ressonância magnética utiliza ondas de radiofreqüência para adquirir informações, não utilizando radiação ionizante. Apesar de alguns elementos poderem ser estudados através da ressonância magnética (como o carbono, oxigênio, sódio, potássio e flúor), na prática clínica utilizamos a avaliação relacionada ao hidrogênio pela sua abundância nos componentes do organismo humano. A ressonância do fósforo pode ser utilizada para espectroscopia, porém sua aplicação clínica na cardiologia ainda é limitada.

Uma vez dentro do aparelho de ressonância, os núcleos dos átomos de hidrogênio se alinham em relação ao campo magnético gerado pelo magneto e apresentam movimento de precessão (como um pião) em relação a este campo. A freqüência de precessão é de aproximadamente $63 \mathrm{MHz}$ para um campo magnético de 1.5 Tesla. Estes núcleos podem ser estimulados por ondas de radiofreqüência apenas nesta faixa de freqüência, o que causa deslocamento do vetor de magnetização por um determinado ângulo de rotação. Finalizado este estímulo, o vetor de magnetização apresenta movimento de precessão ao redor do campo magnético, tendendo a voltar à posição inicial de (relaxação). Enquanto houver um componente do vetor de magnetização perpendicular ao campo magnético haverá transmissão de energia na forma de onda de radiofreqüência, que pode ser captada por uma antena.

0 retorno do vetor de magnetização apresenta 2 componentes. Um deles é paralelo ao campo magnético 
gerado pelo magneto e retorna ao equilíbrio pela interação com moléculas ao redor, processo conhecido como relaxação T1. O outro componente tem orientação transversa ao campo magnético principal, o seu retorno é mais rápido, resultando da interação dos prótons e é denominada relaxação T2. As imagens de ressonância magnética podem ser ponderadas de forma a demonstrar a distribuição predominante de T1, T2 ou apenas a densidade de prótons dos diferentes tecidos. Outros campos magnéticos são acionados através de gradientes em determinados momentos para se fazer a localização da origem dos sinais emitidos pelo organismo.

Um equipamento de RMC é composto do magneto (que produz o campo magnético que deve ser estável e homogêneo, medido em Tesla), as bobinas dos gradientes com os seus amplificadores, a antena de radiofreqüência acoplada ao amplificador de radiofreqüência para estimular o paciente com os pulsos de radiofreqüência e o receptor para captar o sinal emanado pelo paciente. Um computador é necessário para controlar o equipamento e gerar as imagens, que podem ser exibidas de forma estática, dinâmica ou em reconstruções multiplanares.

Através do computador, é gerada uma seqüência de pulso, combinando pulsos de radiofreqüência e alterações do campo magnético produzidas por gradientes. As seqüências de pulso recebem nomes conforme esta combinações ocorrem: spin eco, gradiente eco, precessão livre em estado de equilíbrio e eco planar são as mais comumente utilizadas nos estudos cardiovasculares. As seqüências spin eco são geralmente utilizadas para avaliação anatômica e nelas o sangue em movimento aparece preto. As seqüências gradiente eco e precessão livre em estado de equilíbrio são geralmente utilizadas para avaliação dinâmica (cine) e nelas o sangue aparece branco. Pré-pulsos podem ser adicionados, como nas seqüências do tipo recuperação de inversão, utilizadas para avaliação de infarto/viabilidade, aonde o miocárdio normal aparece enegrecido, enquanto o infarto aparece branco e o sangue apresenta sinal intermediário. Os equipamentos atuais permitem que a aquisição das imagens se faça com períodos de apnéia de 8-20 segundos, o que minimiza artefatos de movimento. É necessária a sincronização da aquisição das imagens com o traçado eletrocardiográfico.

Outras seqüências que podem ter aplicação para o sistema cardiovascular são as técnicas de angiografia por RM (angio-RMC), em que um volume tridimensional de dados é adquirido durante apnéia apos a injeção de contraste intravenoso (baseado no gadolínio). 0 gadolínio tem a propriedade de encurtar o T1, aumentando o sinal da região aonde ele se encontra. Outras seqüências angiográficas que dispensam o uso de contraste podem ser alternativamente utilizadas. Também podem ser utilizadas seqüências rápidas (Fast Low Angle Shot, precessão livre em estado de equilíbrio e eco planar) após a injeção de um bolo de contraste intravenoso para se avaliar a perfusão de primeira passagem do contraste ao mesmo tempo em que se avalia o coração em múltiplos planos. Um outro recurso (comumente chamado de navigator) pode ser utilizado para reduzir os artefatos gerados pela movimentação respiratória e consiste em se monitorar e corrigir a imagem baseado numa interface (geralmente o diafragma), o que permite adquirir imagens de maior resolução, com o paciente respirando. As seqüências do tipo tagging podem ser utilizadas para o estudo da contratilidade do miocárdio. Nela uma grade que se deforma durante a movimentação é superimposta a imagem, o que permite o cálculo da contratilidade segmentar. Finalmente, o mapeamento de velocidade pode ser utilizado para medidas de velocidade e volume de fluxo, de maneira análoga ao Doppler.

Os estudos de RMC são seguros e não foram descritos efeitos deletérios em longo prazo. Claustrofobia pode ser um problema para uma pequena parcela dos pacientes $\left(<2.0 \%\right.$ em estudos clínicos $\left.{ }^{6}\right)$, mas usualmente é contornado com orientações pré-procedimento ou medidas simples como a utilização de ansiolíticos. É extremamente importante ressaltar que não devem ser levados a sala de exame objetos ferromagnéticos, porque estes podem ser atraídos pelo magneto e se comportar como projéteis. Implantes metálicos como próteses de quadril, válvulas cardíacas artificiais produzidas atualmente, stents e suturas metálicas no esterno não são perigosos, pois o material utilizado para sua produção não é ferromagnético (Tabela 1). Isto vale especialmente para os stents coronários que, embora tenham nas recomendações dos fabricantes fabricantes como contra-indicação para RMC nas primeiras semanas após implante (fato que ocorre devido à regulamentação existente na época em que foram lançados no mercado), não representam risco para o paciente mesmo imediatamente após o procedimento 7,8 . No entanto um artefato na imagem na região dos mesmos pode ocorrer pela distorção local do campo magnético. É preciso cuidado com clipes cerebrovasculares, pois estes podem ser deslocados pelo campo magnético. Pacientes com marcapasso, desfibriladores implantados, com eletrodos de marcapasso retidos e outros implantes eletrônicos por enquanto não devem ser submetidos à ressonância magnética. Uma lista completa de itens e situações que podem ou não contra-indicar exames de

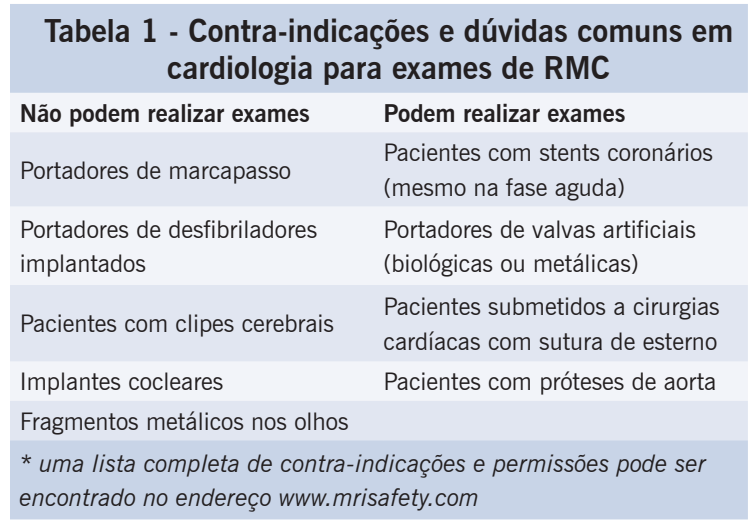


ressonância pode ser encontrada no endereço na internet www.mrisafety.com.

\section{Contraste na RMC}

Para realização da maioria dos exames de RMC e de praticamente todos os exames de angiografia por ressonância, é utilizado um contraste endovenoso baseado no gadolínio ${ }^{9}$. O gadolínio é um metal raro que tem propriedades paramagnéticas, ou seja, de alterar o meio magnético ao seu redor, modificando alguns parâmetros que compõem a imagem da ressonância. Várias moléculas estão disponíveis comercialmente tendo como base este elemento químico. Quando injetadas no sangue rapidamente, elas facilitam a identificação dos vasos a serem estudados, tornando-os mais visíveis em relação aos tecidos ao redor. Esta passagem dos contrastes baseados em gadolínio permite, por exemplo, analisar a perfusão tecidual como realizado na detecção de isquemia miocárdica.

Uma das propriedades do contraste mais utilizadas para realização dos exames é sua difusão pelo sistema vascular após algum tempo e mistura ao meio extracelular exclusivamente. Essa propriedade é utilizada no caso da RMC para diferenciação de trombos (que não captam contraste) versus massas neoplásicas (altamente vascularizadas) e, principalmente, na detecção de áreas de fibrose ou desarranjo estrutural do miocárdio que retém a substância no meio extracelular por mais tempo que o tecido normal.

Estas vantagens da cinética do gadolínio de nada serviriam se o contraste não fosse seguro para o uso na rotina clínica. Em recente meta-análise com mais de 4090 pacientes, mostrou-se que o risco de efeitos adversos graves é inferior a 0,01\% ( 1 evento para cada 10.000 exames). Os sintomas mais leves como cefaléia, náuseas ou alterações de paladar ocorrem em menos de $4 \%$ dos casos e são transitórios ${ }^{10}$. Além disso, pelo fato do contraste ser ligado a moléculas quelantes, ela não apresenta nenhuma contra-indicação para ser utilizada em pacientes com disfunção hepática ou renal ${ }^{11}$, nem precisa de manipulação especial a não ser os de qualquer medicamento endovenoso usual. Finalmente, mesmo em casos de acidentes com extravasamento percutâneo, as conseqüências locais teciduais ou sistêmicas não são importantes ${ }^{12}$.

Por tudo isso, o gadolínio é hoje um contraste amplamente utilizado em diversas situações da RMC e também em casos de exames vasculares sobretudo em pacientes que tenham contra-indicação à contrastes iodados utilizados na tomografia, por exemplo ${ }^{13}$. Não é conhecida reação cruzada entre o gadolínio e os contrastes iodados, não existindo, portanto, contra-indicação do uso do gadolínio em pacientes que já apresentaram alguma reação prévia aos contrastes à base de iodo.

\section{2- Cardiopatias congênitas}

A avaliação diagnóstica em pacientes portadores de cardiopatias congênitas (CC) constitui uma área de intensa pesquisa e prática clínica em cardiologia, radiologia e pediatria. A RMC é considerada uma técnica de imagem complementar à ecocardiografia, fornecendo informação morfofuncional incremental com significativo impacto diagnóstico e terapêutico em pacientes selecionados ${ }^{14}$. A RMC não emprega radiação ionizante, fator importante quando avaliamos seriadamente crianças e adultos jovens. No entanto, sedação é via de regra imprescindível em pacientes com menos de 7 anos e/ou em estado crítico, demandando neste caso suporte e controle intensivo de parâmetros hemodinâmicos no ambiente de exame ${ }^{15}$. Portanto, a RMC é usualmente empregada após a ecocardiografia e como complemento em pacientes pediátricos selecionados com defeitos cardiovasculares simples ou complexos. Futuramente, a RMC poderá também ser útil para guiar terapias percutâneas de tratamento das $\mathrm{CC}^{16}$.

Por outro lado, a RMC torna-se recurso propedêutico de primeira linha em crianças maiores, em adolescentes ou adultos, em anatomias complexas, ou em qualquer idade após intervenções cirúrgicas haja vista que o hábito corporal e a interposição de tecido cicatricial e pulmões representam um problema crescente para a ecocardiografia transtorácica ${ }^{17,18}$. A necessidade, duração e riscos do cateterismo diagnóstico podem ser minimizados pelo emprego prévio da $\mathrm{RMC}^{17,19}$. A definição anatômica do coração e grandes vasos pela RMC apresenta o potencial de reduzir a duração e dose de radiação associados com procedimentos intervencionistas.

A interpretação da RMC em cardiologia pediátrica demanda conhecimentos específicos de anatomia e fisiologia das cardiopatias congênitas, de modo a realizar estudos dirigidos pelo questionamento clínico-cirúrgico que se quer responder, otimizando-se assim protocolos de RMC específicos por doença. Em um protocolo compreensivo de RMC, devem ser realizadas as seguintes seqüências de pulso: 1. Imagens anatômicas ou de sangue preto (black-blood) no planos axial e pelo menos um plano ortogonal adicional (sagital ou coronal). Na avaliação de anomalias da aorta torácica, imagens oblíquas podem ser adquiridas. Estas imagens são usualmente adquiridas com técnica spin-eco; 2 . imagens funcionais com técnica de cine-ressonância cardíaca (sangue branco; brightblood) incluindo cortes contíguos em eixo curto, para avaliação da função biventricular, volumes e massa; 3 . em pacientes selecionados, realiza-se quantificação de velocidades e volume de fluxo sanguíneo no coração e grandes vasos/tubos; 4. angio-RMC com gadolínio para demonstração tridimensional da aorta torácica, artérias e veias pulmonares.

A RMC pode ser empregada nas seguintes anomalias congênitas específicas (Tabela 2):

1- Anomalias de situs víscero-atrial - 0 situs víscero-atrial (solitus, inversus, síndrome heterotáxica) e anomalias de posição (dextrocardia, levocardia) são facilmente demonstrados por métodos diagnósticos 
Tabela 2 - Indicações de RMC nas Cardiopatias Congênitas

\section{Indicação}

Classe

Indicações gerais

1. Seguimento de cardiopatias congênitas do adulto

Indicações específicas

1. Avaliação de shunt sistêmico-pulmonar (Qp/Qs)

।

2. Anomalias de situs víscero-atrial

Anomalias de situs com cardiopatias congênitas complexas ।

Anomalias isoladas de situs

3. Anomalia atrial e do retorno venoso

Retorno venoso pulmonar anômalo, especialmente em

anomalias complexas e cor triatriatum

Retorno venoso sistêmico anômalo

Obstrução de retorno venoso pulmonar ou sistêmico após reparo

intra-atrial ou correção de retorno venoso pulmonar anômalo

Comunicação inter-atrial isolada (secundum e primum)

4. Anomalias das valvas átrio-ventriculares

Anomalia de Ebstein

Anomalias anatômicas das valvas mitral e tricúspide

Anomalias valvares funcionais

Defeito do septo átrio-ventricular isolado

5. Anomalias dos ventrículos

Comunicação interventricular associada com anomalias

complexas

Comunicação interventricular supra-cristal

Avaliação da função ventricular, massa e volumes direito e

esquerdo

Aneurismas e divertículos ventriculares

Comunicação interventricular isolada

6. Anomalias das valvas semilunares

Estenose aórtica supra-valvar

Regurgitação pulmonar

Estenose pulmonar supra-valvar

Estenose aórtica sub-valvar

Valva aórtica bicúspide

Displasia e estenose valvar pulmonar isolada

7. Anomalias das artérias

Avaliação pós-operatória de shunts

Aneurismas do seio de Valsalva

Coarctação da aorta

Anéis vasculares

Janela aorto-pulmonar

Origem anômala de coronárias em adultos e crianças maiores ।

Atresia pulmonar

Estenose pulmonar proximal

Colaterais sistêmico-pulmonares

Má-posição dos grandes vasos

Canal arterial persistente

convencionais. No entanto, na vigência de lesões adicionais (discordância átrio-ventricular ou ventrículoarterial, drenagens venosas sistêmicas ou pulmonar anômalas), podem ocorrer dificuldades na definição da relação topográfica dos respectivos segmentos cardíacos. A RMC fornece informação anatômica ampla incluindo estruturas extra-cardíacas ${ }^{19}$, tornando-se um método diagnóstico com sensibilidade próxima a $100 \%{ }^{20}$. Em pacientes de maior idade, a RMC pode ser considerada exame de imagem fundamental, a fim de oferecer um maior número de informações não-invasivas antes do procedimento intervencionista.

2- Anomalias atriais e venosas - A RMC apresenta valor na avaliação de defeitos do septo inter-atrial, permitindo a quantificação do shunt sistêmico-pulmonar (razão Qp/Qs), de forma bastante acurada e reprodutível, devendo ser considerada uma técnica de primeira escolha ${ }^{21}$. A melhor técnica para avaliação da morfologia do septo inter-atrial é a ecocardiografia transesofágica $(E T T)^{22}$. Em neonatos e lactentes, a RMC é considerada uma técnica de segunda opção após a ecocardiografia transtorácica. A drenagem venosa pulmonar anômala constitui uma limitação da ecocardiografia. Nestes casos, a RMC pode representar a melhor técnica de imagem para avaliação das veias pulmonares ${ }^{23,24}$, considerando que uma demonstração completa e seletiva pode não ser obtida tanto pela ecocardiografia como pelo cateterismo ${ }^{25}$. A RMC pode ser indicada na pesquisa de drenagem venosa parcial anômala parcial em pacientes com comunicações inter-atriais ${ }^{26}$. Pode também demonstrar defeito do septo inter-atrial ou retorno venoso pulmonar anormal em adultos com hipertrofia, dilatação e disfunção ventricular direita de origem indeterminada. A RMC tem potencial utilidade na avaliação pós-operatória de estenoses ou oclusões das veias pulmonares, ou após procedimento de ablação por cateter $^{27}$. É método válido na demonstração enxertos intraatriais estenóticos após a correção de transposição dos grandes vasos e anomalias venosas sistêmicas (veia cava superior bilateral, interrupção da veia cava inferior ${ }^{28,29}$.

3- Anomalias das conexões átrio-ventriculares - A RMC é uma técnica excelente na caracterização morfológica de átrios e ventrículos ${ }^{19}$. Pode demonstrar detalhadamente a discordância átrio-ventricular, dupla via de entrada ventricular, atresia tricúspide e mitral ${ }^{30,31}$. A ecocardiografia é o método inicial de avaliação destas anomalias, reservando-se à RMC um papel suplementar. A RMC é superior à ecocardiografia na quantificação de volumes ventriculares nestas anormalidades, aspecto que pode ser crítico na definição cirúrgica entre correção biventricular ou cirurgia de Fontan.

4- Anomalias dos ventrículos - A RMC é um método de elevada sensibilidade e especificidade na detecção e quantificação de defeitos do septo interventricular ${ }^{32,33}$. Nos defeitos isolados, a RMC oferece pouca informação adicional em defeitos simples já definidos pela ecocardiografia, exceto quando quantificação acurada do shunt se faz necessária para o manuseio do paciente ${ }^{21}$. A RMC apresenta especial valor na definição da anatomia ventricular em anomalias complexas como na tetralogia de Fallot, atresia pulmonar, atresia tricúspide, e corações univentriculares ${ }^{20}$. A RMC pode demonstrar precisamente a localização de comunicações interventriculares em ventrículos com dupla via de saída ${ }^{34}$. A RMC é a técnica de imagem com alta acurácia na quantificação de volumes e massas ventriculares direita e esquerda ${ }^{35}$. 
5- Valvas - A ecocardiografia é a principal modalidade de imagem na definição da morfologia valvar e do significado hemodinâmico das lesões (estenose/regurgitação) valvares. A RMC com técnicas de contraste de fase para análise de fluxo pode avaliar e quantificar o grau de regurgitação valvar em vários casos, podendo ser valiosa no acompanhamento seriado do grau de regurgitação pulmonar no pós-operatório de tetralogia de Fallot ${ }^{36}$, e após a interposição de tubos ventrículo direito-artéria pulmonar ${ }^{37}$. Em conclusão, a RMC pode ser útil na definição do momento cirúrgico para substituição valvar.

6- Anomalias dos vasos da base e tubos - A RMC é um método excelente na avaliação da aorta torácica. Apesar da ecocardiografia ser um método habitualmente suficiente para diagnóstico e estimativa do significado hemodinâmico da coarctação da aorta em neonatos e lactentes, alguma limitação pode ocorrer em crianças maiores e adultos. Neste grupo de pacientes, a gravidade e a extensão da obstrução incluindo o envolvimento do arco aórtico, a circulação colateral e a morfologia da aorta ascendente podem ser claramente demonstradas pela RMC. A técnica de análise hemodinâmica não-invasiva quantifica o gradiente trans-coarctação e o volume de fluxo colateral, medidas precisas na definição de seu significado hemodinâmico ${ }^{38-40}$. A RMC é considerada atualmente, portanto, uma técnica de excelência na avaliação da coarctação da aorta, representando, inclusive, o exame de escolha na avaliação da aorta após intervenção cirúrgica ou percutânea ${ }^{41-43}$. Pode também ser de valor clínico no estudo de aneurismas do seio de Valsalva, dilatação aórtica, aneurismas em pacientes com síndrome de Marfan e Ehler-Danlos e na avaliação seriada das dimensões da aorta. No diagnóstico de anéis vasculares, é o procedimento de escolha ${ }^{44,45}$. Na suspeita de janela aorto-pulmonar, a RMC pode ser útil no diagnóstico diferencial e na identificação do defeito.

A anatomia das artérias pulmonares, essencial à estratégia cirúrgica em pacientes com hipofluxo pulmonar, pode ser caracterizada pela RMC. A ecocardiografia encontra limitações em função da interposição da parede torácica e pulmões, dificultando a análise das imagens. O cateterismo encontra riscos em pacientes cianóticos, uma vez que artérias pulmonares muito pequenas podem ser de difícil abordagem e vasos não-confluentes podem não ser visualizados. O fluxo pulmonar em pacientes com tetralogia de Fallot e atresia tricúspide é bem definido pela $\mathrm{RMC}^{46-49}$. A angio-RMC é o melhor método não-invasivo na definição de colaterais sistêmicopulmonares ${ }^{50}$. A angio-RMC também está indicada na avaliação das artérias pulmonares após tratamento cirúrgico paliativo ou corretivo ${ }^{51}$. Tanto no pré-operatório como no pós-operatório, a angio-RMC tridimensional com gadolínio encontra indicação na detecção de estenoses centrais ou periféricas nas artérias pulmonares ${ }^{52,53}$. 0 significado hemodinâmico destas obstruções pode ser estimado por análise de fluxo nas artérias pulmonares direita e esquerda. Na avaliação de patência de shunts sistêmico-pulmonares e tubos extra-cardíacos, a RMC demonstra especial valor ${ }^{46,54-56}$. Pacientes com shunts ventrículo-pulmonares extra-cardíacos experimentam freqüentemente degeneração do enxerto e, nestes casos, a ecocardiografia pode ser laboriosa devido à posição retroesternal do enxerto. A RMC oferece informação anatômica e funcional acurada, constituindo a técnica de escolha no seguimento destes pacientes ${ }^{57}$.

7- Pós-operatório de cardiopatias congênitas - A ecocardiografia é o método empregado no seguimento da maioria dos pacientes com CC submetidos à intervenção cirúrgica ou percutânea. A análise longitudinal da função e dimensões ventriculares é importante no seguimento clínico. Em relação à ecocardiografia sem contraste, a RMC permite uma quantificação mais acurada e com menor variabilidade da função, massa e volumes ventriculares ${ }^{35,58,59}$, especialmente na avaliação do ventrículo direito que usualmente representa a câmara-alvo nos procedimentos de correção das $\mathrm{CC}^{37,60}$. A avaliação seriada do ventrículo direito é de valor no manuseio pós-cirúrgico de correção intra-atrial de transposição das grandes artérias e tetralogia de Fallot ${ }^{61}$, assim como em outras anormalidades em se faz necessária a interposição de enxerto trans-anular ou inserção de tubos. As conseqüências da regurgitação pulmonar sobre a função ventricular direita e esquerda podem ser avaliadas pela RMC, cujas informações têm implicações terapêuticas e prognósticas em pacientes submetidos à correção de CC. De maneira única, a RMC dá informações prognósticas no seguimento pós operatório de pacientes com tetralogia de Fallot através da análise da quantidade de fibrose no ventrículo direito e esquerdo ${ }^{62,63}$. A RMC está indicada na avaliação morfo-funcional após correção de CC complexas e durante os vários estágios de reparos cirúrgicos específicos, como na síndrome do coração esquerdo hipoplásico e ventrículo único ${ }^{52,64}$.

8- Cardiopatia congênita do adulto - A RMC e a ecocardiografia transesofágica são complementares na avaliação de adultos com CC $^{17}$. O campo de visão limitado e janelas acústicas eventualmente inadequadas tornam a ecocardiografia menos efetiva em adultos. Comparada à ecocardiografia, a RMC tende a ser superior na avaliação de anormalidades da aorta, artérias pulmonares, veias pulmonares, e na quantificação da função ventricular direita e do fluxo sanguíneo pulmonar ${ }^{65}$. Está também indicada quando a qualidade das imagens ecocardiográficas for limitada e a interpretação inconclusiva.

9- Anomalias das artérias coronárias - A RMC é útil na caracterização de anormalidades congênitas e inflamatórias das artérias coronárias, como na coronária esquerda originando-se do tronco pulmonar (síndrome de Bland-White-Garland) e na doença de Kawasaki66-68. Anomalias congênitas no curso proximal das artérias coronárias podem ser demonstradas pela RMC tanto em portadores de CC como também naqueles com anatomia cardíaca normal69-71. A RMC apresenta vantagens sobre o cateterismo na definição das relações espaciais entre a coronária anômala e a aorta/artéria pulmonar, o que 
é fundamental na estimativa de risco associado e no planejamento cirúrgico.

\section{Doenças vasculares - RMC}

A RMC é um método bem estabelecido para avaliação de diversas doenças vasculares ${ }^{72}$. Ela é especialmente eficiente para a realização de angio-RMC onde atualmente se preconiza o uso do contraste endovenoso gadolínio com cinética semelhante à de contrastes iodados convencionais utilizados com raio- $\mathrm{X}^{73}$. Porém, dado à maior segurança e menor nefrotoxicidade, a angio-RMC tem vantagens para o uso em pacientes com insuficiência renal. Através da aquisição em três dimensões, os volumes angiográficos obtidos podem ser manipulados livremente em diversos ângulos e através de técnicas de pós-processamento variadas, permitindo maior acurácia diagnóstica.

Além da possibilidade de realização de angiografias, a RMC também apresenta vantagens por poder definir em determinados vasos a caracterização tecidual da parede e outras estruturas eventuais como trombos, hematomas e inflamação por técnicas de sangue escuro e ponderações de sinal distintas ${ }^{74}$. Finalmente, podese aplicar também a análise de fluxo vascular com a quantificação do volume e da velocidade sanguínea em determinados pontos da vasculatura ${ }^{75}$.

As principais indicações de utilização da RMC para avaliação das doenças vasculares compreendidas nesta diretriz estão na Tabela 3.

\begin{tabular}{|c|c|}
\hline Indicação & Classe \\
\hline 1. Aneurismas de aorta (incluindo Marfan) & I \\
\hline 2. Dissecção de aorta & । \\
\hline 3. Ruptura de aorta & । \\
\hline 4. Hematoma intramural aórtico & । \\
\hline 5. Úlceras aórticas & । \\
\hline 6. Planejamento de abordagem cirúrgica da aorta & । \\
\hline 7. Planejamento de stent aórtico & । \\
\hline 8. Arterites & I \\
\hline 9. Anatomia da artéria pulmonar e fluxo & । \\
\hline 10. Avaliação das veias pulmonares & I \\
\hline 11. Avaliação estenoses renais & । \\
\hline 12. Avaliação de estenoses carótidas extra-cranianas & I \\
\hline 13. Embolia pulmonar & $\mathrm{IIb}$ \\
\hline
\end{tabular}

\section{Aorta}

O estudo da aorta tanto do segmento torácico como abdominal pela $\mathrm{RMC}^{76}$, permite a análise de doenças congênitas e/ou adquiridas ${ }^{77}$ com extrema precisão. Atualmente, estas informações podem ser obtidas na maioria dos aparelhos comerciais disponíveis no mercado. 0 método, pela diversidade e qualidade das imagens estáticas, dinâmicas, angiografias e análise de fluxo, é utilizado largamente na prática clínica e cirúrgica para diagnóstico, acompanhamento clínico e definição de abordagem e táticas cirúrgicas ${ }^{78-80}$.

Devemos realçar a necessidade de se estudar na abordagem das doenças aórticas vários aspectos: a parede do vaso (espessamento, irregularidades), o lúmen (estenoses, obstruções e dilatações, ulcerações) e a dinâmica de fluxo(fluxo rápido, lento e trombos). Estas características do método são as mais importantes quando comparadas à angiografia clássica ${ }^{81}$.

A interpretação e a análise devem, na dependência da doença estudada, ser direcionada para:

1- Parede do vaso ${ }^{82-84}$ : espessura, contorno, integridade, qualidade (trombos intramurais, presença de sangue). A técnica básica é de avaliação estática, multiplanar, acoplado ao eletrocardiograma (ECG) como Spin Eco e Double Inversion Recovery.

2- Vaso: Diâmetro, extensão da lesão, presença e direção do fluxo e identificação de trombos. Utiliza-se a avaliação anatômica estática, acoplado ao ECG, e técnicas dinâmicas como cine ressonância e angiografia com a utilização de gadolínio.

3- Angiografia: análise 2D e 3D para identificação do formato espacial do vaso, luminografia, a qual evidencia a patência, dimensões do vaso, e extensão da lesão. A técnica da angiografia é realizada com a utilização de gadolínio.

4- Análise de fluxo ${ }^{85}$ : Permite a identificação da presença, sentido e mensuração da velocidade do fluxo ${ }^{86}$. Utiliza-se sequência de pulso que fornece imagens de fase (phase contrast) ${ }^{87}$.

\section{Artérias renais}

A avaliação das artérias renais em pacientes com suspeita de hipertensão renovascular pela RMC é atualmente realizada através da técnica de angio-RMC com aquisição em blocos $3 D^{88}$. Apesar da menor resolução espacial em relação à angiografia convencional, a RMC pode fornecer dados quanto à importância de lesões estenóticas de maneira reprodutível e com alta sensibilidade e especificidade $^{89}$, não devendo, porém, ser utilizada para medidas quantitativas das mesmas. Outra vantagem do uso da RMC é a possibilidade de num mesmo exame também realizar a avaliação da fase venosa da perfusão renal, além de acrescentar também dados sobre a anatomia dos rins. Finalmente, por não utilizar contrastes nefrotóxicos, a angioRMC deve ser a técnica de escolha na avaliação das artérias renais de pacientes com função renal alterada. O uso da RMC para avaliação funcional da perfusão renal - como a realizada pela cintilografia - ainda não atingiu a acurácia necessária para seu uso na rotina clínica ${ }^{90}$.

\section{Veias e artérias pulmonares}

A avaliação das veias pulmonares adquiriu grande importância clínica com o advento de técnicas de 
intervenção para ablação de fibrilação atrial ${ }^{91}$. A descrição anatômica das veias pulmonares previamente aos procedimentos de ablação é significante pois auxilia o eletrofisiologista na visualização em três dimensões das variâncias desta anatomia e é de grande valia para o sucesso do procedimento ${ }^{92}$. Mais ainda, a RMC permite a acurada medida e geometria dos óstios das veias pulmonares, auxiliando também na seleção do tamanho correto dos cateteres a serem utilizados para ablação ${ }^{93,94}$. Finalmente, a RMC também pode ser utilizada após o procedimento para avaliação de potenciais complicações como estenoses pós-ablação ou alterações esofágicas ${ }^{95}$.

$\mathrm{Na}$ análise das artérias pulmonares, o uso da RMC é um pouco mais limitado pois para se obter a visualização de toda árvore arterial pulmonar é necessário um tempo de aquisição e pausa respiratória ainda muito longo. Entretanto, alguns estudos mostram que a técnica pode ser utilizada para casos selecionados de embolia pulmonar ${ }^{96}$, ficando esta avaliação limitada, porém, aos segmentos proximais apenas das artérias pulmonares ${ }^{97}$.

\section{Carótidas extra-cranianas}

As artérias carótidas podem ser avaliadas pela RMC pela técnica de time-of-flight que não utiliza contraste, mas atualmente as técnicas de angio-RMC vêm se tornando a melhor forma de visualização das mesmas ${ }^{98,99}$. A angio-RMC das carótidas tem alta sensibilidade e especificidade quando comparada ao método de referência da angiografia por subtração digital 100,101, com discordância de classificação de apenas 3.1\% dos pacientes devido a super-estimação da importância da lesão pela RMC. A utilização da RMC para avaliação não invasiva das artérias carótidas teve concordância similar ao ultra-som com doppler e foi superior à tomografia computadorizada, especialmente em pacientes com obstruções assintomáticas ${ }^{101}$.

\section{Doença arterial coronária}

A RMC vem ganhando espaço na sua importância para a avaliação não invasiva da doença arterial coronária102. Mais que ser simplesmente um novo método, a ressonância trás informações únicas não providas pelos métodos usuais, com maior facilidade e simplicidade na sua aquisição e podendo responder à diversas perguntas clínicas num único exame ${ }^{103,104}$. As indicações para a RMC na avaliação da doença arterial coronária estão sintetizadas na tabela 4 .

\section{Função, massa, volumes e geometria ventricular}

A avaliação de forma reprodutiva, acurada e validada da RMC do ventrículo esquerdo e direito fazem do método um padrão de referência para análise de parâmetros geométricos cardíacos e para a análise seriada ao longo do

\begin{tabular}{|c|c|}
\hline Indicação & Classe \\
\hline $\begin{array}{l}\text { 1. Avaliação da função ventricular global, volumes e massa } \\
\text { (esquerda e direita) }\end{array}$ & I \\
\hline \multicolumn{2}{|l|}{ 2. Detecção isquemia miocárdica } \\
\hline $\begin{array}{l}\text { Avaliação da função ventricular regional em repouso e em } \\
\text { estress (RMC-estresse) }\end{array}$ & Ila \\
\hline Avaliação da perfusão miocárdica & Ila \\
\hline \multicolumn{2}{|l|}{ 3. Infarto agudo e crônico do miocárdio } \\
\hline Detecção e quantificação & I \\
\hline Viabilidade miocárdica & 1 \\
\hline Trombo ventricular & । \\
\hline Avaliação de aneurisma de VE & 1 \\
\hline Diagnóstico de síndrome coronária na fase aguda & Ila \\
\hline Comunicação interventricular & III \\
\hline Insuficiência mitral aguda & III \\
\hline \multicolumn{2}{|l|}{ 4. Angio-RMC de artérias coronárias } \\
\hline Anomalias congênitas & I \\
\hline Doença arterial coronária & III \\
\hline Avaliação de patência de enxertos & III \\
\hline
\end{tabular}

tempo de modificações destes ${ }^{105}$. Também devido à estas características, a RMC é hoje o método de escolha na avaliação precisa de pacientes com insuficiência cardíaca congestiva com disfunção ventricular sistólica ${ }^{106}$.

Diversos estudos tanto ex vivo ${ }^{107}$ tanto in vivo ${ }^{108,109}$ comprovaram que, devido à obtenção dos volumes e massas ventriculares por uma abordagem tridimensional, a RMC tem alta acurácia. Isto foi demonstrado tanto para o ventrículo esquerdo ${ }^{110}$, quanto para o direito ${ }^{111} \mathrm{e}$, em relação à massa ventricular, em comparação direta com corações autopsiados de humanos ${ }^{112,113}$. Em comparação com outros métodos, estudos mostraram que o ecocardiograma sem contraste subestima valores de fração de ejeção e volumes em comparação à ressonância ${ }^{35}$, especialmente quando são comparados às medidas adquiridas por métodos biplanares ${ }^{114,115}$. Também na avaliação destes parâmetros, embora a cintilografia com SPECT possa fornecer estes dados, grandes variações individuais são observadas e a RMC mostrou-se superior quando medidas mais acuradas destes parâmetros são necessários ${ }^{116}$. Mais importante, embora os valores obtidos com a RMC sejam comparáveis aos obtidos pelo ecocardiograma ou cintilografia, estes valores não são intercambiáveis e não devem ser comparados diretamente ${ }^{117}$.

$\mathrm{Na}$ avaliação de pacientes com aneurimas ventriculares, a RMC pode fornecer dados mais precisos dos volumes e geometria do ventrículo (além da área infartada), sendo importante também no seguimento pós-operatório na avaliação da melhora da função cardíaca e anatomia ventricular $^{118}$. Para avaliação de variações da contratilidade regional, a RMC também mostrou-se eficaz em comparação com outros métodos ${ }^{119}$, sendo superior ao ecocardiograma sem contraste e a ventriculografia e similar ao ecocardiograma com contraste, embora todos os métodos tenham demonstrado alta variabilidade interobservador ${ }^{35}$. 
Porém, para esta avaliação, a técnica de tagging é mais precisa pois permite quantificar as distorções de movimento regional de pontos marcados magneticamente na imagem durante todo o ciclo cardíaco ${ }^{120,121}$. Embora a técnica ainda exija um grande trabalho de pós processamento e está mais limitado ao uso em pesquisa, ela pode ser aplicada também clinicamente ${ }^{122}$

Em conclusão, devido à capacidade da RMC de fornecer dados precisos e com alta reprodutibilidade dos parâmetros de volumes, massa e contratilidade global e regional ventriculares, o método vem se tornando o exame de escolha para seguimento longitudinal de pacientes que necessitam de alta precisão no acompanhamento ${ }^{58,123}$. As medidas pela RMC também são bastante úteis como desfechos primários em diversos estudos, permitindo uma redução do número de pacientes na amostra ${ }^{124-126}$.

\section{Detecção de doença arterial coronária}

Existem diversas formas de se pesquisar a presença doença arterial coronária utilizando a RMC. As técnicas mais frequentemente utilizadas envolvem a visualização direta dos efeitos da isquemia induzida por estresse farmacológico sobre a perfusão miocárdica ou sobre a contratilidade segmentar. De fato, a RMC apresenta a característica única de proporcionar os dois tipos de informação em um único exame, combinando a maior sensibilidade da perfusão miocárdica com a maior especificidade da avaliação da função regional sob estresse.

\section{Avaliação da contratilidade segmentar (RMC-Estresse)}

O exercício físico no interior do magneto causa degradação da qualidade das imagens devido a artefatos de movimento e, portanto, o estresse farmacológico é o mais frequentemente empregado ${ }^{127-131}$. A RMC de estresse com dobutamina já é, atualmente, uma técnica estabelecida para a detecção de alterações da contratilidade segmentar induzidas por isquemia miocárdica, apresentando inclusive diretrizes publicadas para sua aplicação na prática clínica ${ }^{132}$. Técnicas de cine-RM com pausa respiratória são empregadas para a avaliação detalhada da função regional do VE, tanto em repouso como sob estresse farmacológico. A RMC apresenta a vantagem de proporcionar excelente delimitação das bordas endocárdicas e do espessamento sistólico, além de permitir uma avaliação completa do $\mathrm{VE}$, examinando a contratilidade regional desde o ápice até a base ventricular. Os resultados diagnósticos são excelentes, e estudos comparativos com a ecocardiografia de estresse demonstraram superioridade da $\mathrm{RMC}^{133}$ devido a melhor qualidade das imagens ${ }^{134}$. A RMC de estresse com dobutamina se mostrou muito efetiva para o diagnóstico de DAC no grupo de pacientes inadequados para a avaliação pela ecocardiografia devido à janela acústica sub-ótima ${ }^{135}$. A avaliação quantitativa da função regional pela RMC tem o potencial de melhorar ainda mais a acurácia dignóstica do método, especialmente nos casos de DAC univascular ${ }^{136,137}$.
Além de valor diagnóstico, a avaliação da isquemia miocárdica pela RMC também tem importante valor prognóstico. Quando a RMC de estresse com dobutamina é normal, os pacientes apresentam uma baixa taxa de eventos, enquanto quando a isquemia está presente, a taxa de eventos é alta ${ }^{138}$. A RMC também tem sido utilizada com bons resultados na avaliação do risco pré-operatório em cirurgias não-cardíacas ${ }^{139}$. Recentemente, a RMC de estresse foi considerada a técnica com maior acurácia para determinação da presença de isquemia miocárdica em pacientes sem antecedentes de infarto agudo do miocárdio em comparação com estudos de perfusão ${ }^{140}$. Finalmente, a segurança do método também se mostrou bastante alta, em comparação aos demais métodos que utilizam dobutamina como agente provocador de isquemia ${ }^{141}$.

Outras técnicas de RMC tem sido avaliadas como ferramentas diagnósticas potencialmente úteis na avaliação dos pacientes com DAC, dentre as quais a técnica de tagging miocárdico ${ }^{121,142}$, a RMC em tempo real' ${ }^{143}$ e a avaliação complementar da função diastólica

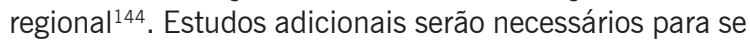
determinar o papel dessas metodologias inovadoras na prática clínica diária.

\section{Avaliação da perfusão miocárdica}

A RMC de perfusão miocárdica permite a cobertura completa do VE utilizando uma aquisição simultânea de múltiplos cortes contíguos do eixo-curto ventricular, ou uma combinação de eixos-curtos e longos do VE ${ }^{145}$. Uma injeção intravenosa em bôlus do contraste gadolínio-DTPA (na dose de 0.025 a $0.1 \mathrm{mmol} / \mathrm{kg}$ ) é habitualmente administrada pela fossa antecubital utilizando uma bomba injetora para garantir que a injeção seja efetuada de forma rápida e uniforme (em geral de $5 \mathrm{~mL} / \mathrm{s})^{146,147}$. Idealmente, a aquisição das imagens de todos os cortes deve ser executada a cada ciclo cardíaco, i.e., a resolução temporal deve ser de 1 intervalo RR. Em alguns casos, uma resolução temporal de 2 intervalos RR também pode ser considerada adequada. As imagens de perfusão miocárdica podem ser avaliadas de forma visual subjetiva, através da identificação de regiões escuras de hipoperfusão segmentar nos diversos cortes obtidos, ou a intensidade de sinal do miocárdio pode ser quantificada durante a primeira passagem do contraste e analisada com o auxílio de computadores. Clinicamente, a avaliação visual subjetiva é a mais empregada. Não obstante, avaliações quantitativas podem ser obtidas através da análise das curvas de aumento da intensidade de sinal do miocárdio ou da avaliação de mapas paramétricos coloridos representativos da perfusão miocárdica regional ${ }^{148-150}$. Métodos analíticos mais complexos incluem os algoritmos de correção dos movimentos respiratórios ${ }^{151}$ e a análise de deconvolução, que permite a quantificação em termos absolutos dos índices de perfusão regional e da reserva de perfusão miocárdica ${ }^{152}$. Essas técnicas, ainda que complexas, já foram extensamente revisadas ${ }^{153,154}$ e validadas em estudos experimentais $^{155-157}$. Foram também validadas em estudos 
clínicos contra a reserva perfusional medida pelo PET ${ }^{150}$

Com relação à aplicação clínica, a RMC de perfusão miocárdica vem apresentando grande desenvolvimento nos últimos anos e existem, atualmente, duas estratégias principais. A primeira abordagem, mais simples, consiste em adquirir as imagens de perfusão miocárdica apenas na fase de estresse (vasodilatação) utilizando dipiridamol ou adenosina e utilizar as imagens de realce tardio para definir as regiões não-viáveis fibróticas. A segunda abordagem, mais completa, consiste em adquirir imagens de perfusão miocárdica tanto durante estresse como em repouso. Essa abordagem se assemelha mais às técnicas de cintilografia convencionais. É importante ressaltar, entretanto, que a combinação das informações sobre perfusão miocárdica, função regional e injúria miocárdica irreversível (realce tardio) proporcionada pela RMC permite uma interpretação mais detalhada e acurada da resposta cardíaca ao estresse farmacológico. Além disso, a RMC também tem a vantagem de poder ser realizada em menos de uma hora de exame com mesmo nível de conforto do paciente que outros métodos de perfusão ${ }^{158}$. De fato, diversos estudos clínicos avaliando a detecção não-invasiva da DAC demonstraram que os resultados da RMC de perfusão miocárdica são excelentes quando comparados à cineangiocoronariografia invasiva ${ }^{148-}$ ${ }^{150}$, ao $\mathrm{PET}^{150}$ ou ao SPECT ${ }^{149}$. Em comparação a esta última técnica de medicina nuclear, a ressonância mostrou-se superior na detecção de gradientes transmurais de alterações de fluxo sanguíneo no miocárdio ${ }^{156}$. Adicionalmente, a RMC foi capaz demonstrar melhora da reserva de perfusão miocárdica após intervenções coronárias percutâneas ${ }^{159,160}$ e redução da perfusão regional na CMP hipertrófica ${ }^{161}$. Também mostrou utilidade na identificação de pacientes com coronariopatia em situações pré-operatórias de cirurgias vasculares ${ }^{162}$. Além disso, quando aplicada na fase aguda de síndromes coronárias agudas, a técnica de perfusão miocárdica mostrou-se capaz de identificar pacientes com doença coronária mesmo em indivíduos com síndromes instáveis sem supradesnível de segmento ST e com marcadores cardíacos negativos ${ }^{163}$. Também em situações agudas, a aplicação da avaliação de perfusão pela RMC em pacientes com eletrocardiograma inespecífico e troponina negativo mostrou uma sensibilidade de $100 \%$ e especificidade de $93 \%$ para diagnóstico de DAC ou eventos adversos em até um ano de seguimento, mostrando a utilização prognóstica do exame também nestas situações ${ }^{164}$. Finalmente, pela maior resolução espacial, a RMC também provou ser capaz de detectar isquemia miocárdica em territórios com coronárias aparentemente normais ${ }^{165}$, em repouso em pacientes com miocárdio hibernado ${ }^{166}$ e comprometimento da perfusão subendocárdica em pacientes com síndrome X cardíaca ${ }^{167}$.

\section{Angiografia/fluxo coronário}

A ressonância magnética é um excelente exame para a avaliação dos vasos sistêmicos. A visualização das artérias coronárias, no entanto, é dificultada por vários fatores: movimentação cardíaca e respiratória, fino calibre e complexidade anatômica. Diversas técnicas têm sido desenvolvidas para superar estas dificuldades, desde as seqüências de aquisição bidimensional de primeira geração ${ }^{168,169}$ até as mais recentes de aquisição tridimensional, utilizando pausa respiratória ou navegador, com ou sem administração de contraste ${ }^{170-}$ 173. Compilações recentes dos principais estudos de angiografia coronária por RMC empregando diversas técnicas de aquisição revelaram valores moderados de sensibilidade (72-77\%) e especificidade (71-87\%) para a detecção de estenoses coronárias quando comparadas à angiografia invasiva ${ }^{174,175}$. Mesmo utilizando apenas técnicas mais atuais, estes valores ainda foram bastante próximos destas revisões históricas (sensibilidade de 75\%, especificidade de $77 \%$ e acurácia de $77 \%)^{176}$, mostrando que a angiografia por RMC ainda carece de resolução espacial e temporal suficientes para a adequada avaliação da doença arterial coronária clinicamente, especialmente das porções mais distais da árvore coronária.

Por outro lado, existe evidência científica suficiente para o emprego da angio-RMC na visualização de anomalias de trajeto ${ }^{177-179}$ e de enxertos coronários ${ }^{180-182}$. A menor resolução espacial necessária para observar a emergência e trajeto inicial dos troncos coronários permite à angioRMC ter boa acurácia para a detecção de anomalias. No caso dos enxertos, seu maior calibre e pouca movimentação também conferem ao método resultados satisfatórios em relação à cineangiocoronariografia invasiva. Essa aplicação pode ser útil nos casos de dor torácica pós-cirurgia de revascularização miocárdica, a fim de se determinar a perviedade dos enxertos ${ }^{183}$.

Outra aplicação da RMC é a determinação não-invasiva do fluxo e reserva coronária. Utilizando a técnica de contraste de fase, é possível caracterizar o fluxo pelas artérias coronárias em repouso e durante estresse farmacológico ${ }^{184,185}$. Tal propriedade pode ser útil para a avaliação funcional de artérias nativas ${ }^{184}$, pós-implante de stent ${ }^{186}$ ou de enxertos ${ }^{187,188}$. Essa aplicação, contudo, atualmente ainda é restrita ao campo investigacional.

\section{Detecção do infarto do miocárdio}

As técnicas de RMC atuais, especialmente os protocolos baseados na técnica do realce tardio, permitem uma precisa delimitação das áreas de necrose ou fibrose miocárdica nos pacientes com infarto prévio. A técnica de realce tardio se desenvolveu a partir dos estudos pioneiros de Lima et al avaliando a detecção e caracterização das áreas de infarto através da RMC contrastada com gadolínio ${ }^{189}$. Foi utilizada inicialmente nos trabalhos experimentais e clínicos do grupo liderado pelos Drs. Kim e Judd ${ }^{190-195}$, e descrita do ponto de vista técnico por Simonetti et al ${ }^{196}$. A técnica de realce tardio se baseia numa seqüência de pulsos do tipo gradiente-eco rápida ponderada em T1, com um prépulso de inversão-recuperação e um tempo de inversão (TI) ajustado para anular o sinal do miocárdio normal. Portanto, nas imagens adquiridas com essa técnica, o miocárdio íntegro aparece com intensidade de sinal muito 
baixo (escuro). Outra característica da técnica de realce tardio é a utilização do contraste endovenoso gadolínio, que não penetra membranas celulares íntegras e, portanto, tem distribuição extra-celular. Nas regiões de infarto ocorre ruptura das membranas dos miócitos necróticos e, portanto, o gadolínio pode se distribuir livremente (maior volume de distribuição) ${ }^{197,198}$. Além disso, a necrose dos miócitos também causa uma alteração da cinética de distribuição do contraste, de modo que a saída do gadolínio das áreas de infarto ocorre mais lentamente

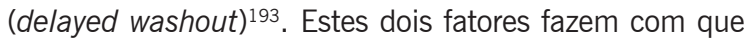
a concentração do contraste, cerca de 10 a 20 minutos após a injeção, seja muito maior nas regiões necróticas do que no tecido miocárdico normal ${ }^{199}$, tornando as áreas de infarto brancas (sinal intenso) nas imagens de realce tardio. Em resumo, ao aumentar a intensidade de sinal do infarto (utilizando o gadolínio e ponderando as imagens em T1) e diminuir a intensidade de sinal do miocárdio normal (com o pré-pulso de inversão e TI em torno de 200-300 ms), a técnica do realce tardio otimiza o contraste entre os dois tecidos (diferença de sinal de até $1080 \%)^{196}$ e permite a precisa delimitação das áreas de necrose miocárdica. No caso dos infartos antigos, a fibrose, e não a necrose, é o fenômeno patológico subjacente. Nesses casos, o maior espaço extracelular verificado no tecido fibrótico, quando comparado ao miocárdio normal, é a causa do maior volume de distribuição e da alteração da cinética do gadolínio ${ }^{199}$. Diversos estudos prévios já demonstraram que a RMC com técnica de realce tardio permite a delimitação precisa das áreas de necrose ou fibrose miocárdica nos pacientes com infarto prévio ${ }^{191-}$ ${ }_{193,200}$. Em especial, Kim et al demonstraram de forma contundente uma correlação quase perfeita entre os valores de massa infartada obtidos pela RMC e pela anatomia patológica (coloração por cloreto de trifeniltetrazolium [TTC]), tanto nos infartos agudos $(R=0,99, P<0,001)$ e subagudos $(R=0,99, P<0,001)$, como nos crônicos $(R=0,97, P<0,001)^{192}$. Devido à sua excelente resolução espacial, a RMC permite a caracterização detalhada não apenas dos grandes infartos transmurais, mas também dos pequenos infartos subendocárdicos. Num importante estudo publicado por Wagner et al foi demonstrado que a cintigrafia miocárdica detectou apenas $28 \%$ dos segmentos com infarto subendocárdico enquanto a RMC foi capaz de detectar $92 \%$ dos segmentos ${ }^{201}$. Outro estudo recente demonstrou que não apenas a acurácia, mas também a reprodutibilidade da RMC é superior à da cintilografia em termos de quantificação da massa infartada ${ }^{194}$. Mesmo os pequenos infartos focais relacionados a procedimentos de intervenção percutânea são prontamente identificados ${ }^{202}$. Sobretudo, Wu et al demonstraram que o tamanho do infarto, expresso como um percentual da massa do ventrículo esquerdo, tem importante valor prognóstico nos pacientes com infarto agudo do miocárdio ${ }^{203}$. Este cálculo pode ser realizado de maneira rápida e precisa visualmente, de maneira semi-quantitativa, permitindo a aplicação clínica desta quantificação no dia-a-dia ${ }^{204}$. Adicionalmente, a RMC permite identificar regiões de obstrução microvascular (fenômeno de no-reflow)200,203,205, um marcador de injúria miocárdica grave e que também está associado a pior prognóstico pós-IAM ${ }^{203}$.

\section{Viabilidade miocárdica - fase aguda}

Usualmente, o IAM era avaliado pela ecocardiografia através da análise da contratilidade segmentar e a identificação de uma região de importante disfunção regional aguda (hipocinesia grave, acinesia e discinesia). Entretanto, essa avaliação inicial não permitia a distinção entre miocárdio atordoado (tecido miocárdico viável porém com disfunção segmentar apesar do restabelecimento da perfusão regional)206,207 e tecido necrosado (injúria miocárdica irreversível). Em outras palavras, dada uma determinada área de disfunção regional, não era possível determinar o quanto desta disfunção era causada por atordoamento miocárdico e o quanto, de fato, representava necrose tecidual irreversível. Convencionalmente, essa resposta só era esclarecida através do acompanhamento evolutivo da disfunção segmentar. Se houvesse melhora evolutiva tratava-se de atordoamento, senão de necrose.

A RMC com técnica de cine permite o mesmo tipo de análise da contratilidade segmentar que a ecocardiografia. Entretanto, ao combinar essa informação com a avaliação detalhada do território infartado proporcionada pela técnica do realce tardio, a RMC permite determinar com precisão o que é tecido miocárdico atordoado e o que é necrose irreversível. Portanto, se um dado segmento apresenta disfunção regional pós-infarto mas não apresenta nenhuma área de realce tardio, trata-se de atordoamento miocárdico. Por outro lado, se o segmento apresentar acinesia associado a realce tardio transmural, podemos afirmar com segurança que trata-se de um segmento infartado.

De fato, como demonstrado por Choi et al, a determinação da transmuralidade do infarto permite predizer a recuperação da contratilidade segmentar do VE em pacientes com IAM $^{190}$. Neste estudo, o grau de transmuralidade do infarto correlacionou-se inversamente com a probabilidade de recuperação da função regional 8 a 12 semanas após o evento agudo. De forma semelhante, Gerber et al demonstraram que o potencial de recuperação da contratilidade regional, desta vez medida de forma quantitativa pela técnica do tagging miocárdico, pode ser definido através da avaliação dos padrões de realce tardio dos pacientes com IAM ${ }^{208}$. Sobretudo, é importante reconhecer que a distinção entre miocárdio atordoado e injúria irreversível tem importante valor prognóstico. Já foi amplamente demonstrado que pacientes portadores de disfunção ventricular esquerda aguda causada primariamente por necrose miocárdica apresentam prognóstico muito pior do que pacientes nos quais a disfunção ventricular é predominantemente reversível ${ }^{209,210}$.

$\mathrm{Na}$ fase aguda, a RMC pode ainda auxiliar na predição da evolução da função ventricular ao avaliar a presença e extensão das áreas de no-reflow. Segmentos com obstrução 
microvascular demonstrados pela RMC têm redução da espessura da parede infartada com ausência de recuperação funcional após 5 meses, versus uma melhora significativa naqueles indivíduos sem a presença de obstrução ${ }^{211}$. Da mesma forma, a RMC pela caracterização do tamanho do infarto agudo, da existência da obstrução microvascular e da quantidade de infarto transmural também foi capaz de predizer quais pacientes teriam pior evolução com remodelamento adverso após 6 meses $^{212}$.

\section{Viabilidade miocárdica - fase crônica}

Embora seja possível a avaliação da viabilidade crônica utilizando-se técnicas de RMC com dobutamina

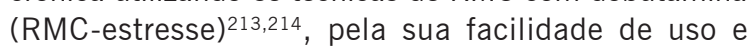
ausência de necessidade de drogas vasoativas a técnica de realce tardio é atualmente a mais utilizada com esta finalidade ${ }^{215}$. No infarto crônico, a técnica também foi amplamente validada em modelos animais ${ }^{192,193}$ e em humanos ${ }^{195}$ com alta reprodutibilidade ${ }^{194}$. A RMC mostrou-se superior a cintilografia por SPECT ${ }^{201}$ e com mesma sensibilidade e especificidade que o PET para a identificação de áreas de infarto crônico ${ }^{216,217}$, especialmente em regiões de infarto subendocárdico.

Porém, mais que determinar apenas áreas de infarto, a determinação da viabilidade miocárdica para predizer quais pacientes terão melhora da função ventricular global ou regional após cirurgias de revascularização do miocárdio é de extrema utilidade clínica ${ }^{218}$. A RMC, através do realce tardio, permite a visualização não só da área de infarto crônico mas também da área não infartada, sendo a relação entre a extensão destas duas áreas na parede ventricular fundamental para se determinar uma possível recuperação funcional ou não do miocárdio ${ }^{219}$. Graças a esta capacidade única de permitir a visualização de extensão de ambos os tecidos infartados e normais, a RMC tem alta sensibilidade e especificidade, com acurácia de $72-77 \%$ e valores preditivos positivos e negativos de $66-85 \%$ e $82-92 \%$, respectivamente, para determinação da recuperação funcional de segmentos do miocárdio pós revascularização213,220,221: segmentos do miocárdio com menos de $50 \%$ de extensão da parede com presença de realce tardio tem alta probabilidade de melhora funcional, enquanto segmentos com mais de $50 \%$ de extensão do infarto tem baixa probabilidade de recuperação. Estes resultados são ainda superiores quando aplicados apenas em pacientes com disfunção ventricular grave ${ }^{222}$ ou analisando-se segmentos que já apresentam hipocinesia importante ou acinesia220.

\section{Cardiomiopatias}

\section{Cardiomiopatia hipertrófica}

A cardiomiopatia hipertrófica $(\mathrm{CH})$ é uma doença cardíaca complexa, com características fisiopatológicas específicas e uma grande diversidade de apresentação clínica, morfológica e funcional. Considerando-se o seu caráter familiar, é caracterizada como uma doença genética de herança autossômica dominante e atualmente reconhecida como uma doença do sarcômero cardíaco, uma vez que entre os mecanismos fisiopatológicos estão implicadas mutações nos genes que codificam as principais proteínas estruturais da arquitetura miocárdica. A heterogeneidade genética é uma característica dessa doença,observando-se diversos padrões de localização e extensão da hipertrofia223.

A despeito da ecocardiografia ser o método atualmente mais disponível para acessar as alterações morfológicas e funcionais da $\mathrm{CH}$, o método possui algumas limitações significativas na avaliação desta doença ${ }^{224}$. A RMC por ser um método tridimensional, multiplanar e de excelente resolução espacial, se impõe como uma ferramenta importante para melhor avaliação dos portadores da doença e investigação de pacientes assintomáticos a partir de casos índices ${ }^{225}$. A RMC contribui significativamente para um estudo mais detalhado da localização e extensão da hipertrofia, visualização dos mecanismos de obstrução, avaliação mais precisa da função e, utilizando-se a técnica do realce tardio, detecção de áreas de fibrose no miocárdio de portadores da doença. A distribuição da fibrose nessa doença segue um padrão multifocal e mesocárdico, diferente daquele observado no infarto agudo do miocárdio, que obedece uma correlação com a distribuição do território coronário ${ }^{226}$. Essas áreas de realce tardio na $\mathrm{CH}$ apresentam implicações prognósticas, uma vez que podem significar substrato para o desenvolvimento de arritmias e morte súbita 227,228 . Recomenda-se também a RMC como metodologia útil na avaliação de portadores de doença de Fabry ${ }^{229}$ e síndrome de Noonan ${ }^{230}$, para melhor avaliação morfológica e funcional do coração, pela associação dessas entidades clínicas com a $\mathrm{CH}$. A RMC dispõe ainda de diferentes técnicas de avaliação da função, dentre elas o tagging que fornece, de modo objetivo, dados relativos ao strain miocárdico, usualmente comprometido nessa doença ${ }^{231-}$ 234. No diagnóstico da forma apical da $\mathrm{CH}$, a RMC é mais sensível que a cintilografia ${ }^{235}$ e a ecocardiografia que pode subestimar esse diagnóstico ${ }^{236,237}$, além de, nesses casos, apresentar forte contribuição no diagnóstico diferencial com a endomiocardiofibrose. Finalmente, a RMC é útil também no seguimento do tratamento da $\mathrm{CH}$, com a avaliação de pacientes submetidos à ablação septal para melhor definição da área e extensão do infarto provocado ${ }^{238}$.

Considerando os aspectos de sensibilidade e características do método, a indicação desse documento é de que a RMC seja classe I para pacientes com diagnóstico de $\mathrm{CH}$, porque além de fornecer dados mais fidedignos a respeito da massa ventricular, possibilita maior detalhamento dos aspectos funcionais e permite a detecção e quantificação da fibrose de modo não invasivo (Tabela 5).

\section{Hipertrofia ventricular esquerda e coração de atleta}

A RMC permite uma avaliação mais acurada da massa ventricular, apresentando elevada sensibilidade na detecção da hipertrofia ventricular esquerda (HVE) ${ }^{239,240}$. A elevada resolução espacial do método possibilita uma 


\begin{tabular}{|c|c|}
\hline Indicação & Classe \\
\hline 1. Cardiomiopatia hipertrófica & 1 \\
\hline $\begin{array}{l}\text { 2. Cardiomiopatia dilatada - diagnóstico diferencial com } \\
\text { etiologia isquêmica }\end{array}$ & I \\
\hline $\begin{array}{l}\text { 3. Displasia/cardiomiopatia arritmogênica do ventrículo } \\
\text { direito }\end{array}$ & 1 \\
\hline $\begin{array}{l}\text { 4. Cardiomiopatia siderótica, especialmente secundária à } \\
\text { talassemia }\end{array}$ & 1 \\
\hline 5. Miocárdio não compactado & । \\
\hline 6. Cardiomiopatia chagásica & I \\
\hline 7. Miocardite (fase aguda ou crônica) & Ila \\
\hline 8. Diagnóstico diferencial do coração de atleta & Ila \\
\hline 9. Cardiomiopatia restritiva & Ila \\
\hline 10. Sarcoidose cardíaca & Ila \\
\hline
\end{tabular}

melhor definição do endocárdio e, portanto, uma maior precisão das medidas relativas à espessura das paredes, localização e extensão da hipertrofia, configurando-se como o padrão de referência para esse diagnóstico ${ }^{114}$. Considerando-se que a HVE representa um fator de risco independente para eventos cardíacos, a utilização de um método com elevada sensibilidade diagnóstica poderá implicar em medidas terapêuticas mais precoces no sentido de promover a sua redução e conseqüente benefício. $A$ melhor reprodutibilidade do método tem permitido também sua utilização em protocolos de pesquisa ${ }^{125,239}$, permitindo uma diminuição do número da amostra e com implicações positivas no custo final da droga.

Por outro lado a sua utilização no diagnóstico e acompanhamento da hipertrofia benigna do atleta, bem como sua diferenciação com a $\mathrm{CH}$ ou com a cardiomiopatia dilatada, tem sido importante no que se refere às considerações para a definição de liberação para a atividade desportiva ${ }^{241-243}$. Dadas as limitações previamente mencionadas do ecocardiograma e mesmo de testes fisiológicos como o teste ergoespirométrico ${ }^{244}$, a RMC pode contribuir na diferenciação do coração de atleta de outras situações patológicas através da avaliação da geometria ventricular ${ }^{245,246}$ e também da presença ou ausência de realce tardio no miocárdio. Porém, não deve nunca ser utilizada como único critério nesta diferenciação, sendo sempre incluída num contexto clínico e fisiopatológico apropriado.

\section{Cardiomiopatia dilatada}

A RMC é capaz de demonstrar e quantificar de forma clara e eficaz as alterações anatômicas e funcionais da cardiomiopatia dilatada $(C M D)^{241}$. Esta técnica tem se mostrado útil na avaliação de pacientes com insuficiência cardíaca por calcular, de modo preciso, a função ventricular tanto do ventrículo direito quanto esquerdo ${ }^{58,117,247-249}$ e por distinguir a CMD de outras formas de disfunção ventricular, como a disfunção ventricular causada pela doença arterial coronária (DAC).
Na DAC, a técnica de realce tardio (RT) com gadolínio mostra áreas de fibrose subendocárdica e transmural em territórios coronários, típicos de infarto prévio. Este padrão não é observado nos pacientes com CMD com áreas de realce tardio se localizando predominantemente no mesocárdio ou e não seguindo a distribuição segmentar das coronárias ${ }^{250,251}$. Estudos recentes mostram que a presença de realce tardio em pacientes com CMD é um marcador de pior prognóstico, sendo este mais um dado fornecido pela RMC na avaliação da CMD ${ }^{252}$.

\section{Cardiomiopatia chagásica}

A doença de Chagas é uma doença infecciosa crônica causada pelo Trypanosoma cruzi. É uma causa importante de insuficiência cardíaca na América Latina253,254. A cardiomiopatia chagásica é caracterizada por fibrose miocárdica nos estudos patológicos ${ }^{255-257}$, causando dilatação e disfunção ventricular esquerda e direita, além de arritmias ventriculares. A RMC pode avaliar as alterações morfológicas de forma precisa e medir a fração de ejeção de VE e VD no seguimento destes pacientes ${ }^{258}$.

Recentemente foi mostrado que a técnica de realce tardio miocárdico pode detectar fibrose miocárdica em todos os três estágios distintos de evolução da doença de Chagas: desde os assintomáticos com função normal, passando pelos com cardiopatia chagásica estabelecida, até aqueles com disfunção de VE grave associada à taquicardia ventricular documentada ${ }^{258}$.

Os segmentos inferolateral basal e apical do VE são os mais frequentemente afetados pela fibrose miocárdica, em concordância com os estudos patológicos. A fibrose miocárdica quantificada correlacionou-se diretamente com o estágio de gravidade da doença, a classe funcional da NYHA e com o grau de disfunção regional e global do VE.

Portanto, o realce tardio por RMC pode detectar a fibrose miocárdica na doença de Chagas, mesmo nos estágios mais precoces da doença, quando outros métodos não podem detectar qualquer envolvimento cardíaco. A fibrose miocárdica progride em paralelo aos fatores prognósticos bem estabelecidos e a função global e segmentar do VE. Esta informação única da RMC pode ajudar a estratificar mais precisamente os estágios de gravidade da cardiopatia chagásica, melhorando a estimativa prognóstica e nosso entendimento da fisiopatologia da cardiopatia chagásica.

\section{Displasia/cardiomiopatia arritmogênica do ventrículo direito}

A displasia/cardiomiopatia arritmogênica do ventrículo direito (DAVD) se caracterizada pela substituição segmentar ou difusa do miocárdio normal do ventriculo direito por tecido gorduroso ou fibro-gorduroso ${ }^{259-261}$. Em geral os pacientes são homens jovens que apresentam arritmias ventriculares, freqüentemente grave e associada morte súbita, particularmente durante atividade física ${ }^{262-}$ 
264. A DAVD possui um componente familiar sendo observada mais frequentemente em algumas regiões geográficas do globo 260 . A DAVD é considerada uma doença progressiva que potencialmente pode levar a insuficiência cardíaca e a morte após um período de tempo variável. O diagnóstico se baseia em critérios clínicos e laboratoriais internacionalmente aceitos ${ }^{265}$.

A RMC é atualmente considerada o melhor método diagnóstico tanto para a avaliação da anatomia quando para a função do VD ${ }^{266}$. Por esse motivo passou a ter um papel significativo no diagnóstico e no acompanhamento da DAVD ${ }^{267}$. Trabalhos recentes sugerem que os achados anormais na RMC são preditores de eventos adversos na $\mathrm{DAVD}^{268}$. Devido à capacidade da RMC em detectar tecido gorduroso e fibro-gorduroso, tem sido sugerido que esse método possui a capacidade de realizar o diagnóstico da DAVD baseado no reconhecimento do marcador histopatológico dessa doença ${ }^{269}$. Contudo, uma série de considerações teóricas e práticas devem ser levadas em consideração nesse caso: a presença de tecido gorduroso no VD é encontrado em várias situações, inclusive em indivíduos normais ${ }^{270-272}$. Além disso, apesar da presença de focos de fibrose no VD possuir uma boa correlação com achados histopatológicos e como preditor de focos de taquicardia ventricular durante a realização de estudos eletrofisiológicos ${ }^{273}$, as limitações técnicas associadas à resolução espacial ainda não permitem a detecção de pequenos depósitos de infiltração gordurosa e fibrogordurosa. Por essa razão, a detecção de gordura e fibrose pela RMC para o diagnóstico de DAVD é atualmente menos importante que no passado sendo as alterações funcionais e morfológicas (como a presença de aneurisma ou o desarranjo trabecular) mais importantes ${ }^{274}$. Muitos desses achados são discretos sendo demonstrados apenas pela RMC. A experiência na interpretação em relação ao VD é um fator necessário para a correta interpretação dos achados, devido as variantes normais do VD serem maiores que as do VE. Portanto os achados isolados devem ser interpretados com precaução para se evitar excessos de diagnóstico da doença ${ }^{275}$.

\section{Cardiomiopatia siderótica}

Uma causa normalmente pouco considerada de insuficiência cardíaca congestiva inclui o depósito de ferro no miocárdio. Esta situação é bastante comum em pacientes com hemocromatose por diversas doenças ou em anemias graves hereditárias que requerem transfusões repetidas desde o nascimento ${ }^{276}$. Destas, a beta-talassemia major se destaca, sendo a insuficiência cardíaca a maior causa de morte nestes pacientes ${ }^{277}$. A quantificação do depósito precoce do ferro miocárdico pode ser realizada através da RMC utilizando os valores de T2* (lê-se T2 estrela) ${ }^{278}$, com alta reprodutibilidade ${ }^{279,280}$ e facilidade de realização ${ }^{281}$, sendo valores abaixo de $20 \mathrm{~ms}$ associados à disfunção ventricular ${ }^{278}$. Além disso, a possibilidade de num mesmo exame também se estudar com a técnica de $\mathrm{T} 2{ }^{*}$ a concentração de ferro hepático permite uma investigação bastante abrangente do paciente. Dada a limitação de biópsias invasivas seriadas do miocárdio e da quantificação de ferro menos acurada por outros métodos, a RMC vendo sendo utilizada para seguimento de pacientes em terapia quelante $282-285 \mathrm{com}$ grande valor na prática clínica ${ }^{286}$.

\section{Cardiomiopatia restritiva}

A cardiomiopatia restritiva se caracteriza por apresentar disfunção diastólica, sendo as causas mais freqüentes em nosso meio a amiloidose e endomiocardiofibrose.

As alterações encontradas são rigidez das paredes ventriculares, dificultando o enchimento ventricular, função sistólica relativamente normal, dilatação biatrial e ventrículo esquerdo com tamanho normal ${ }^{287}$. A presença de trombos é comum e necessita ser descartada ${ }^{288}$. 0 ecocardiograma identifica estas alterações adequadamente, porém o espessamento pericárdico, importante para o diagnóstico diferencial de pericardite constritiva ${ }^{289}$, pode não ser visualizado pelo método ${ }^{290}$.

Com o uso da RMC na amiloidose podemos detectar a perda de sinal em T1 e T2 indicando infiltrado amilóide no miocárdio, bem como a dilatação biatrial, espessamento parietal atrial e ventricular e do tecido valvular, em 4 câmaras e em eixo curto $^{291}$.

A endomiocardiofibrose é caracterizada por fibrose endocárdica, geralmente associada à eosinofilia (síndrome de Loeffler), acometendo um ou ambos os ventrículos. A fibrose pode preencher o ápex dos ventrículos como uma massa fibrosa, calcificação e trombos, nem sempre diferenciados pelo ecocardiograma ${ }^{292,293}$. A RMC é mais efetiva em demonstrar a extensão da fibrose, principalmente no ventrículo direito e a ausência de espessamento pericárdico (diagnóstico diferencial com pericardite constritiva) ${ }^{294}$, definindo também, devido à diferença de sinal, miocárdio normal adjacente à fibrose endocárdica.

\section{Miocardite}

O diagnóstico definitivo da miocardite é feito pela biopsia endomiocárdica. A RMC pode nos direcionar para este diagnóstico, principalmente através de duas técnicas.

A primeira, voltada para a pesquisa de inflamação, utiliza imagens ponderadas em T1 e T2 que podem demonstrar aumento de sinal de forma precoce, logo após a administração de contraste, permitindo, inclusive, acompanhar a evolução da inflamação no miocárdio $295-297$.

A segunda utiliza a técnica do realce tardio ${ }^{298}$, sendo realizada dez a quinze minutos após a administração do contraste, onde se avalia áreas de necrose ou fibrose. Por esta técnica é possível fazer o diagnóstico da doença tanto na fase aguda como após algumas semanas da manifestação da mesma, sendo possível diferenciar a miocardite do infarto agudo do miocárdio, caracterizando padrões distintos de necrose ou fibrose ${ }^{299}$. O padrão na miocardite muitas vezes é visto como sendo multifocal, 
heterogêneo, que poupa a região subendocárdica e sem relação com a topografia coronária, bastante diferentes do padrão de realce por isquemia miocárdica ${ }^{252}$.

A combinação das técnicas de T1/T2 juntamente com a detecção de áreas de realce tardio dá à RMC uma alta capacidade diagnóstica com sensibilidade de $76 \%$, especificidade de $96 \%$ e acurácia de $85 \%{ }^{300}$, superior à cintilografia e podendo ser considerada como um dos métodos de escolha para avaliação da doença ${ }^{301,302}$.

\section{Miocárdio não compactado}

Esta é uma doença de herança autossômica dominante, com conseqüente falha no desenvolvimento embrionário do miocárdio ${ }^{303,304}$. Está correlacionada com arritmias ventriculares e disfunção, havendo relato de casos com indicação de transplante ${ }^{305}$. Estudos recentes têm apontado a RMC como o método ideal para diagnóstico desta doença dada a alta resolução espacial ${ }^{306}$. Recentemente foi demonstrado que um índice de miocárdio não compactado sobre miocárdio compactado acima de 2.3 na diástole determinado pela RMC tem sensibilidade de $86 \%$ e especificidade de $99 \%$ para detecção da doença ${ }^{307}$. A RMC pode, ainda, determinar possíveis defeitos de perfusão subendocárdicos presentes também em pacientes com esta alteração miocárdica ${ }^{308}$.

\section{Sarcoidose cardíaca}

Sarcoidose cardíaca é uma condição infreqüente, porém relacionada a arritmias, com possibilidade de morte súbita, podendo ser esta sua apresentação inicial. O grande desafio nesta doença é o diagnóstico de forma não invasiva. Neste sentido, a RMC tem se mostrado de grande valor ${ }^{309,310}$. 0 uso do realce tardio trás informações adicionais por demonstrar maior intensidade de sinal quando na presença de sarcoidose ${ }^{311-313}$. Além do diagnóstico, a ressonância agrega informações no seguimento destes pacientes já que a intensidade de sinal vista com o auxílio do realce tardio diminui com o tratamento ${ }^{314}$.

\section{Cardiomiopatia periparto}

Atualmente considera-se a cardiomiopatia periparto (CMP) uma cardiomiopatia de causa desconhecida que incide no período periparto em mulheres sem doença cardíaca prévia, com taxas de mortalidade variando de 18 a $56 \% 315,316$.

Estudos recentes demonstraram que o exame de RMC com o uso de contraste paramagnético (gadolínio) com técnica de realce tardio é um método não-invasivo, rápido e acurado no delineamento de miocárdio irreversivelmente lesado ${ }^{196}$. A aplicação da técnica de realce tardio em modelos animais e pacientes com cardiomiopatia é bastante rara, provavelmente em função de limitações técnicas apenas superadas nos últimos 5 anos. Hiroko et al demonstraram, em modelo animal de cardiomiopatia, que a RMC pode detectar fibrose miocárdica como áreas de elevado sinal decorrentes da concentração do contraste paramagnético nestas regiões ${ }^{317}$.

Recentemente foi demonstrado que também em humanos a RMC podia detectar fibrose miocárdica nestas pacientes, de forma não-invasiva, com áreas de realce tardio de padrão heterogêneo e presentes em $25 \%$ das mulheres seguidas.

Pelo seu caráter não-invasivo e possibilidade de estudos seriados, poderá tornar-se recurso diagnóstico complementar à biópsia endomiocárdica possivelmente na avaliação de progressão da fibrose miocárdica, uma vez que esta tem limitações importantes por sua natureza invasiva e focal.

\section{Transplante cardíaco}

A avaliação da função ventricular após o transplante cardíaco é essencial para o seguimento dos pacientes transplantados. A variabilidade anatômica pós-transplante torna a RMC um método de excelência pela sua boa reprodutibilidade, com resultados concordantes aos obtidos pela ventriculografia radioisotópica ${ }^{318}$.

Detectar episódios de rejeição aguda ao transplante e identificar doença vascular do enxerto (considerada rejeição crônica) são dois problemas comuns nos pacientes transplantados. A identificação da rejeição aguda requer avaliação histopatológica, mas pode ser indicada por alterações vistas com a RMC: aumento da massa ventricular ${ }^{319}$, áreas de maior intensidade de sinal do miocárdio, com aumento nos valores de T2 ${ }^{320,321}$, além de perspectivas ainda em estudo dadas pela espectroscopia que avalia variação no estado metabólico no miocárdio ${ }^{322,323}$. Todas estas alterações descritas se correlacionam com edema de miocárdio ou infiltrado de mononucleares.

Outra complicação freqüentemente descrita no pós transplante é a disfunção do ventrículo direito, cuja visualização pela RMC é reconhecidamente superior aos outros métodos de imagem ${ }^{324}$.

A clássica técnica cirúrgica de transplante cardíaco resulta em aumento da cavidade atrial, de forma que a análise dos volumes atriais complementam o seguimento dos pacientes transplantados, sendo realizado de forma confiável com o uso da RMC ${ }^{325}$.

A RMC pode ainda ajudar a detectar doença arterial coronária associada ao transplante cardíaco $0^{326}$, complicações como doenças pericárdicas, massas intracavitárias ${ }^{327}$ e os efeitos do tratamento de medicamentoso ${ }^{328}$ no remodelamento associado ao uso prolongado de ciclosporina ${ }^{329}$.

\section{Doenças do pericárdio}

A RMC é bem indicada para avaliação e definição de alterações anatômicas do pericárdio incluindo aí espessamentos e derrames deste ${ }^{330}$. A ressonância tem como principal característica a habilidade de definir e quantificar as alterações funcionais e dinâmicas que podem estar relacionadas às pericardiopatias. A grande 
área de visualização da RMC é também de grande ajuda em prover uma visão completa da extensão do dano pericárdico e definir seus limites junto a estruturas adjacentes $^{331}$. Na suspeita de espessamento pericárdico a RMC pode ser considerada como um método de imagem de primeira escolha. As indicações da RMC na avaliação do pericárdio estão resumidas na tabela 6 .

\section{Tabela 6 - Indicações de RMC na avaliação de doenças pericárdicas, tumores e trombos}

Indicação

Classe

1. Detecção e caracterização de tumores cardíacos e pericardíacos

2. Detecção e diagnóstico diferencial de trombos ventriculares

3. Pericardite constritiva

I

4. Derrame pericárdico isolado

IIa

5. Detecção de trombos atriais e em apêndice atrial

III

\section{Derrame pericárdico}

Derrames pericárdicos, na sua maioria, são facilmente identificados pelo ecocardiograma transtorácico. A RMC, utilizando técnicas de cine, também facilmente visualiza derrames pericárdicos como áreas de grande intensidade de sinal devido ao seu conteúdo líquido ${ }^{332}$. Em casos de tamponamento pericárdico, a fisiologia constritiva também pode ser facilmente identificada. A RMC, em muitos casos, é de grande valia na identificação de derrames septados e complexos, auxiliando na sua localização e planejamento cirúrgico quando estes dados não são possíveis pelo ecocardiograma.

\section{Pericardite constritiva}

As alterações anatômicas e funcionais características da doença pericárdica constritiva (alongamento e estreitamento do ventrículo direito, movimento anormal do septo interventricular, aumento atrial direito e da veia cava inferior, fluxo atrial lento e espessamento pericárdico) são facilmente identificadas com cine RMC associada a imagens anatômicas de sangue escuro. Técnicas de tempo real $^{333}$ e avaliações geométricas do septo ${ }^{289}$ permitem à RMC fazer o diagnóstico diferencial entre pericardite constritiva e cardiomiopatias restritivas.

A RMC é superior a ecocardiografia na mensuração do espessamento pericárdico ${ }^{334}$ embora a ecocardiografia tenha a vantagem de possibilitar a mensuração hemodinâmica mais facilmente. 0 espessamento pericárdico é classicamente a principal característica da pericardite constritiva, no entanto casos de constrição pericárdica na ausência de espessamento já foram descritos ${ }^{335}$. Devemos então considerar que a ausência de espessamento pericárdico não exclui o diagnóstico quando verificamos a presença de fisiologia constritiva ${ }^{336}$.

\section{Anomalias congênitas do pericárdio}

Cistos pericárdicos podem ser identificados e distinguidos de outros tumores baseando-se em suas características de intensidade de sinal e localização ${ }^{337}$. Agenesia de pericárdio pode ser identificada simplesmente pelo desvio do eixo do coração para esquerda ou herniação de parte do coração no caso de agenesia parcial ${ }^{338}$.

\section{Tumores e trombos}

A ecocardiografia transtorácica é a técnica mais disponível na avaliação inicial dos tumores intra-cardíacos. Entretanto, na maioria dos casos a caracterização do tipo histológico e relações com estruturas anatômicas é incompleta. Neste sentido, a RMC é particularmente útil, determinando precisamente a relação com estruturas anatômicas normais, a extensão do tumor, a invasão ou não de estruturas vasculares e mediastinais adjacentes e para planejamento cirúrgico ${ }^{339}$. Além disso, há múltiplas características que a RMC pode fornecer na definição do tipo histológico tumoral ${ }^{340}$. A intensidade de sinal de uma lesão é dependente na interação entre a composição do tecido e os parâmetros da RMC empregado para a arquisição da imagem. $\mathrm{O}$ diagnóstico diferencial de uma lesão com alto sinal em seqüências ponderadas em T1 incluem tumores com grande conteúdo de gordura (lipoma, liposarcoma), hemorragias subagudas (devido ao produto de degradação da metahemoglobina), algumas lesões císticas (devido à elevado conteúdo de proteína nos cistos), e melanoma (devido aos efeitos da melanina) ${ }^{341}$. Uma lesão com baixa intensidade de sinal em seqüencias ponderadas em T1, podem representar um cisto cheio de líquido com baixo conteúdo protéico, um sinal de fluxo turbulento em uma malformação vascular, uma lesão calcificada ou a presença de ar. Cistos tipicamente apresentam alta intensidade de sinal em T2, independente da concetração protéica do líquido ${ }^{342}$. Seqüências com saturação de gordura podem ser usados para diagnosticar conteúdo de gordura ${ }^{343}$. Diferenciações adicionais dos tumores podem ser feitos com a administração de um meio de contraste, o gadolínio. Durante a primeira passagem, tumores vasculares (hemangioma, angiosarcoma) mostra realce precoce e pequenos vasos podem ser facilmente identificados. Na fase precoce, após a injeção em 1-2 minutos, áreas necróticas em tumores malignos mostramse como áreas escuras circundados por realce periférico. $\mathrm{Na}$ fase tardia, tumores malignos apresentam realce ao contraste, indicando vascularização do tecido. 0 realce é geralmente ausente em lesões císticas e a maioria de tumores benignos (hemangiomas e mixomas que são exceções). Os trombos dentro dos ventrículos são bem demonstrados na RMC, sobretudo em seqüências de realce tardio, sendo mais sensível do que a echocardiografia ${ }^{344}$. As indicações da RMC na avaliação dos tumores e de trombos estão na tabela 6.

\section{Doenças valvares}

Um método de imagem potencialmente contribui na investigação de lesões valvares de três formas: avaliação morfológica das valvas, detecção de disfunções valvares e 
quantificação destas disfunções. O método de RMC oferece a opção de múltiplos planos de corte para a avaliação da morfologia valvar. Como as valvas são estruturas dinâmicas, idealmente devem ser avaliadas em movimento e para isto se utiliza a técnica de cine-ressonância. Esta seqüência possui duas limitações na avaliação valvar: o baixo contraste entre a estrutura valvar e as cavidades cardíacas e a relativa baixa resolução temporal. Estas duas características fazem do ecocardiograma um método superior à ressonância na avaliação de morfologia e dinâmica valvar.

A partir da imagem de cine-ressonância, pode-se observar a presença de lesões regurgitantes e estenoses. Normalmente a cavidade cardíaca na seqüência de gradiente eco apresenta hiperintensidade homogênea de sinal. Na presença de fluxo turbulento, ocorre redução acentuada do sinal nestas regiões (sinal negativo). Assim, um fluxo turbulento é caracterizado por uma área mais escura dentro da respectiva cavidade. Desta forma, a simples detecção de disfunção valvar é facilmente obtida pelo método de ressonância. Intuitivamente, pode-se imaginar que a gravidade das lesões guarda relação com o tamanho da área de sinal negativo. De fato, esta associação tem sido demonstrada em lesões regurgitantes ${ }^{345}$. No entanto, a área de sinal negativo varia significativamente com parâmetros de aquisição de imagem (tempo de eco, espessura do corte, dimensão do pixel, etc), o que pode alterar a estimativa da gravidade da lesão ${ }^{346}$. A orientação da imagem também pode influenciar neste dado, principalmente em jatos excêntricos. Devido a estas limitações, a inspeção visual da área de sinal negativo deve ser considerado um método semi-quantitativo na avaliação das lesões regurgitantes. Apesar destas limitações, os métodos semi-quantitativos tem boa correlação com 0 doppler ecocardiográfico ${ }^{347}$, podendo ser utilizados para caracterizar a gravidade das lesões regurgitantes.

A função semi-quantitativa deste método para lesões estenóticas está menos estabelecida. Recentemente, porém, foi demonstrado que a RMC pode realizar a planimetria da abertura tanto da valva mitral ${ }^{348}$ quanto da valva aórtica ${ }^{349,350} \mathrm{com}$ alta acurácia e pode ser utilizado como um método adicional em casos de dúvidas do grau de importância destas estenoses.

A quantificação mais precisa de lesões valvares pode ser realizada pela ressonância magnética utilizando a seqüência de contraste de fase (phase-contrast). Resumidamente, a intensidade de sinal obtido da respectiva cavidade cardíaca ou vascular se correlaciona com a velocidade de fluxo ${ }^{346}$. Desta forma, curvas da variação da velocidade de fluxo em relação ao momento do ciclo cardíaco podem ser obtidas, com cálculo do gradiente transvalvar pela equação de Bernoulli e a área valvar pela equação de continuidade, nos casos de lesões estenóticas. Em lesões regurgitantes, utilizando a integral desta curva e o tamanho do pixel, pode-se calcular fluxo anterógrado e retrógrado, obtendo-se assim o fluxo regurgitante. Portanto, matematicamente, a técnica de contrate de fase tem o potencial de quantificar de forma acurada e precisa lesões valvares.
Em relação à estenose ${ }^{351}$ e insuficiência aórtica ${ }^{86}$, há trabalhos envolvendo pequeno número de pacientes sugerindo ser um método acurado quando comparado à avaliação hemodinâmica invasiva e preciso quando realizada mais de uma medida no mesmo indivíduo. Quanto à estenose mitral, o jato produzido por esta é mais complexo do que na estenose aórtica, muitas vezes em mais de uma direção. Devido a isto, a acurácia da ressonância tende a ser menor do que na estenose aórtica, porém ainda em níveis satisfatórios ${ }^{352}$. Na regurgitação mitral, a técnica de cálculo do fluxo regurgitante não parece adequada, pois há intensa movimentação longitudinal do plano do anel mitral durante o ciclo cardíaco. Alternativamente, estima-se o volume sistólico pela técnica geométrica de Simpson, subtraindo este pelo volume efetivo obtido pelo contraste de fase da via de saída do ventrículo esquerdo. Assim, obtém-se o volume regurgitante, com acurácia satisfatória sugerida por trabalhos envolvendo pequeno número de indivíduos ${ }^{353,354}$. Tecnicamente as valvas pulmonar e tricúspide podem ser avaliadas da mesma forma que as respectivas valvas esquerdas. Porém a acurácia da ressonância em relação a estas valvas tem sido menos estudada.

Quanto à avaliação de próteses valvares, a interação destas com o campo magnético não tem relevância clínica a ponto de contra-indicar o exame. No entanto, o artefato gerado pelo metal da prótese impede que estas sejam visualizadas. Experiência inicial com prótese aórtica demonstra que, obtendo uma amostra distante da prótese, é possível quantificar fluxo ${ }^{355}$, porém a acurácia desta medida ainda não foi definitivamente validada.

A RMC possui alta reprodutibilidade no cálculo de volumes ventriculares e fração de ejeção, sendo assim um excelente método para acompanhamento destes parâmetros ao longo do tempo, em um mesmo indivíduo com lesão regurgitante. Assim, pode-se detectar com precisão pequenas mudanças que indicariam o momento ideal de uma intervenção cirúrgica. Atualmente se utiliza o ecocardiograma para fazer este tipo de acompanhamento. No entanto, reprodutibilidade do ecocardiograma é significativamente inferior à ressonância em relação a medidas de volumes ventriculares e fração de ejeção $0^{58}$. Desta forma, ressonância pode ser um método vantajoso para esta indicação. Porém não há trabalhos confirmando que a decisão do momento cirúrgico obtida pela ressonância influencia no desfecho clínico em relação à decisão baseada no ecocardiograma. Este dado é importante em se considerando o maior custo e menor disponibilidade do método de ressonância.

Em conclusão, apesar de não ser um método ideal para avaliação anatômica e dinâmica de valvas cardíacas, a RMC é capaz de detectar a disfunção valvar e quantificála com acurácia e precisão satisfatória. Por outro lado, deve-se considerar que estes dados são provenientes de pequenos trabalhos e não há estudos testando a associação de informações obtidas por ressonância com quadro clínico, prognóstico e resposta terapêutica em pacientes portadores de lesões valvares. Além disso, a ressonância é um método 
laborioso para avaliação quantitativa de lesões valvares. Desta forma, podemos concluir que o ecocardiograma é o método de escolha para avaliação de lesões valvares isoladamente, em se considerando seu maior nível de validação, alta disponibilidade e baixo custo. Devido à sua alta reprodutibilidade, a ressonância pode ser útil no acompanhamento longitudinal de volumes e fração de ejeção em indivíduos portadores de lesões regurgitantes. As principais indicações do uso da RMC para avaliação das valvas cardíacas estão indicadas na tabela 7.

\begin{tabular}{|c|c|}
\hline Indicação & Classe \\
\hline 1. Avaliação da anatomia função ventricular & 1 \\
\hline 2. Quantificação da regurgitação & 1 \\
\hline 3. Quantificação e planimetria de estenoses & Ilb \\
\hline 4. Avaliação de próteses valvares & III \\
\hline \multicolumn{2}{|l|}{ 5. Morfologia valvar } \\
\hline Valva aórtica bicúspide & III \\
\hline Demais valvas & III \\
\hline Vegetações & III \\
\hline
\end{tabular}

\section{Espectroscopia}

O uso clínico da espectroscopia por RMC (ERMC) está limitado ao esstudo dos fosfatos miocárdicos que contém fósforo-31 ( $\left.{ }^{3} \mathrm{P}\right)$ e presentes em compostos bioquímicos importantes que fazem parte do metabolismo energético do miocárdio. Estes compostos são o trifosfato de adenosina (ATP), a fosfocreatina (PCr), fosfato inorgânico (Pi) e esters de mono fosfato (MPE).

$A$ ERMC do ${ }^{31} \mathrm{P}$ guiada espacialmente por imagem pode atualmente ser, de forma rotineira, aplicada para estudo dos fosfatos de alta energia da parede anterior do miocárdio, em repouso ou durante estresse, em muitos casos de pacientes estáveis.

A relação média PCr/ATP na parede anterior do ventrículo esquerdo têm sido o foco das pesquisas clínicas atuais em cardiopatias com esta técnica e fornece informações de cunho diagnóstico e prognóstico sobre o estado energético do miocárdio. Na ICC leve a relação PCr/ATP é normal ${ }^{356,357}$ e cai abruptamente com o aumento da gravidade ${ }^{356,358}$. Índices reduzidos apresentaram melhora com tratamento da $\mathrm{ICC}^{356}$ e foram preditores independentes de eventos (mais que a fração de ejeção) ${ }^{359}$. Isquemia miocárdica pode ser detectada pela queda do índice PCr/ATP durante estresse com handgrip, que desaparece após revascularização ${ }^{360}$. Miocárdio viável tem níveis normais de PCr/ATP, enquanto miocárdio nãoviável tem níveis reduzidos ${ }^{361}$. Miocárdio atordoado tem níveis da relação PCr/ATP normais ${ }^{362}$. Recente importante publicação demonstrou que em 20\% das mulheres com dor torácica e sem estenose coronária epicárdica significativa, os níveis de PCr/ATP estavam reduzidos, sugerindo papel importante da doença microvascular como causa de isquemia nesta população ${ }^{363}$.
A ERMC de outros núcleos também foi realizada em trabalhos experimentais e clínicos e tem apresentado resultados com potencial relevância clínica. São eles os núcleos de: hidrogênio $(1 \mathrm{H})^{364,365}$, sódio-23 $(23 \mathrm{Na})^{366,367}$ e o potássio-39 (39K) ${ }^{368}$. A dificuldade de aplicação rotineira deve-se ao baixo sinal destes núcleos, devido à baixa sensibilidade nuclear e baixa concentração destes elementos.

No momento a ERMC pode apenas investigar a parede anterior do coração, mas com os novos magnetos de alto campo magnético (3 Tesla) e novas bobinas especializadas, vislumbram-se grandes perspectivas futuras para o método, em função da melhora significativa na performance da técnica de ERMC. Assim, enquanto a ERMC ainda está para encontrar um papel definitivo no diagnóstico e tratamento da doença cardíaca, esta técnica oferece um meio único e não invasivo para se ter acesso ao metabolismo energético, essencial para a função cardíaca, entendimento básico de muitos distúrbios que afetam o miocárdio e, finalmente, para utilização clínica na elucidação de casos selecionados.

\section{Análise de custo-efetividade}

A crescente percepção de que os recursos financeiros disponíveis para a promoção e o atendimento da saúde da população não são ilimitados tornam as análises de custo-benefício dos procedimentos médicos cada vez mais importantes ${ }^{369}$. O desenvolvimento de novos métodos diagnósticos e procedimentos terapêuticos cada vez mais dependentes de alta tecnologia faz com que exista uma perspectiva de que este tipo de análise adquira relevância ainda maior no futuro ${ }^{370}$.

No caso específico dos métodos diagnósticos, é importante que se compare os novos testes propostos para avaliar uma determinada doença com os testes diagnósticos convencionalmente utilizados para este $\mathrm{fim}^{4,5}$. Nesta comparação devem ser considerados 3 aspectos distintos pelo médico que solicitar o exame:

1. Deve-se comparar a qualidade da informação proporcionada por cada teste, tanto em termos de volume de informações, como em termos de acurácia dos dados obtidos. Como já discutidos nas sessões anteriores, a RMC proporciona, em um único exame, um grande volume de informações (caracterização anatômica e funcional detalhadas, perfusão miocárdica, detecção e quantificação do infarto, viabilidade miocárdica, diagnóstico etiológico das cardiomiopatias, etc), com excelentes índices de acurácia quando comparada às demais modalidades diagnósticas.

2. Deve-se avaliar os riscos relacionados aos procedimentos diagnósticos. A RMC é um método nãoinvasivo que não utiliza nenhum tipo de radiação ionizante ou qualquer tipo de contraste iodado. 0 gadolínio é o meio de contraste padrão utilizado nos exames de RM e apresenta excelente perfil de segurança, com efeitos colaterais muito raros e, quando presentes, discretos. 
O estresse farmacológico no ambiente da RM apresenta o mesmo perfil de segurança do ecocardiograma com dobutamina e da cintilografia miocárdica ${ }^{141}$.

3. Finalmente, deve-se comparar o custo financeiro direto dos procedimentos diagnósticos (incluindo filmes, medicamentos, contrastes).

No caso da ressonância e da tomografia cardiovascular, um aspecto importante também deve ser citado em comparação com outros exames convencionais de ressonância e tomografia de demais órgãos. A aquisição das imagens cardíaca usualmente requer a presença de um médico especializado ao lado do técnico, muitas vezes sendo este diretamente responsável pela realização direta do procedimento. Além disso, a preparação e a aquisição das imagens na área cardíaca é também mais longa que em exames de outras localidades pois no caso do coração os exames exigem pausas respiratórias diversas, uso de medicamentos antes ou durante o procedimento, sendo não incomum estes exames durarem o dobro de tempo de exames convencionais. Finalmente, também o pós-processamento é mais longo já que o número de imagens obtidas é extremamente alto e as reconstruções são fundamentais para a correta interpretação do exame. Todos estes fatores devem ser considerados ao se estimar o custo final de cada procedimento.

Baseado numa pesquisa de custos entre diversos centros no Brasil, atualmente o custo de um exame de RMC ou tomografia de coronárias é semelhante a um exame de cintilografia miocárdica para avaliação de perfusão miocárdica por medicina nuclear considerando os valores relativos a honorários médicos, medicamentos e filme utilizados.

\section{Tomografia Computadorizada}

O uso da tomografia computadorizada (TC) para avaliação cardiovascular ganhou força desde o início da década com o surgimento e maior disponibilização de aparelhos de múltiplos detectores ou multislice (TCMD) ${ }^{371}$. Deve-se lembrar que o termo tomografia computadorizada é um termo genérico que pode ser aplicado para diversas modalidades (por exemplo, no SPECT), mas por convenção neste texto estaremos nos referindo apenas ao seu uso através da captação de raio-X.

O uso da TC está ligado principalmente ao diagnóstico da doença coronária372. 0 escore de cálcio já é utilizado há algum tempo e, mais recentemente, a angiotomografia vem sendo empregada para avaliação da anatomia coronária. Com os novos aparelhos e softwares disponíveis no mercado, além da avaliação coronária também é possível através da TC a avaliação da função global e regional dos ventrículos, cálculo de massa e avaliação valvar. A evolução tecnológica dos aparelhos de TC é extremamente rápida, com quase duplicação da quantidade de imagens obtidas por segundo a cada 2 anos, o que torna as indicações para sua aplicação clínica também bastante dinâmica, exigindo uma atualização constante dos especialistas na área ${ }^{373}$.

\section{Técnica, radiação e contraste na tomografia}

A introdução da TC na prática clínica se deu em 1973 com a aplicação em massa a partir da década de 80 . O princípio básico da TC é baseado na emissão de um feixe de raio- $X$ no formato de hélice que passa pelo corpo por diversos ângulos permitindo a criação de imagens seccionais $^{374}$. A projeção destes raios é coletada por detectores na outra ponta do aparelho e estas informações são transformadas em pontos digitais. 0 valor de cada um destes pontos é medido a partir de uma unidade de referência denominada unidade de Hounsfield (HU), sendo preconizado o valor $0 \mathrm{HU}$ para água, $-1000 \mathrm{HU}$ para o ar e $+1000 \mathrm{HU}$ para o osso cortical. Assim, baseado nesta escala de 2000 valores distintos, é possível se definir a densidade dos diferentes tecidos atingidos pelos raios- $X$.

Esta técnica de TC pode foi empregada de duas maneiras distintas na fabricação dos equipamentos de tomografia $^{375}$. Em determinados tipos de aparelho, a formação dos raios-X se dá pela emissão de um feixe de elétrons rotativos - são os aparelhos de emissão de feixes de elétrons (EBT). Este tipo de aparelho, embora não tenha a mesma resolução espacial que os atuais aparelhos de TCMD, possui alta resolução temporal, permitindo imagens com até $50-100$ ms. a resolução espacial destes aparelhos está na ordem de $0.8 \times 0.8$ $X 1.5 \mathrm{~mm}^{376}$. Os aparelhos de EBT, embora possam ser utilizados para outros fins e até para detecção de estenoses coronárias $^{377}$, são especificamente empregados na determinação da calcificação arterial coronária dado sua alta resolução temporal.

Nos demais tipos de aparelho, os raios- $X$ são gerados a partir de tubo que gira em torno do paciente enquanto o mesmo é gradativamente movido através deste arco, formando uma imagem em espiral (helicoidal) ${ }^{378}$. $\mathrm{Na}$ outra ponta do tubo, a $180^{\circ}$ no arco, existe uma ou mais colunas de detectores que captam os raios. Com o desenvolvimento da tecnologia de TC, vários detectores foram acrescentados aos aparelhos dando origem aos atuais TCMD. Atualmente, existem para uso clínico aparelhos de 4, 8, 16 e 64 detectores e, mais recentemente, já foi disponibilizado no mercado um aparelho com duas fontes simultâneas de raio- $X$ com 64 detectores para cada tubo gerador. A resolução espacial dos atuais aparelhos de TCMD está em 0.4 $\times 0.4 \times 0.4 \mathrm{~mm}$, o que resulta em um voxel isotrópico (com medidas semelhantes em ambos os lados), ainda aquém da resolução espacial da angiografia convencional (0.1 a $0.2 \mathrm{~mm}$, com resolução temporal de $8 \mathrm{~ms}$ ) mas já em níveis que permitem a definição de estenoses coronárias. A resolução temporal dos atuais aparelhos depende não só do número de detectores mas também 
da velocidade de rotação do tubo gerador, atualmente num máximo de 0.33 segundos, permitindo resoluções de $165 \mathrm{~ms}$, chegando até $100 \mathrm{~ms}$ através da utilização de determinados algoritmos de software ${ }^{379}$. Com os aparelhos de duas fontes, a resolução espacial chega a 83 ms, muito próximo da resolução espacial ideal de 50 ms para se "congelar" a imagem cardíaca independente do número de batimentos por minuto ${ }^{380}$.

Assim como na RMC, as imagens adquiridas por TC são sempre ajustadas pelo monitoramento do eletrocardiograma do paciente e dependem de um ritmo regular e, no caso da angiotomografia, de uma freqüência cardíaca a mais próxima possível de 60 batimentos por minuto. Para aquisição das imagens de TC cardiovascular também é necessário que o paciente faça pausas respiratórias com duração entre 8-20 segundos dependendo do tipo de aparelho utilizado, tamanho do paciente e tipo de exame. Na realização de exames para detecção apenas do escore de cálcio, não é necessário o uso de contraste endovenoso, porém no caso da angiotomografia este é fundamental (ver abaixo). Também no caso da angiotomografia de coronárias, é rotina na maioria dos serviços a utilização de doses de beta-bloqueadores ou bloqueadores de canal de cálcio, utilizados por via oral ou endovenosa, para a redução da freqüência cardíaca do paciente caso esta esteja acima de 60 a 65 batimentos por minuto ${ }^{381}$. Isto é necessário devido à baixa resolução temporal dos atuais aparelhos de TCMD, mas pode deixar de um pré-requisito para a realização do exame conforme novas tecnologias surjam para uso clínico. Alguns serviços também preconizam o uso de nitratos sublinguais previamente ao exame para dilatar as coronárias e aumentar o diâmetro das mesmas, potencialmente melhorando a qualidade da imagem obtida ${ }^{382}$.

Finalmente, com os novos tomógrafos, a quantidade de imagens obtidas por exame aumentou consideravelmente ${ }^{383}$. Assim, as imagens de tomografia, sejam para escore de cálcio ou angiotomografia de coronárias, exigem que estas sejam analisadas numa estação de trabalho a parte utilizando técnicas de reconstrução tridimensionais como as já aplicadas na $\mathrm{RMC}^{384}$.

\section{Radiação}

Diferentemente da ressonância, os exames de TC são baseados na emissão de raios- $X$ e, portanto, expõem 0 paciente a doses clinicamente significativas de radiação. Isto é de extrema importância principalmente quando analisamos que a TC pode eventualmente se tornar um exame de triagem para doença coronária ou ser utilizado para seguimento crônico, submetendo o paciente a repetidos exames seriados ao longo de sua vida. Para comparação das doses de radiação das diversas técnicas de tomografia com outros exames realizados convencionalmente na doença coronária, destacamos a tabela $8^{385-392}$. Da tabela, podemos observar que a angiotomografia atualmente realizada tem dose muito próxima de um exame de cintilografia para pesquisa de isquemia, mas é superior ao de um cateterismo diagnóstico não terapêutico.

É importante notar que a radiação efetivamente absorvida depende não apenas do próprio paciente, mas

\begin{tabular}{|c|c|}
\hline \multicolumn{2}{|c|}{$\begin{array}{c}\text { Tabela } 8 \text { - Radiação dos métodos de tomografia e } \\
\text { demais métodos diagnósticos em cardiologia }\end{array}$} \\
\hline Situação & \\
\hline Exposição natural ao ambiente (anual) & 2,5 a 3,6 \\
\hline Radiografia de tórax - 2 incidências & 0,1 a 0,3 \\
\hline Escore de cálcio (EBTC) & 1,1 \\
\hline Escore de cálcio (TCMD) & 1,7 a 2,5 \\
\hline Angiotomografia (EBTC) & 1,7 \\
\hline Angiotomografia (TCMD) 16 detectores & 9,3 a 11,3 \\
\hline Angiotomografia (TCMD) 64 detectores & 13 a 17 \\
\hline $\begin{array}{l}\text { Angiotomografia (TCMD) } 16 \text { detectores com } \\
\text { modulação de dose }\end{array}$ & 5,0 a 6,4 \\
\hline $\begin{array}{l}\text { Angiotomografia (TCMD) } 64 \text { detectores com } \\
\text { modulação de dose }\end{array}$ & 5,4 a 9,4 \\
\hline SPECT repouso + stress (99Tc-sestamibi) & 7,0 \\
\hline SPECT repouso (201TI) & 18 \\
\hline Angiografia coronária diagnóstica & 2,3 a 5,6 \\
\hline Angioplastia coronária terapêutica & 10 a 19 \\
\hline \multicolumn{2}{|c|}{$\begin{array}{l}\text { EBTC, tomografia computadorizada por feixe de elétrons; TCMD, } \\
\text { tomografia computadorizada de múltiplos detectores; mSv, } \\
\text { milisievert; Tc, tecnésio; TI, tálio } \\
\text { * Média homens e mulheres }\end{array}$} \\
\hline
\end{tabular}

também da corrente do tubo aplicada durante o exame e do uso ou não de técnicas que atenuam a aplicação do raio- $X^{393}$. Atualmente, a modulação da dose utilizada na angiotomografia de coronárias ocorre através da redução da corrente nas fases do ciclo cardíaco onde o coração está em maior movimento (próximo à sístole, por exemplo), voltando à voltagem normal na diástole, onde a maior parte das informações relativas às coronárias será extraída. Isto permite uma redução de cerca de $40 \%$ da dose aplicada ao paciente ${ }^{394}$. Além disso, sobretudo nos estudos de escore de cálcio, pode-se aplicar a corrente no tubo de forma prospectiva, ligada ao ECG do paciente, reduzindo-se ainda mais a radiação emitida.

Deve-se lembrar que, na eventualidade de existirem classes de indicações similares para exames de ressonância e tomografia, salvo algum benefício específico de uma determinada técnica, o exame de RMC deve ser preferido devido à inexistência de radiação ionizante.

\section{Contraste}

Também diferentemente da RMC, o contraste utilizado na TC para a realização da angiotomografia tem algumas desvantagens em relação ao gadolínio. Na angiotomografia são utilizados usualmente cerca de $80-120 \mathrm{ml}$ de contraste, em comparação com o uso de cerca de $150 \mathrm{ml}$ na angiografia invasiva. Os contrastes de tomografia são todos iodados e podem ser divididos entre aqueles de alta e baixa osmolalidade em relação ao sangue e também quanto ao fato de serem iônicos ou não iônicos. Os contrastes com alta osmolalidade tem maior propensão a 
causarem reações adversas e não são utilizados de rotina nos exames de tomografia coronária. Da mesma forma, os contrastes não-iônicos também causam menores efeitos adversos, sendo o custo o principal fator limitante ao uso indiscriminado dos mesmos.

Os pacientes com maior risco para efeitos adversos pelos contrastes iodados são principalmente aqueles com histórico de efeitos adversos prévios (urticária, broncoespasmo, edemas, etc) e pacientes com asma. Além disso, também devem ser considerados de maior risco pacientes com insuficiência renal prévia, insuficiência cardíaca, diabetes, desidratação e idade superior a 70 anos $^{395}$. Reações leves, usualmente auto-limitadas, ao contraste ocorrem em $10 \%$ dos pacientes que utilizam contrastes iônicos e 3\% dos que utilizam contrastes não iônicos. Reações graves são mais raras e ocorrem em 1 a cada 100 a 1000 pacientes ${ }^{396}$. Reações tardias podem ocorrer em 0.5 a $2.0 \%$ dos pacientes depois de 3 horas a 2 dias após 0 exame, desaparecendo usualmente com uma semana ${ }^{397}$. A nefrotoxicidade dos contrastes iodados é conhecida e é caracterizada quando ocorre uma elevação dos níveis de creatinina em $25 \%$ dos valores de base até 3 dias após 0 exame (pico do efeito nefrotóxico) ${ }^{398}$. Geralmente também é auto-limitada e a função renal se normaliza em até 10 dias. $\mathrm{Na}$ eventualidade do paciente estar utilizando metformina, este deve interromper a medicação com pelo menos 24 horas antes do exame e só reiniciá-la 48 horas após para reduzir o risco de acidose metabólica associado ao uso deste hipoglicemiante oral ${ }^{399}$

Para a prevenção de efeitos adversos aos contrastes utilizados na angiotomografia, deve-se sempre preconizar a boa hidratação do paciente (tanto na forma oral quanto endovenosa em casos selecionados) ${ }^{399}$. Além disso, a utilização de corticóides e antihistamínicos em pacientes com reações anteriores também é recomendada ${ }^{400}$. Finalmente, para a prevenção da nefrotoxicidade renal, além da hidratação já mencionada, também pode-se utilizar acetilcisteína no dia anterior e após o estudo, embora os resultados de diversos estudos ainda sejam inconsistentes ${ }^{401}$.

Assim como colocado no item da radiação, também aqui, na eventualidade de existirem classes de indicações similares para exames de ressonância e tomografia, salvo algum benefício específico de uma determinada técnica, o exame de RMC deve ser preferido devido à inexistência do uso de contrastes iodados.

\section{Escore de cálcio}

A tomografia computadorizada detecta e quantifica a calcificação arterial coronária (CAC), um marcador da presença e extensão da doença aterosclerótica. Atualmente, duas abordagens estão disponíveis para sua detecção: a tomografia computadorizada por EBTC e TCMD. Ambas apresentam capacidade similar para detecção de quantidades moderadas a importantes de aterosclerose subclínica ${ }^{402}$, porém esta última é a única disponível em nosso meio.
A calcificação coronária pela TCMD é definida como uma lesão hiperatenuante acima do limiar de densidade de 130 unidades Hounsfield (HU) em uma área de dois ou mais pixels adjacentes. 0 produto da área total de cálcio por um fator derivado da densidade máxima é o escore de cálcio publicado por Agatston et al ${ }^{403}$ e que tem o seu nome. Um escore volumétrico e medidas de massa também foram propostos para quantificação da $\mathrm{CAC}^{404}$. 0 uso da massa de cálcio vem sendo considerado o melhor índice segundo estudos recentes ${ }^{404}$, entretanto a maior parte dos estudos epidemiológicos e de prognóstico foi baseada no escore de Agatston avaliado pela EBTC $^{403}$, que continua a ser amplamente utilizado como padrão ouro. Em 2003 foram publicados estudos de prevalência de escores de cálcio para população branca assintomática brasileira ${ }^{405,406}$.

Até recentemente, muito se questionava se o escore de cálcio representaria um marcador de risco independente para eventos coronários, ou seja, se haveria adição de informação em relação à avaliação dos fatores de risco tradicionais ${ }^{1,407,408}$. Estudos consistentes publicados recentemente mostram que a avaliação do escore de cálcio adiciona de forma complementar às informações de estratificação de risco clínico, podendo alterar e acrescentar condutas clínicas principalmente aos pacientes considerados como de risco intermediário pelos escores de Framingham ${ }^{409-416}$. Esta mesma afirmação também foi observada para a população brasileira, num estudo de homens assintomáticos ${ }^{417}$. Mais ainda, o conhecimento do escore de cálcio mostrou-se como uma ferramenta adicional no convencimento à aderência ao tratamento com o aumento do uso de estatinas entre aqueles indivíduos que sabidamente tinham escores mais elevados ${ }^{418}$. Interessantemente, o escore de cálcio não só adicionou novo valor prognóstico ao escore de Framingham mas também aos valores isolados de proteína C-reativa, um marcador inflamatório também importante na avaliação de risco de eventos cardiovasculares ${ }^{415,419}$.

Entretanto, embora a CAC esteja presente na doença aterosclerótica coronária e possa ser quantificada de forma rápida e não-invasiva pela TCMD, sua determinação não apresenta boa especificidade para a obstrução luminal ${ }^{420}$. Ela também não deve ser utilizada para monitoramento dos efeitos terapêutico de curto prazo (até 12 meses), com os escores de cálcio permanecendo os mesmos apesar do tratamento com doses diferentes de estatinas ${ }^{415,421}$. Finalmente, o escore de cálcio também não deve ser utilizado de rotina para avaliação de probabilidade de doença coronária em pacientes que apresentam dor torácica ${ }^{422}$ ou que já apresentem diagnóstico estabelecido de doença arterial coronária, incluindo pacientes já submetidos ao implante de stents ou revascularizados cirurgicamente.

Baseados nos dados discutidos acima, aceitam-se as seguintes afirmações em relação ao uso clínico do escore de cálcio:

1 ) escore de cálcio negativo $(C A C=0)$ indica uma baixa probabilidade de DAC e de eventos 
cardiovasculares futuros;

2) ausência de CAC é preditiva de baixo risco em um período de 2-5 anos;

3) escore de cálcio positivo $(\mathrm{CAC}>0)$ confirma a presença de DAC;

4) valor de escore de cálcio alto ( $>400^{413}$ ou $>$ percentil 75 para a idade e sexo ${ }^{423}$ ) significa risco moderado a alto de eventos clínicos em 2-5 anos;

5) medida da CAC é preditora independente de eventos e acrescenta valor prognóstico em relação aos fatores de risco tradicionais de Framingham e à proteína C-reativa;

6) a quantificação da CAC pode alterar a conduta clínica, principalmente em pacientes de risco intermediário. Nesses casos os pacientes poderiam ser tratados como de alto risco para eventos cardiovasculares - recomendação baseada em opinião de especialistas, não testada em estudos prospectivos.

As classes de indicação do uso da TCMD para detecção do escore de cálcio estão listadas na tabela 9.

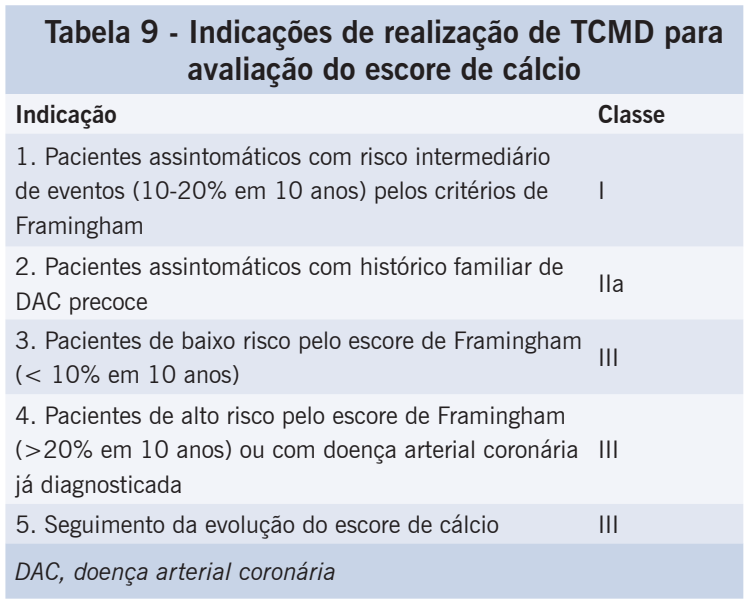

\section{Angio-tomografia de coronárias}

O grande salto de uso recentemente observado pela TCMD foi secundário ao amadurecimento das técnicas de angiotomografia que possibilitaram o uso desta tecnologia para realização da angiografia coronária de forma não invasiva. 0 advento os aparelhos de 16 detectores e, mais recentemente, de 64 detectores proporcionou a resolução e velocidade de aquisição minimamente necessária para que o uso da TCMD fosse aplicável numa rotina clínica. Se antes era possível realizar a angiotomografia com aparelhos de EBTC, estes ainda não apresentavam qualidade suficiente para a aplicação em massa já que mais de $25 \%$ dos segmentos arteriais não eram possíveis de serem avaliados ${ }^{377}$.

\section{Artérias coronárias nativas}

Atualmente, o uso da TCMD para realização de angiografias coronárias é alvo de intensa pesquisa e foi tema de editoriais das mais importantes revistas na área de cardiologia, radiologia e medicina interna ${ }^{424-}$ 430. A aplicação da angiotomografia com aparelhos de 16 detectores foi realizada por inúmeros autores com os resultados expressos na tabela 10176,431-445. Recentemente, também foram publicados estudos utilizando os novos aparelhos de 64 detectores ${ }^{446-449}$ (Tabela 10) que, se não aumentaram significativamente a resolução temporal e espacial dos aparelhos anteriores, permitiram um aumento na velocidade de aquisição das coronárias realizando exames antes feitos com pausas de 15-20 segundos para $8-12$ segundos. A abreviação do tempo de aquisição é interessante na medida que reduz artefatos causados pela movimentação respiratória e variações no ritmo cardíaco durante a apnéia, melhorando a qualidade das imagens e aumentando o número de pacientes que fazem o exame com sucesso.

Desta experiência inicial, é importante destacar que a maioria dos estudos atuais foram realizados em pacientes com testes não invasivos prévios positivos e que tinham uma indicação clínica para realização da angiografia convencional.

Tabela 10 - Desempenho diagnóstico da TCMD na detecção de estenoses coronárias em artérias nativas

\begin{tabular}{|c|c|c|c|c|c|c|c|c|c|}
\hline Estudo & $\begin{array}{l}\text { Cortes por } \\
\text { rotação }\end{array}$ & $\mathrm{n}$ & Vasos & Risco de DAC & $\begin{array}{l}\text { Exclusão } \\
(\%)\end{array}$ & Sens. & Especif. & VPP & VPN \\
\hline Nieman $2002^{76}$ & 12 & 58 & $>2.0 \mathrm{~mm}$ & Alto & - & 95 & 86 & 80 & 97 \\
\hline Ropers $2003^{64 *}$ & 12 & 77 & $>1.5 \mathrm{~mm}$ & Alto & 12 & 92 & 93 & 79 & 97 \\
\hline Hoffmann $2004^{77}$ & 16 & 33 & segmento & Alto & 17 & 63 & 95 & 64 & 96 \\
\hline Mollet $2004^{78 *}$ & 16 & 128 & $>2.0 \mathrm{~mm}$ & Baixo-mod. & - & 92 & 95 & 79 & 98 \\
\hline Martuscelli $2004^{79}$ & 16 & 64 & $>1.5 \mathrm{~mm}$ & Mod. & 16 & 89 & 98 & 90 & 98 \\
\hline Hoffmann $2005^{63}$ & 16 & 103 & $>1.5 \mathrm{~mm}$ & Mod-alto & 6.4 & 97 & 87 & 90 & 95 \\
\hline Kefer $2005^{34}$ & 16 & 52 & $>1.5 \mathrm{~mm}$ & Mod & - & 82 & 79 & 56 & 83 \\
\hline Kuettner $2005^{80}$ & 16 & 120 & segmento & Mod-alto & - & 85 & 98 & 91 & 96 \\
\hline Mollet 200565* & 64 & 52 & segmento & Alto & - & 99 & 95 & 76 & 99 \\
\hline Leber $2005^{81}$ & 64 & 55 & segmento & Mod-alto & 7 & 73 & 97 & 75 & 97 \\
\hline Raff $2005^{82 *}$ & 64 & 70 & segmento & Alto & 12 & 95 & 90 & 93 & 93 \\
\hline Ropers $2006^{83 *}$ & 64 & 84 & $>1.5 \mathrm{~mm}$ & Alto & 4 & 96 & 91 & 76 & 100 \\
\hline
\end{tabular}


Assim, nenhum estudo comparativo entre técnicas não invasivas como o teste ergométrico, eco-estresse, cintilografia ou RMC foi realizado com a angiotomografia. Além disso, nenhum estudo até o momento foi realizado considerando a angiotomografia como um exame para auxílio na decisão diagnóstica ou terapêutica de pacientes com suspeita de doença coronária. Também devemos observar que a maior parte dos paciente estudados foram de médio e alto risco para eventos cardiovasculares, o que limita a aplicação dos achados a populações de mais baixo risco pelos fatores tradicionais e a utilização da angiotomografia como exame de triagem para DAC numa população não selecionada geral. Do ponto de vista técnico, também deve-se notar que a maioria dos estudos excluiu de suas análises vasos menores que $1.5 \mathrm{~mm}$ e as análises dos parâmetros de acuidade do método foram realizados apenas nos vasos analisados. Isto foi parcialmente corrigido nos últimos trabalhos quando foram reportados não mais as avaliações por segmento coronário mas levando em conta o paciente como um todo. A razão de exclusão destes segmentos deveuse a problemas como excesso de calcificação coronária, movimento respiratório ou borramento da imagem devido à freqüências cardíacas elevadas. Finalmente, embora alguns autores tenham mostrado que a angiotomografia possa ser usada para avaliação quantitativa das estenoses coronárias ${ }^{450}$, para 0 uso clínico a correlação direta entre porcentagem de estenose pela angiotomografia e a obtida na angiografia convencional não está bem estabelecida, mesmo com o uso dos aparelhos de 64 detectores $^{447}$. A TCMD tem boa correlação com o grau de estenose mas apenas correlação moderada com a extensão da mesma, frequentemente superestimando os valores das medidas observadas ${ }^{451,452}$. Assim, embora a classificação qualitativa da obstrução da luz coronária seja factível com o uso da TCMD, a indicação quantitativa destas obstruções ainda não é viável clinicamente.

Assim, conclui-se a partir da literatura atual, que a indicação da angiotomografia deve ser realizada para uma população bastante selecionada e não utilizada indiscriminadamente em todos os pacientes com DAC. Baseado nos trabalhos atuais, a angiotomografia tem maior valor diagnóstico em pacientes com probabilidade intermediária de DAC e com teste funcional (teste ergométrio, eco-estresse, cintilografia ou RMC) não diagnósticos ou conflitantes. Também tem maior valor em pacientes com baixa probabilidade pré-teste de DAC mas com teste funcional positivo. $\mathrm{O}$ alto valor preditivo negativo do exame mostra que a angiotomografia pode ter algum benefício nestes pacientes ao reduzir a necessidade de exames mais invasivos. Como exemplo no trabalho de Hoffmann et al ${ }^{433}$, caso a tomografia tivesse sido realizada com o intuito de se realizar o cateterismo invasivo ou não, $40 \%$ dos pacientes não o teriam feito e apenas $2 \%$ dos pacientes teriam sido erroneamente classificados como normais. Porém, em pacientes mais idosos ( $>65$ anos) e/ou com DAC avançada, onde a quantidade de cálcio coronário geralmente é maior ${ }^{453}$, a indicação da angiotomografia é mais limitada.

\section{Re-estenose intra-stent}

Para avaliação da restenose intra-stent em geral, a acurácia diagnóstica da TCMD é apenas moderada ${ }^{454-}$ 456. Embora tenha-se obtido valores de sensibilidade e especificidade de $81 \%$ e $89 \%$, respectivamente, com valores preditivos negativos de $97 \%$ para re-estenoses importantes, o valor preditivo positivo neste caso foi de apenas $47 \%$. Estes números foram ainda menores quando incluídas todas as re-estenoses, independente do grau de obstrução luminal. A razão disto se dá pelos artefatos provocados pelos atuais stents coronários que impedem a ampla visualização da luz coronária devido à resolução espacial inferior da TCMD em comparação com angiografia convencional. Apesar disso, a acurácia da TCMD aumenta quando são analisados apenas stents com diâmetros maiores de $3 \mathrm{~mm}$ ou no tronco da artéria coronária esquerda, sendo possível nestes casos obter valores preditivos positivos e negativos de $100 \%$ e $99 \%$ respectivamente ${ }^{457,458}$, podendo, assim, ser indicado nestas situações específicas.

\section{Enxertos coronários cirúrgicos}

Para avaliação dos enxertos coronários, a TCMD também tem alta acurácia diagnóstica pois estas tem menor movimento que as coronárias nativas ${ }^{459-463}$. A sensibilidade para enxertos está reportada entre 85-100\% e especificidade entre 95-100\%. Entretanto, os clipes cirúrgicos podem interferir com a qualidade da imagem ao longo do trajeto do enxerto e a avaliação das anastomoses distais também é de difícil avaliação. Além disso, frequentemente os pacientes tratados cirurgicamente tem DAC avançada, com presença de calcificação importante, dificultando ainda mais a qualidade do diagnóstico. Assim, embora a determinação da patência dos enxertos cirúrgicos seja possível, a avaliação completa da anatomia coronária nestes casos é usualmente limitada nestas situações.

\section{Angio-tomografia na avaliação da dor torácica}

Por último, na fase aguda das síndromes coronárias, o uso da TCMD pode ter alguma aplicação clínica na identificação de pacientes com ECG inespecífico e ausência de alterações nos marcadores cardíacos ${ }^{464,465}$. Num estudo prospectivo, a acurácia da TCMD em corretamente identificar lesões obstrutivas em pacientes com suspeita de síndromes coronárias agudas foi de $87 \%$, sendo que em $11 \%$ dos pacientes o exame não foi possível de ser avaliado por problemas técnicos ${ }^{466}$. A TCMD pode fornecer informações relevantes para a triagem de pacientes agudos rapidamente ${ }^{467}$ e tem grande potencial em modificar os atuais protocolos em unidades de dor torácica no futuro ${ }^{468}$, com uma redução significativa no número de internações desnecessárias ${ }^{469}$. Além disso, por também adquirir no mesmo exame informações relativas à aorta e às artérias pulmonares, permite a realização do chamado descarte trip/o, ou seja, a exclusão simultânea 
com diagnóstico diferencial de síndromes coronárias agudas, dissecção de aorta e embolia pulmonar ${ }^{470}$.

Outra aplicação clínica da angiotomografia inclui ainda a avaliação de coronárias anômalas ${ }^{471}$. Neste caso 0 trajeto anatômico da coronária, sua relação com demais vasos e outras estruturas torácicas tornam o método de grande valia diagnóstica ${ }^{472}$.

\section{Outras indicações clínicas}

Outra aplicação clínica da angiotomografia inclui ainda a avaliação de coronárias anômalas ${ }^{471}$. Neste caso 0 trajeto anatômico da coronária, sua relação com demais vasos e outras estruturas torácicas tornam o método de grande valia diagnóstica ${ }^{472}$.

$\mathrm{Na}$ avaliação peri-operatória de pacientes com suspeita ou risco intermediário de DAC, a TCMD também pode auxiliar na exclusão de estenoses coronárias significativas. Isto é válido tanto para cirurgias cardíacas não coronárias ${ }^{473}$ quanto para outras cirurgias não cardíacas. Embora com grande potencial, devido à inexistência de estudos nesta área, a indicação do método para tal fim ainda é limitado.

No paciente que, por alguma razão, se recusa a fazer a angiografia invasiva, a TCMD pode ser também oferecida como opção diagnóstica, se respeitando possíveis limitações técnicas como já comentado acima.

Outra aplicação da TCMD inclui a avaliação coronária de pacientes com doença de Kawasaki, onde o método pode ser utilizado como uma opção à angiografia invasiva para seguimento da doença ${ }^{474}$.

Finamente, a TCMD também tem um grande potencial na avaliação da DAC na medida que pode avaliar não apenas a luz coronária mas também a parede do vaso, com seus diversos componentes ${ }^{475,476}$. Isto permite a visualização de placas ateroscleróticas que não causam obstruções significativas mas ainda assim tem remodelamento positivo com alto conteúdo lipídico e maior propensão à ruptura ${ }^{477,478}$. Esta análise ainda é inicial e não é utilizada de rotina na prática clínica.

Um resumo das indicações atuais da angiotomografia de coronária está na tabela 11 .

\section{Doenças vasculares}

\section{Aorta}

Assim como a ressonância, a tomografia também é um método que permite a completa visualização da aorta torácica e abdominal com aquisição e pós-processamento das imagens em três dimensões. Com o surgimento dos aparelhos de TCMD, hoje é possível completar um exame inteiro da aorta torácica e abdominal em menos de 20 segundos com alta resolução espacial ${ }^{479}$.

A TCMD permite além da visualização da luz aórtica também a identificação de alterações da parede da mesma como no caso dos hematomas intramurais. Se a ressonância é superior à tomografia na identificação

\begin{tabular}{|c|c|}
\hline Indicação & Classe \\
\hline 1. Avaliação de coronárias anômalas & 1 \\
\hline $\begin{array}{l}\text { 2. Avaliação de estenoses coronárias em pacientes com } \\
\text { probabilidade intermediária de DAC e testes de isquemia } \\
\text { duvidosos ou conflitantes }\end{array}$ & Ila \\
\hline $\begin{array}{l}\text { 3. Avaliação de estenoses coronárias em pacientes com } \\
\text { baixa probabilidade de DAC e testes de isquemia positivos }\end{array}$ & Ila \\
\hline 4. Avaliação da patência de enxertos cirúrgicos & Ila \\
\hline $\begin{array}{l}\text { 5. Opção à angiografia invasiva no diagnóstico diferencial } \\
\text { de cardiomiopatias isquêmicas versus não isquêmicas }\end{array}$ & Ila \\
\hline $\begin{array}{l}\text { 6. Opção à angiografia invasiva no seguimento de } \\
\text { pacientes com doença de Kawasaki }\end{array}$ & Ila \\
\hline $\begin{array}{l}\text { 7. Diagnóstico de estenoses coronárias em pacientes com } \\
\text { média/alta probabilidade de DAC com dor torácica aguda }\end{array}$ & $\mathrm{Ilb}$ \\
\hline $\begin{array}{l}\text { 8. Diagnóstico de estenoses intra-stents (vide observações } \\
\text { no texto) }\end{array}$ & $\mathrm{Ilb}$ \\
\hline $\begin{array}{l}\text { 9. Pacientes com baixa probabilidade de DAC, } \\
\text { assintomáticos e/ou com teste de isquemia negativo }\end{array}$ & III \\
\hline $\begin{array}{l}\text { 10. Seguimento de lesões obstrutivas coronárias } \\
\text { identificadas em angiografia prévia (invasiva ou não } \\
\text { invasiva) }\end{array}$ & III \\
\hline DAC, doença arterial coronária & \\
\hline
\end{tabular}

de ateromas ou da caracterização tecidual da parede aórtica, a tomografia, por sua vez, permite a avaliação pós operatória do implante de stents com excelente acurácia ${ }^{480}$. Além disso, devido à sua maior velocidade de aquisição também apresenta maior facilidade para realização do exame em síndromes aórticas agudas onde o paciente muitas vezes apresenta-se instável.

As principais indicações de tomografia da aorta, assim como dos demais vasos abordados nestas diretrizes, estão listados na tabela 12 .

\begin{tabular}{|c|c|}
\hline Indicação & Classe \\
\hline 1. Aneurismas de aorta (incluindo Marfan) & I \\
\hline 2. Dissecção de aorta (aguda e crônica) & I \\
\hline 3. Ruptura de aorta & I \\
\hline 4. Hematoma intramural aórtico & 1 \\
\hline 5. Úlceras aórticas & I \\
\hline 6. Planejamento de abordagem cirúrgica da aorta & I \\
\hline 7. Planejamento de stent aórtico & 1 \\
\hline 8. Avaliação pós operatória de implantes de stents & 1 \\
\hline 9. Anatomia da artéria pulmonar & 1 \\
\hline 10. Embolia Pulmonar & 1 \\
\hline 11. Avaliação das veias pulmonares & 1 \\
\hline 12. Avaliação estenoses renais & I \\
\hline 13. Avaliação de estenoses carótidas extra-cranianas & 1 \\
\hline 14. Avaliação das artérias mesentéricas e tronco celíaco & 1 \\
\hline 15. Arterites & Ila \\
\hline
\end{tabular}




\section{Artérias e Veias pulmonares}

A doença adquirida mais comum das artérias pulmonares é o tromboembolismo pulmonar, sendo no Brasil também causa importante de hipertensão pulmonar a esquistossomose mansônica. O emprego da tomografia no diagnóstico da embolia pulmonar vem se tornando mais freqüente, principalmente após o advento dos aparelhos de TCMD. Os resultados do PIOPED II (Prospective Investigation of Pulmonary Embolism Diagnosis II), um estudo prospectivo, randomizado e multicêntrico dos diferentes métodos para o diagnóstico da embolia pulmonar será publicado em breve ${ }^{481}$, mas diversos trabalhos já ilustram o papel importante deste método, que pode realizar em um exame único o diagnóstico de embolia pulmonar e trombose venosa profunda, com ótima sensibilidade e especificidade ${ }^{482}$.

A TCMD possibilita o diagnóstico de doenças habituais do pulmão, como pneumonia e derrame plural além de diagnósticos diferenciais alternativos importantes da dor torácica como a dissecção aórtica ${ }^{483}$, o tromboembolismo pulmonar ${ }^{484}$ e possivelmente também eventos coronários agudos ${ }^{467}$.

Recentemente o estudo anatômico das veias pulmonares recebeu grande atenção devido aos procedimentos de intervenção eletrofisiológica na ablação da fibrilação atrial e suas complicações ${ }^{485}$. A TCMD tem ótima resolução espacial e temporal, mas trás menos informações funcionais que a RMC, além do fato de utilizar radiação ionizante e contraste iodado. A TCMD é um método alternativo àqueles pacientes com contraindicação à RMC ou que possuem arritmias cardíacas que limitam o exame de ressonância ${ }^{486}$.

\section{Carótidas}

Tanto a TC como a RM são métodos apropriados e superiores ao ultrassom para a avaliação das estenoses carotídeas com sensibilidade e especificidade de $85 \%$ e 93\% (para estenoses entre $70-90 \%$ ) e de 97 e 99\% para detecção de oclusões, sendo assim um método apropriado para o diagnóstico não invasivo destes vasos ${ }^{487}$.

\section{Vasos mesentéricos}

A avaliação angiográfica dos vasos mesentéricos (artérias e veias) é geralmente realizada em duas situações principais:
- Neoplasias abdominais para avaliação de possível envolvimento vascular e critérios de excisão da lesão.

- Angina abdominal.

A angina abdominal é uma síndrome infreqüente caracterizada por dor abdominal pós-prandial devido à redução do fluxo sanguíneo para os órgãos irrigados pelo tronco celíaco e artérias mesentéricas superior e inferior. A angiografia tradicional é considerada o padrão ouro na investigação do paciente com suspeita clínica de isquemia mesentérica, porém é um exame invasivo e não isento de complicações. A TCMD tem se tornado o exame de escolha na avaliação destes pacientes por se tratar de um exame minimamente invasivo e pela capacidade de fornecer dados relevantes ao diagnóstico. Ela pode demonstrar com precisão a presença e o grau de estenose, a presença de circulação colateral e excluir outras causas de obstrução vascular secundária. Pode também ser utilizada para seguimento de pacientes que se submetem ao tratamento intervencionista percutâneo. Limitações deste método incluem a impossibilidade de avaliação dinâmica do fluxo intravascular e a avaliação de vasos densamente calcificados. Não obstante, a TCMD realizada com protocolo e pós-processamento adequados é altamente efetiva para a avaliação, diagnóstico, e seguimento do paciente com suspeita de angina mesentérica ${ }^{488}$.

\section{Artérias renais}

Assim como na avaliação das carótidas, a angiografia por TCMD é um método confiável para a detecção da anatomia e da estenose arterial, com resultados semelhantes aos obtidos na RM, com sensibilidade e especificidade de $92 \%$ e $99 \%$, respectivamente, sendo superior à avaliação ultrasonográfica com Doppler, embora a resolução espacial seja ainda algo inferior à angiografia digital. A principal limitação do método está relacionada à sua escassa informação funcional e, embora programas de análise de perfusão com potencial aplicação renal já estejam disponíveis, não existem ainda dados significativos validando esta técnica. Assim sendo, a TCMD é um exame complementar à cintilografia renal com captopril e uma alternativa em relação à $\mathrm{RM}^{489}$.

\section{REFERÊNCIAS}

1. O'Rourke RA, Brundage BH, Froelicher VF, Greenland P, Grundy SM, Hachamovitch R, Pohost GM, Shaw LJ, Weintraub WS, Winters WL, Jr. American College of Cardiology/American Heart Association Expert Consensus Document on electron-beam computed tomography for the diagnosis and prognosis of coronary artery disease. J Am Coll Cardiol 2000;36:326-340.

2. The clinical role of magnetic resonance in cardiovascular disease. Task Force of the European Society of Cardiology, in collaboration with the Association of European Paediatric Cardiologists. Eur Heart J. 1998;19:19-39.
3. Pennell DJ, Sechtem UP, Higgins CB, Manning WJ, Pohost GM, Rademakers FE, van Rossum AC, Shaw LJ, Yucel EK. Clinical indications for cardiovascular magnetic resonance (CMR): Consensus Panel report. Eur Heart J. 2004;25:1940-65.

4. Patel MR, Spertus JA, Brindis RG, Hendel RC, Douglas PS, Peterson ED, Wolk MJ, Allen JM, Raskin IE. ACCF proposed method for evaluating the appropriateness of cardiovascular imaging. J Am Coll Cardiol. 2005;46:1606-13.

5. Gluud C, Gluud LL. Evidence based diagnostics. BMJ. 2005;330:724-6. 
6. Francis JM, Pennell DJ. Treatment of claustrophobia for cardiovascular magnetic resonance: use and effectiveness of mild sedation. $J$ Cardiovasc Magn Reson. 2000;2:139-41.

7. Porto I, Selvanayagam J, Ashar V, Neubauer S, Banning AP. Safety of magnetic resonance imaging one to three days after bare metal and drug-eluting stent implantation. Am J Cardiol. 2005;96:366-8.

8. Gerber TC, Fasseas P, Lennon RJ, Valeti VU, Wood CP, Breen JF, Berger $\mathrm{PB}$. Clinical safety of magnetic resonance imaging early after coronary artery stent placement. J Am Coll Cardiol. 2003;42:1295-8.

9. Schneider G, Fries P, Ahlhelm F, Kindermann I, Kramann B, Bohm M. Contrast-enhanced cardiac MR imaging. Eur Radiol. 2003;13 Suppl 3:N11-8.

10. Kirchin MA, Runge VM. Contrast agents for magnetic resonance imaging: safety update. Top Magn Reson Imaging. 2003;14:426-35.

11. Spinosa DJ, Kaufmann JA, Hartwell GD. Gadolinium chelates in angiography and interventional radiology: a useful alternative to iodinated contrast media for angiography. Radiology. 2002;223:31925; discussion 326-7.

12. Runge VM, Dickey KM, Williams NM, Peng X. Local tissue toxicity in response to extravascular extravasation of magnetic resonance contrast media. Invest Radiol. 2002;37:393-8.

13. Runge VM. Safety of magnetic resonance contrast media. Top Magn Reson Imaging. 2001;12:309-14.

14. Tsai-Goodman B, Geva T, Odegard KC, Sena LM, Powell AJ. Clinical role, accuracy, and technical aspects of cardiovascular magnetic resonance imaging in infants. Am J Cardiol. 2004;94:69-74.

15. Sanborn PA, Michna E, Zurakowski D, Burrows PE, Fontaine PJ, Connor L, Mason KP. Adverse cardiovascular and respiratory events during sedation of pediatric patients for imaging examinations. Radiology. 2005;237:288-94.

16. Krueger JJ, Ewert P, Yilmaz S, Gelernter D, Peters B, Pietzner K, Bornstedt A, Schnackenburg B, Abdul-Khaliq H, Fleck E, Nagel E, Berger $F$, Kuehne T. Magnetic resonance imaging-guided balloon angioplasty of coarctation of the aorta: a pilot study. Circulation. 2006;113:1093-100.

17. Hirsch R, Kilner PJ, Connelly MS, Redington AN, John Sutton MG, Somerville J. Diagnosis in adolescents and adults with congenital heart disease. Prospective assessment of individual and combined roles of magnetic resonance imaging and transesophageal echocardiography. Circulation. 1994;90:2937-2951.

18. Hoppe UC, Dederichs B, Deutsch HJ, Theissen P, Schicha H, Sechtem $U$. Congenital heart disease in adults and adolescents: comparative value of transthoracic and transesophageal echocardiography and MR imaging. Radiology. 1996;199:669-677.

19. Geva T, Vick GW, III, Wendt RE, Rokey R. Role of spin echo and cine magnetic resonance imaging in presurgical planning of heterotaxy syndrome. Comparison with echocardiography and catheterization. Circulation. 1994;90:348-356.

20. Kersting-Sommerhoff BA, Diethelm L, Stanger P, Dery R, Higashino SM, Higgins SS, Higgins CB. Evaluation of complex congenital ventricular anomalies with magnetic resonance imaging. Am. Heart J. 1990;120:133-142.

21. Hundley WG, Li HF, Lange RA, Pfeifer DP, Meshack BM, Willard JE, Landau C, Willett D, Hillis LD, Peshock RM. Assessment of left-to-right intracardiac shunting by velocity-encoded, phase-difference magnetic resonance imaging. A comparison with oximetric and indicator dilution techniques. Circulation. 1995;91:2955-2960.

22. Taylor AM, Stables RH, Poole-Wilson PA, Pennell DJ. Definitive clinical assessment of atrial septal defect by magnetic resonance imaging. J.Cardiovasc. Magn Reson. 1999;1:43-47.

23. Valsangiacomo ER, Levasseur S, McCrindle BW, MacDonald C, Smallhorn JF, Yoo SJ. Contrast-enhanced MR angiography of pulmonary venous abnormalities in children. Pediatr.Radiol. 2003;33:92-98.

24. Greil GF, Powell AJ, Gildein HP, Geva T. Gadolinium-enhanced threedimensional magnetic resonance angiography of pulmonary and systemic venous anomalies. J.Am.Coll.Cardiol. 2002;39:335-341.

25. Masui T, Seelos KC, Kersting-Sommerhoff BA, Higgins CB. Abnormalities of the pulmonary veins: evaluation with MR imaging and comparison with cardiac angiography and echocardiography. Radiology. 1991;181:645-649.

26. White CS, Baffa JM, Haney PJ, Pace ME, Campbell AB. MR imaging of congenital anomalies of the thoracic veins. Radiographics. 1997; 17:595-608.

27. Dill T, Neumann T, Ekinci O, Breidenbach C, John A, Erdogan A, Bachmann G, Hamm CW, Pitschner HF. Pulmonary vein diameter reduction after radiofrequency catheter ablation for paroxysmal atrial fibrillation evaluated by contrast-enhanced three-dimensional magnetic resonance imaging. Circulation. 2003;107:845-850.

28. Chung KJ, Simpson IA, Glass RF, Sahn DJ, Hesselink JR. Cine magnetic resonance imaging after surgical repair in patients with transposition of the great arteries. Circulation. 1988;77:104-109.

29. Kersting-Sommerhoff BA, Diethelm L, Teitel DF, Sommerhoff CP, Higgins SS, Higashino SS, Higgins CB. Magnetic resonance imaging of congenital heart disease: sensitivity and specificity using receiver operating characteristic curve analysis. Am. Heart J. 1989;118:155-161.

30. Araoz PA, Reddy GP, Thomson PD, Higgins CB. Images in cardiovascular medicine. Magnetic resonance angiography of criss-cross heart. Circulation. 2002;105:537-538.

31. Yoo SJ, Kim YM, Choe YH. Magnetic resonance imaging of complex congenital heart disease. Int.J.Card Imaging. 1999;15:151-160.

32. Mirowitz SA, Gutierrez FR, Canter CE, Vannier MW. Tetralogy of Fallot: MR findings. Radiology. 1989;171:207-212.

33. Didier D, Higgins CB. Identification and localization of ventricular septal defect by gated magnetic resonance imaging. Am.J.Cardiol. 1986;57:1363-1368.

34. Mayo JR, Roberson D, Sommerhoff B, Higgins CB. MR imaging of double outlet right ventricle. J Comput Assist Tomogr 1990;14:336-339.

35. Hoffmann R, von Bardeleben S, Kasprzak JD, Borges AC, ten Cate F, Firschke C, Lafitte S, Al-Saadi N, Kuntz-Hehner S, Horstick G, Greis C, Engelhardt M, Vanoverschelde JL, Becher H. Analysis of regional left ventricular function by cineventriculography, cardiac magnetic resonance imaging, and unenhanced and contrast-enhanced echocardiography: a multicenter comparison of methods. J Am Coll Cardiol. 2006;47:121-8.

36. Rebergen SA, Chin JG, Ottenkamp J, van der Wall EE, de Roos A. Pulmonary regurgitation in the late postoperative follow-up of tetralogy of Fallot. Volumetric quantitation by nuclear magnetic resonance velocity mapping. Circulation. 1993;88:2257-2266.

37. Holmqvist C, Oskarsson G, Stahlberg F, Thilen U, Bjorkhem G, Laurin $S$. Functional evaluation of extracardiac ventriculopulmonary conduits and of the right ventricle with magnetic resonance imaging and velocity mapping. Am.J.Cardiol. 1999;83:926-932.

38. Steffens JC, Bourne MW, Sakuma H, O'Sullivan M, Higgins CB. Quantification of collateral blood flow in coarctation of the aorta by velocity encoded cine magnetic resonance imaging. Circulation. 1994;90:937-943.

39. Mohiaddin RH, Kilner PJ, Rees S, Longmore DB. Magnetic resonance volume flow and jet velocity mapping in aortic coarctation. J.Am.Coll. Cardiol. 1993;22:1515-1521.

40. Nielsen JC, Powell AJ, Gauvreau K, Marcus EN, Prakash A, Geva T. Magnetic resonance imaging predictors of coarctation severity. Circulation. 2005; 111:622-8. 
41. Bogaert J, Kuzo R, Dymarkowski S, Janssen L, Celis I, Budts W, Gewillig M. Follow-up of patients with previous treatment for coarctation of the thoracic aorta: comparison between contrastenhanced MR angiography and fast spin-echo MR imaging. Eur.Radiol. 2000;10:1847-1854.

42. Rees S, Somerville J, Ward C, Martinez J, Mohiaddin RH, Underwood $\mathrm{R}$, Longmore DB. Coarctation of the aorta: MR imaging in late postoperative assessment. Radiology. 1989;173:499-502.

43. Simpson IA, Chung KJ, Glass RF, Sahn DJ, Sherman FS, Hesselink $\mathrm{J}$. Cine magnetic resonance imaging for evaluation of anatomy and flow relations in infants and children with coarctation of the aorta. Circulation. 1988;78:142-148.

44. Jaffe RB. Magnetic resonance imaging of vascular rings. Semin. Ultrasound CT MR. 1990;11:206-220.

45. Kersting-Sommerhoff BA, Sechtem UP, Fisher MR, Higgins CB. MR imaging of congenital anomalies of the aortic arch. AJR Am.J.Roentgenol. 1987;149:9-13.

46. Gomes AS, Lois JF, Williams RG. Pulmonary arteries: MR imaging in patients with congenital obstruction of the right ventricular outflow tract. Radiology. 1990;174:51-57.

47. Vick GW, III, Rokey R, Huhta JC, Mulvagh SL, Johnston DL. Nuclear magnetic resonance imaging of the pulmonary arteries, subpulmonary region, and aorticopulmonary shunts: a comparative study with two-dimensional echocardiography and angiography. Am. Heart J. 1990;119:1103-1110.

48. Julsrud PR, Ehman RL, Hagler DJ, Ilstrup DM. Extracardiac vasculature in candidates for Fontan surgery: MR imaging. Radiology. 1989;173:503-506.

49. Kersting-Sommerhoff BA, Sechtem UP, Higgins CB. Evaluation of pulmonary blood supply by nuclear magnetic resonance imaging in patients with pulmonary atresia. J.Am.Coll.Cardiol. 1988; $11: 166-171$.

50. Geva T, Greil GF, Marshall AC, Landzberg M, Powell AJ. Gadoliniumenhanced 3-dimensional magnetic resonance angiography of pulmonary blood supply in patients with complex pulmonary stenosis or atresia: comparison with x-ray angiography. Circulation. 2002;106:473-478.

51. Rebergen SA, Ottenkamp J, Doornbos J, van der Wall EE, Chin JG, de Roos A. Postoperative pulmonary flow dynamics after Fontan surgery: assessment with nuclear magnetic resonance velocity mapping. J.Am. Coll.Cardiol. 1993;21:123-131.

52. Kondo C, Takada K, Yokoyama U, Nakajima Y, Momma K, Sakai F. Comparison of three-dimensional contrast-enhanced magnetic resonance angiography and axial radiographic angiography for diagnosing congenital stenoses in small pulmonary arteries. Am.J.Cardiol. 2001;87:420-424.

53. Greenberg SB, Crisci KL, Koenig P, Robinson B, Anisman P, Russo P. Magnetic resonance imaging compared with echocardiography in the evaluation of pulmonary artery abnormalities in children with tetralogy of Fallot following palliative and corrective surgery. Pediatr.Radiol. 1997;27:932-935.

54. Canter CE, Gutierrez FR, Mirowitz SA, Martin TC, Hartmann $A F, J r$. Evaluation of pulmonary arterial morphology in cyanotic congenital heart disease by magnetic resonance imaging. Am. Heart J. 1989;118:347-354.

55. Canter CE, Gutierrez FR, Molina P, Hartmann AF, Jr., Spray TL. Noninvasive diagnosis of right-sided extracardiac conduit obstruction by combined magnetic resonance imaging and continuouswave Doppler echocardiography. J.Thorac. Cardiovasc. Surg. 1991;101:724-731.

56. Wang ZJ, Reddy GP, Gotway MB, Yeh BM, Higgins CB. Cardiovascular shunts: MR imaging evaluation. Radiographics. 2003;23 Spec No: S181-94.
57. Martinez JE, Mohiaddin RH, Kilner PJ, Khaw K, Rees S, Somerville J, Longmore DB. Obstruction in extracardiac ventriculopulmonary conduits: value of nuclear magnetic resonance imaging with velocity mapping and Doppler echocardiography. J.Am.Coll.Cardiol. 1992;20:338-344.

58. Grothues F, Smith GC, Moon JC, Bellenger NG, Collins P, Klein HU, Pennell DJ. Comparison of interstudy reproducibility of cardiovascular magnetic resonance with two-dimensional echocardiography in normal subjects and in patients with heart failure or left ventricular hypertrophy. Am.J.Cardiol. 2002;90:29-34.

59. Helbing WA, Bosch HG, Maliepaard C, Rebergen SA, van der Geest RJ, Hansen B, Ottenkamp J, Reiber JH, de Roos A. Comparison of echocardiographic methods with magnetic resonance imaging for assessment of right ventricular function in children. Am.J.Cardiol. 1995;76:589-594.

60. Roest AA, Helbing WA, Kunz P, van den Aardweg JG, Lamb HJ, Vliegen $H W$, van der Wall EE, de Roos A. Exercise MR imaging in the assessment of pulmonary regurgitation and biventricular function in patients after tetralogy of fallot repair. Radiology. 2002;223:204-211.

61. Niezen RA, Helbing WA, van der Wall EE, van der Geest RJ, Rebergen $S A$, de Roos A. Biventricular systolic function and mass studied with MR imaging in children with pulmonary regurgitation after repair for tetralogy of Fallot. Radiology. 1996;201:135-140.

62. Babu-Narayan SV, Kilner PJ, Li W, Moon JC, Goktekin O, Davlouros PA, Khan M, Ho SY, Pennell DJ, Gatzoulis MA. Ventricular fibrosis suggested by cardiovascular magnetic resonance in adults with repaired tetralogy of fallot and its relationship to adverse markers of clinical outcome. Circulation. 2006;113:405-13.

63. Oosterhof T, Mulder BJ, Vliegen HW, de Roos A. Cardiovascular magnetic resonance in the follow-up of patients with corrected tetralogy of Fallot: a review. Am Heart J. 2006;151:265-72.

64. Fogel MA, Weinberg PM, Chin AJ, Fellows KE, Hoffman EA. Late ventricular geometry and performance changes of functional single ventricle throughout staged Fontan reconstruction assessed by magnetic resonance imaging. J.Am.Coll.Cardiol. 1996;28:212-221.

65. Baron MG, Book WM. Congenital heart disease in the adult: 2004. Radiol Clin North Am. 2004;42:675-90, vii.

66. Greil GF, Stuber M, Botnar RM, Kissinger KV, Geva T, Newburger JW, Manning WJ, Powell AJ. Coronary magnetic resonance angiography in adolescents and young adults with kawasaki disease. Circulation . 2002;105:908-911.

67. Duerinckx AJ, Troutman B, Allada V, Kim D. Coronary MR angiography in Kawasaki disease. AJR Am.J.Roentgenol. 1997;168:114-116.

68. Niwa K, Tashima K, Kawasoe Y, Okajima Y, Nakajima H, Terai M, Nakajima $\mathrm{H}$. Magnetic resonance imaging of myocardial infarction in Kawasaki disease. Am. Heart J. 1990;119:1293-1302.

69. Bunce NH, Lorenz CH, Keegan J, Lesser J, Reyes EM, Firmin DN, Pennell DJ. Coronary artery anomalies: assessment with freebreathing three-dimensional coronary MR angiography. Radiology. 2003;227:201-208.

70. McConnell MV, Ganz P, Selwyn AP, Li W, Edelman RR, Manning WJ. Identification of anomalous coronary arteries and their anatomic course by magnetic resonance coronary angiography. Circulation. 1995;92:3158-3162.

71. Post JC, van Rossum AC, Bronzwaer JG, de Cock CC, Hofman MB, Valk $J$, Visser CA. Magnetic resonance angiography of anomalous coronary arteries. A new gold standard for delineating the proximal course? Circulation. 1995;92:3163-3171.

72. Joarder R, Gedroyc WM. Magnetic resonance angiography: the state of the art. Eur Radiol. 2001;11:446-53.

73. Montgomery ML, Case RS. Magnetic resonance imaging of the vascular system: a practical approach for the radiologist. Top Magn Reson Imaging. 2003;14:376-85. 
74. Goldman JP. New techniques and applications for magnetic resonance angiography. Mt Sinai J Med. 2003;70:375-85.

75. Gatehouse PD, Keegan J, Crowe LA, Masood S, Mohiaddin RH, Kreitner KF, Firmin DN. Applications of phase-contrast flow and velocity imaging in cardiovascular MRI. Eur Radiol. 2005;15:2172-84.

76. Fattori R, Nienaber CA. MRI of acute and chronic aortic pathology: pre-operative and postoperative evaluation. J.Magn Reson.Imaging. 1999;10:741-750.

77. Tatli S, Lipton MJ, Davison BD, Skorstad RB, Yucel EK. From the RSNA refresher courses: MR imaging of aortic and peripheral vascular disease. Radiographics. 2003;23 Spec No:S59-78.

78. Longmore DB, Klipstein RH, Underwood SR, Firmin DN, Hounsfield GN, Watanabe M, Bland C, Fox K, Poole-Wilson PA, Rees RS, . Dimensional accuracy of magnetic resonance in studies of the heart. Lancet. 1985;1:1360-1362.

79. Tsai TT, Nienaber CA, Eagle KA. Acute aortic syndromes. Circulation. 2005;112:3802-13.

80. Isselbacher EM. Thoracic and abdominal aortic aneurysms. Circulation. 2005;111:816-28.

81. Kunz RP, Oberholzer K, Kuroczynski W, Horstick G, Krummenauer F, Thelen M, Kreitner KF. Assessment of chronic aortic dissection: contribution of different ECG-gated breath-hold MRI techniques. AJR Am J Roentgenol. 2004;182:1319-26.

82. Fayad ZA, Nahar T, Fallon JT, Goldman M, Aguinaldo JG, Badimon JJ, Shinnar M, Chesebro JH, Fuster V. In vivo magnetic resonance evaluation of atherosclerotic plaques in the human thoracic aorta: a comparison with transesophageal echocardiography. Circulation. 2000;101:2503-2509.

83. Fayad ZA, Fuster V. Characterization of atherosclerotic plaques by magnetic resonance imaging. Ann.N.Y.Acad.Sci. 2000;902:173-186.

84. Murray JG, Manisali M, Flamm SD, VanDyke CW, Lieber ML, Lytle BW, White RD. Intramural hematoma of the thoracic aorta: MR image findings and their prognostic implications. Radiology. 1997;204:349-355.

85. Cesare ED, Giordano AV, Cerone G, De Remigis F, Deusanio G, Masciocchi C. Comparative evaluation of TEE, conventional MRI and contrast-enhanced 3D breath-hold MRA in the post-operative follow-up of dissecting aneurysms. Int.J.Card Imaging. 2000;16:135-147.

86. Sondergaard L, Lindvig K, Hildebrandt P, Thomsen C, Stahlberg F, Joen T, Henriksen O. Quantification of aortic regurgitation by magnetic resonance velocity mapping. Am. Heart J. 1993;125:1081-1090.

87. Bryant DJ, Payne JA, Firmin DN, Longmore DB. Measurement of flow with NMR imaging using a gradient pulse and phase difference technique. J.Comput.Assist. Tomogr. 1984;8:588-593.

88. Mittal TK, Evans C, Perkins T, Wood AM. Renal arteriography using gadolinium enhanced 3D MR angiography--clinical experience with the technique, its limitations and pitfalls. Br J Radiol. 2001;74:495-502.

89. Leiner T, de Haan MW, Nelemans PJ, van Engelshoven JM, Vasbinder $\mathrm{GB}$. Contemporary imaging techniques for the diagnosis of renal artery stenosis. Eur Radiol. 2005;15:2219-29.

90. Huang AJ, Lee VS, Rusinek H. MR imaging of renal function. Radiol Clin North Am. 2003;41:1001-17.

91. Tsai CF, Tai CT, Chen SA. Pulmonary vein ablation: role in preventing atrial fibrillation. Curr Opin Cardiol. 2003;18:39-46.

92. Kato R, Lickfett L, Meininger G, Dickfeld T, Wu R, Juang G, Angkeow P, LaCorte J, Bluemke D, Berger R, Halperin HR, Calkins H. Pulmonary vein anatomy in patients undergoing catheter ablation of atrial fibrillation: lessons learned by use of magnetic resonance imaging. Circulation. 2003;107:2004-10.

93. Wittkampf FH, Vonken EJ, Derksen R, Loh P, Velthuis B, Wever EF, Boersma LV, Rensing BJ, Cramer MJ. Pulmonary vein ostium geometry: analysis by magnetic resonance angiography. Circulation. 2003;107:21-3.

94. Vonken EP, Velthuis BK, Wittkampf FH, Rensing BJ, Derksen R, Cramer MJ. Contrast-enhanced MRA and 3D visualization of pulmonary venous anatomy to assist radiofrequency catheter ablation. $J$ Cardiovasc Magn Reson. 2003;5:545-51.

95. Ghaye B, Szapiro D, Dacher JN, Rodriguez LM, Timmermans C, Devillers D, Dondelinger RF. Percutaneous ablation for atrial fibrillation: the role of cross-sectional imaging. Radiographics. 2003;23 Spec No: S19-33; discussion S48-50.

96. Oudkerk M, van Beek EJ, Wielopolski P, van Ooijen PM, BrouwersKuyper EM, Bongaerts AH, Berghout A. Comparison of contrastenhanced magnetic resonance angiography and conventional pulmonary angiography for the diagnosis of pulmonary embolism: a prospective study. Lancet. 2002;359:1643-7.

97. Hoffmann U, Schima W, Herold C. Pulmonary magnetic resonance angiography. Eur Radiol. 1999;9:1745-54.

98. Fellner FA, Fellner C, Wutke R, Lang W, Laub G, Schmidt M, Janka R, Denzel C, Bautz W. Fluoroscopically triggered contrast-enhanced 3D MR DSA and 3D time-of-flight turbo MRA of the carotid arteries: first clinical experiences in correlation with ultrasound, $\mathrm{x}$-ray angiography, and endarterectomy findings. Magn Reson Imaging. 2000; 18:575-85.

99. Nederkoorn PJ, Elgersma OE, van der Graaf Y, Eikelboom BC, Kappelle LJ, Mali WP. Carotid artery stenosis: accuracy of contrast-enhanced MR angiography for diagnosis. Radiology. 2003;228:677-82.

100. Cosottini M, Pingitore A, Puglioli M, Michelassi MC, Lupi G, Abbruzzese A, Calabrese R, Lombardi M, Parenti G, Bartolozzi C. Contrast-enhanced three-dimensional magnetic resonance angiography of atherosclerotic internal carotid stenosis as the noninvasive imaging modality in revascularization decision making. Stroke. 2003;34:660-4.

101. Nonent M, Serfaty JM, Nighoghossian N, Rouhart F, Derex L, Rotaru C, Chirossel P, Guias B, Heautot JF, Gouny P, Langella B, Buthion V, Jars I, Pachai C, Veyret C, Gauvrit JY, Lamure M, Douek PC. Concordance rate differences of 3 noninvasive imaging techniques to measure carotid stenosis in clinical routine practice: results of the CARMEDAS multicenter study. Stroke. 2004;35:682-6.

102. Fuster V, Kim RJ. Frontiers in cardiovascular magnetic resonance. Circulation. 2005;112:135-44.

103. Sensky PR, Jivan A, Hudson NM, Keal RP, Morgan B, Tranter JL, de Bono D, Samani NJ, Cherryman GR. Coronary artery disease: combined stress MR imaging protocol-one-stop evaluation of myocardial perfusion and function. Radiology. 2000;215:608-14.

104. Plein S, Ridgway JP, Jones TR, Bloomer TN, Sivananthan MU. Coronary artery disease: assessment with a comprehensive MR imaging protocol--initial results. Radiology. 2002;225:300-7.

105. Pujadas S, Reddy GP, Weber O, Lee JJ, Higgins CB. MR imaging assessment of cardiac function. J Magn Reson Imaging. 2004; 19:789-99.

106. Rajappan K, Bellenger NG, Anderson L, Pennell DJ. The role of cardiovascular magnetic resonance in heart failure. Eur $\mathrm{J}$ Heart Fail. $2000 ; 2: 241-52$

107. Longmore DB, Klipstein RH, Underwood SR, Firmin DN, Hounsfield GN, Watanabe M, Bland C, Fox K, Poole-Wilson PA, Rees RS, et al. Dimensional accuracy of magnetic resonance in studies of the heart. Lancet. 1985;1:1360-2.

108. Sechtem U, Pflugfelder PW, Gould RG, Cassidy MM, Higgins $\mathrm{CB}$. Measurement of right and left ventricular volumes in healthy individuals with cine MR imaging. Radiology. 1987;163:697-702.

109. Kondo C, Caputo GR, Semelka R, Foster E, Shimakawa A, Higgins CB. Right and left ventricular stroke volume measurements with velocity- 
encoded cine MR imaging: in vitro and in vivo validation. AJR Am J Roentgenol. 1991;157:9-16.

110. Nayler GL, Firmin DN, Longmore DB. Blood flow imaging by cine magnetic resonance. J Comput Assist Tomogr. 1986;10:715-22.

111. Helbing WA, Rebergen SA, Maliepaard C, Hansen B, Ottenkamp J, Reiber JH, de Roos A. Quantification of right ventricular function with magnetic resonance imaging in children with normal hearts and with congenital heart disease. Am Heart J. 1995;130:828-37.

112. Katz J, Milliken MC, Stray-Gundersen J, Buja LM, Parkey RW, Mitchell $\mathrm{JH}$, Peshock RM. Estimation of human myocardial mass with MR imaging. Radiology. 1988;169:495-8.

113. Katz J, Whang J, Boxt LM, Barst RJ. Estimation of right ventricular mass in normal subjects and in patients with primary pulmonary hypertension by nuclear magnetic resonance imaging. J Am Coll Cardiol. 1993;21:1475-81.

114. Chuang ML, Hibberd MG, Salton CJ, Beaudin RA, Riley MF, Parker RA, Douglas PS, Manning WJ. Importance of imaging method over imaging modality in noninvasive determination of left ventricular volumes and ejection fraction: assessment by two- and three-dimensional echocardiography and magnetic resonance imaging. J Am Coll Cardiol. 2000;35:477-84.

115. Bottini PB, Carr AA, Prisant LM, Flickinger FW, Allison JD, Gottdiener JS. Magnetic resonance imaging compared to echocardiography to assess left ventricular mass in the hypertensive patient. Am J Hypertens. 1995;8:221-8.

116. Ioannidis JP, Trikalinos TA, Danias PG. Electrocardiogram-gated single-photon emission computed tomography versus cardiac magnetic resonance imaging for the assessment of left ventricular volumes and ejection fraction: a meta-analysis. J Am Coll Cardiol. 2002;39:2059-68.

117. Bellenger NG, Burgess MI, Ray SG, Lahiri A, Coats AJ, Cleland JG, Pennell DJ. Comparison of left ventricular ejection fraction and volumes in heart failure by echocardiography, radionuclide ventriculography and cardiovascular magnetic resonance; are they interchangeable? Eur. Heart J. 2000;21:1387-1396.

118. Versteegh MI, Lamb HJ, Bax JJ, Curiel FB, van der Wall EE, de Roos A, Dion RA. MRI evaluation of left ventricular function in anterior LV aneurysms before and after surgical resection. Eur J Cardiothorac Surg. 2003;23:609-13.

119. Peshock RM, Rokey R, Malloy GM, McNamee P, Buja LM, Parkey RW, Willerson JT. Assessment of myocardial systolic wall thickening using nuclear magnetic resonance imaging. J Am Coll Cardiol. 1989;14:653-9.

120. Reichek N. MRI myocardial tagging. J Magn Reson Imaging. 1999;10:609-16.

121. Zerhouni EA, Parish DM, Rogers WJ, Yang A, Shapiro EP. Human heart: tagging with MR imaging--a method for noninvasive assessment of myocardial motion. Radiology. 1988;169:59-63.

122. Moore CC, McVeigh ER, Zerhouni EA. Quantitative tagged magnetic resonance imaging of the normal human left ventricle. Top Magn Reson Imaging. 2000;11:359-71.

123. Grothues F, Moon JC, Bellenger NG, Smith GS, Klein HU, Pennell DJ. Interstudy reproducibility of right ventricular volumes, function, and mass with cardiovascular magnetic resonance. Am Heart J. 2004; 147:218-23.

124. Britten MB, Abolmaali ND, Assmus B, Lehmann R, Honold J, Schmitt J, VogI TJ, Martin H, Schachinger V, Dimmeler S, Zeiher AM. Infarct remodeling after intracoronary progenitor cell treatment in patients with acute myocardial infarction (TOPCARE-AMI): mechanistic insights from serial contrast-enhanced magnetic resonance imaging. Circulation. 2003;108:2212-8.

125. Pitt B, Reichek N, Willenbrock R, Zannad F, Phillips RA, Roniker B, Kleiman J, Krause S, Burns D, Williams GH. Effects of eplerenone, enalapril, and eplerenone/enalapril in patients with essential hypertension and left ventricular hypertrophy: the 4E-left ventricular hypertrophy study. Circulation. 2003;108:1831-8.

126. Bellenger NG, Rajappan K, Rahman SL, Lahiri A, Raval U, Webster J, Murray GD, Coats AJ, Cleland JG, Pennell DJ. Effects of carvedilol on left ventricular remodelling in chronic stable heart failure: a cardiovascular magnetic resonance study. Heart. 2004;90:760-4.

127. Baer FM, Voth E, Theissen P, Schneider CA, Schicha H, Sechtem U. Coronary artery disease: findings with GRE MR imaging and Tc-99mmethoxyisobutyl-isonitrile SPECT during simultaneous dobutamine stress. Radiology. 1994;193:203-209.

128. Baer FM, Voth E, Theissen P, Schicha H, Sechtem U. Gradientecho magnetic resonance imaging during incremental dobutamine infusion for the localization of coronary artery stenoses. Eur. Heart $\mathrm{J}$. 1994;15:218-225.

129. Baer FM, Smolarz K, Jungehulsing M, Theissen P, Sechtem U, Schicha $\mathrm{H}$, Hilger $\mathrm{HH}$. Feasibility of high-dose dipyridamole-magnetic resonance imaging for detection of coronary artery disease and comparison with coronary angiography. Am.J.Cardiol. 1992;69:51-56.

130. Pennell DJ, Underwood SR, Manzara CC, Swanton RH, Walker JM, EII PJ, Longmore DB. Magnetic resonance imaging during dobutamine stress in coronary artery disease. Am.J.Cardiol. 1992;70:34-40.

131. Zhao S, Croisille P, Janier M, Roux JP, Plana A, Magnin I, Revel D. Comparison between qualitative and quantitative wall motion analyses using dipyridamole stress breath-hold cine magnetic resonance imaging in patients with severe coronary artery stenosis. Magn Reson. Imaging. 1997;15:891-898.

132. Nagel E, Lorenz C, Baer F, Hundley WG, Wilke N, Neubauer S, Sechtem $U$, van der WE, Pettigrew R, de Roos A, Fleck E, van Rossum A, Pennell DJ, Wickline S. Stress cardiovascular magnetic resonance: consensus panel report. J.Cardiovasc. Magn Reson. 2001;3:267-281.

133. Nagel E, Lehmkuhl HB, Bocksch W, Klein C, Vogel U, Frantz E, Ellmer $A$, Dreysse $S$, Fleck E. Noninvasive diagnosis of ischemia-induced wall motion abnormalities with the use of high-dose dobutamine stress MRI: comparison with dobutamine stress echocardiography. Circulation. 1999;99:763-770.

134. Nagel E, Lehmkuhl HB, Klein C, Schneider U, Frantz E, Ellmer A, Bocksch W, Dreysse S, Fleck E. [Influence of image quality on the diagnostic accuracy of dobutamine stress magnetic resonance imaging in comparison with dobutamine stress echocardiography for the noninvasive detection of myocardial ischemia]. Z.Kardiol. 1999;88:622-630.

135. Hundley WG, Hamilton CA, Thomas MS, Herrington DM, Salido TB, Kitzman DW, Little WC, Link KM. Utility of fast cine magnetic resonance imaging and display for the detection of myocardial ischemia in patients not well suited for second harmonic stress echocardiography. Circulation. 1999;100:1697-1702.

136. Kuijpers D, Ho KY, van Dijkman PR, Vliegenthart R, Oudkerk M. Dobutamine cardiovascular magnetic resonance for the detection of myocardial ischemia with the use of myocardial tagging. Circulation. 2003;107:1592-1597.

137. van Rugge FP, van der Wall EE, Spanjersberg SJ, de Roos A, Matheijssen NA, Zwinderman AH, van Dijkman PR, Reiber JH, Bruschke AV. Magnetic resonance imaging during dobutamine stress for detection and localization of coronary artery disease. Quantitative wall motion analysis using a modification of the centerline method. Circulation. 1994;90:127-138.

138. Hundley WG, Morgan TM, Neagle CM, Hamilton CA, Rerkpattanapipat $P$, Link KM. Magnetic resonance imaging determination of cardiac prognosis. Circulation. 2002;106:2328-2333.

139. Rerkpattanapipat P, Morgan TM, Neagle CM, Link KM, Hamilton CA, Hundley WG. Assessment of preoperative cardiac risk with magnetic resonance imaging. Am.J.Cardiol. 2002;90:416-419. 
140. Paetsch I, Jahnke C, Wahl A, Gebker R, Neuss M, Fleck E, Nagel E. Comparison of dobutamine stress magnetic resonance, adenosine stress magnetic resonance, and adenosine stress magnetic resonance perfusion. Circulation. 2004;110:835-42.

141. Wahl A, Paetsch I, Gollesch A, Roethemeyer S, Foell D, Gebker R, Langreck $H$, Klein $C$, Fleck E, Nagel E. Safety and feasibility of highdose dobutamine-atropine stress cardiovascular magnetic resonance for diagnosis of myocardial ischaemia: experience in 1000 consecutive cases. Eur. Heart J. 2004;25:1230-1236.

142. Azevedo CF, Amado LC, Kraitchman DL, Gerber BL, Edvardsen T, Osman NF, Rochitte CE, Wu KC, Lima JA. The effect of intra-aortic balloon counterpulsation on left ventricular functional recovery early after acute myocardial infarction: a randomized experimental magnetic resonance imaging study. Eur. Heart J. 2005;26:1235-1241.

143. Schalla S, Klein C, Paetsch I, Lehmkuhl H, Bornstedt A, Schnackenburg $B$, Fleck E, Nagel E. Real-time MR image acquisition during high-dose dobutamine hydrochloride stress for detecting left ventricular wallmotion abnormalities in patients with coronary arterial disease. Radiology. 2002;224:845-851.

144. Azevedo CF, Amado LC, Kraitchman DL, Gerber BL, Osman NF, Rochitte CE, Edvardsen T, Lima JA. Persistent diastolic dysfunction despite complete systolic functional recovery after reperfused acute myocardial infarction demonstrated by tagged magnetic resonance imaging. Eur. Heart J. 2004;25:1419-1427.

145. Klassen C, Nguyen M, Siuciak A, Wilke NM. Magnetic resonance first pass perfusion imaging for detecting coronary artery disease. Eur $\mathrm{J}$ Radiol. 2006;57:412-6.

146. Wolff SD, Schwitter J, Coulden R, Friedrich MG, Bluemke DA, Biederman RW, Martin ET, Lansky AJ, Kashanian F, Foo TK, Licato PE, Comeau CR. Myocardial first-pass perfusion magnetic resonance imaging: a multicenter dose-ranging study. Circulation. 2004;110:732-737.

147. Giang TH, Nanz D, Coulden R, Friedrich M, Graves M, al Saadi N, Luscher TF, von Schulthess GK, Schwitter J. Detection of coronary artery disease by magnetic resonance myocardial perfusion imaging with various contrast medium doses: first European multi-centre experience. Eur. Heart J. 2004;25:1657-1665.

148. Nagel E, Klein C, Paetsch I, Hettwer S, Schnackenburg B, Wegscheider $\mathrm{K}$, Fleck E. Magnetic resonance perfusion measurements for the noninvasive detection of coronary artery disease. Circulation. 2003;108:432-437.

149. Panting JR, Gatehouse PD, Yang GZ, Jerosch-Herold M, Wilke N, Firmin DN, Pennell DJ. Echo-planar magnetic resonance myocardial perfusion imaging: parametric map analysis and comparison with thallium SPECT. J.Magn Reson.Imaging. 2001;13:192-200.

150. Schwitter J, Nanz D, Kneifel S, Bertschinger K, Buchi M, Knusel PR, Marincek B, Luscher TF, von Schulthess GK. Assessment of myocardial perfusion in coronary artery disease by magnetic resonance: a comparison with positron emission tomography and coronary angiography. Circulation. 2001;103:2230-2235.

151. Yang GZ, Burger P, Panting J, Gatehouse PD, Rueckert D, Pennell DJ, Firmin DN. Motion and deformation tracking for short-axis echo-planar myocardial perfusion imaging. Med.Image Anal. 1998;2:285-302.

152. Jerosch-Herold M, Wilke N, Stillman AE. Magnetic resonance quantification of the myocardial perfusion reserve with a Fermi function model for constrained deconvolution. Med.Phys. 1998;25:73-84.

153. Kroll K, Wilke N, Jerosch-Herold M, Wang Y, Zhang Y, Bache RJ, Bassingthwaighte JB. Modeling regional myocardial flows from residue functions of an intravascular indicator. Am.J.Physiol. 1996;271: H1643-H1655.

154. Wilke N, Jerosch-Herold M, Stillman AE, Kroll K, Tsekos N, Merkle H, Parrish T, Hu X, Wang Y, Bassingthwaighte J, . Concepts of myocardial perfusion imaging in magnetic resonance imaging. Magn Reson.Q. 1994;10:249-286.
155. Wilke N, Simm C, Zhang J, Ellermann J, Ya X, Merkle H, Path G, Ludemann H, Bache RJ, Ugurbil K. Contrast-enhanced first pass myocardial perfusion imaging: correlation between myocardial blood flow in dogs at rest and during hyperemia. Magn Reson.Med. 1993;29:485-497.

156. Lee DC, Simonetti OP, Harris KR, Holly TA, Judd RM, Wu E, Klocke FJ. Magnetic resonance versus radionuclide pharmacological stress perfusion imaging for flow-limiting stenoses of varying severity. Circulation. 2004;110:58-65.

157. Kraitchman DL, Wilke N, Hexeberg E, Jerosch-Herold M, Wang Y, Parrish TB, Chang CN, Zhang Y, Bache RJ, Axel L. Myocardial perfusion and function in dogs with moderate coronary stenosis. Magn Reson. Med. 1996;35:771-780.

158. Sparrow P, Plein S, Jones TR, Thorley PJ, Hale C, Sivananthan MU. Tolerance of MRI vs. SPECT myocardial perfusion studies--a patient survey. J Magn Reson Imaging. 2004;19:410-6.

159. Lauerma K, Virtanen KS, Sipila LM, Hekali P, Aronen HJ. Multislice MRI in assessment of myocardial perfusion in patients with singlevessel proximal left anterior descending coronary artery disease before and after revascularization. Circulation. 1997;96:2859-2867.

160. al Saadi N, Nagel E, Gross M, Schnackenburg B, Paetsch I, Klein C, Fleck E. Improvement of myocardial perfusion reserve early after coronary intervention: assessment with cardiac magnetic resonance imaging. J.Am.Coll.Cardiol. 2000;36:1557-1564.

161. Sipola P, Lauerma K, Husso-Saastamoinen M, Kuikka JT, Vanninen $\mathrm{E}$, Laitinen T, Manninen $\mathrm{H}$, Niemi P, Peuhkurinen K, Jaaskelainen $\mathrm{P}$, Laakso M, Kuusisto J, Aronen HJ. First-pass MR imaging in the assessment of perfusion impairment in patients with hypertrophic cardiomyopathy and the Asp 175Asn mutation of the alphatropomyosin gene. Radiology. 2003;226:129-137.

162. Ishida M, Sakuma H, Kato N, Ishida N, Kitagawa K, Shimono T, Yada I, Takeda K. Contrast-enhanced MR imaging for evaluation of coronary artery disease before elective repair of aortic aneurysm. Radiology. 2005;237:458-64.

163. Kwong RY, Schussheim AE, Rekhraj S, Aletras AH, Geller N, Davis J, Christian TF, Balaban RS, Arai AE. Detecting acute coronary syndrome in the emergency department with cardiac magnetic resonance imaging. Circulation. 2003;107:531-7.

164. Ingkanisorn WP, Kwong RY, Bohme NS, Geller NL, Rhoads KL, Dyke CK, Paterson DI, Syed MA, Aletras AH, Arai AE. Prognosis of Negative Adenosine Stress Magnetic Resonance in Patients Presenting to an Emergency Department With Chest Pain. J Am Coll Cardiol. 2006;47:1427-32.

165. Rodrigues de Avila LF, Fernandes JL, Rochitte CE, Cerri GG, Filho JP. Perfusion impairment in patients with normal-appearing coronary arteries: identification with contrast-enhanced MR imaging. Radiology. 2006;238:464-72.

166. Selvanayagam JB, Jerosch-Herold M, Porto I, Sheridan D, Cheng AS, Petersen SE, Searle N, Channon KM, Banning AP, Neubauer S. Resting myocardial blood flow is impaired in hibernating myocardium: a magnetic resonance study of quantitative perfusion assessment. Circulation. 2005;112:3289-96.

167. Panting JR, Gatehouse PD, Yang GZ, Grothues F, Firmin DN, Collins P, Pennell DJ. Abnormal subendocardial perfusion in cardiac syndrome $\mathrm{X}$ detected by cardiovascular magnetic resonance imaging. N.Eng/. J.Med. 2002;346:1948-1953.

168. Manning WJ, Li W, Edelman RR. A preliminary report comparing magnetic resonance coronary angiography with conventional angiography. N Engl J Med. 1993;328:828-32.

169. Post JC, van Rossum AC, Hofman MB, de Cock CC, Valk J, Visser CA. Clinical utility of two-dimensional magnetic resonance angiography in detecting coronary artery disease. Eur Heart J. 1997;18:426-33.

170. Kim WY, Danias PG, Stuber M, Flamm SD, Plein S, Nagel E, Langerak SE, Weber OM, Pedersen EM, Schmidt M, Botnar RM, Manning 
WJ. Coronary magnetic resonance angiography for the detection of coronary stenoses. N Eng/ J Med. 2001;345:1863-9.

171. Post JC, van Rossum AC, Hofman MB, Valk J, Visser CA. Threedimensional respiratory-gated MR angiography of coronary arteries: comparison with conventional coronary angiography. AJR Am J Roentgenol. 1996;166:1399-404.

172. van Geuns RJ, Wielopolski PA, de Bruin HG, Rensing BJ, Hulshoff M, van Ooijen PM, de Feyter PJ, Oudkerk M. MR coronary angiography with breath-hold targeted volumes: preliminary clinical results. Radiology. 2000;217:270-7.

173. Li D, Dolan RP, Walovitch RC, Lauffer RB. Three-dimensional MRI of coronary arteries using an intravascular contrast agent. Magn Reson Med. 1998;39:1014-8.

174. Budoff MJ, Achenbach S, Duerinckx A. Clinical utility of computed tomography and magnetic resonance techniques for noninvasive coronary angiography. J Am Coll Cardiol. 2003;42:1867-78.

175. Schuijf JD, Bax JJ, Shaw LJ, de Roos A, Lamb HJ, van der Wall EE, Wijns W. Meta-analysis of comparative diagnostic performance of magnetic resonance imaging and multislice computed tomography for noninvasive coronary angiography. Am Heart J. 2006;151:404-11.

176. Kefer J, Coche E, Legros G, Pasquet A, Grandin C, Van Beers BE, Vanoverschelde JL, Gerber BL. Head-to-head comparison of threedimensional navigator-gated magnetic resonance imaging and 16-slice computed tomography to detect coronary artery stenosis in patients. $J$ Am Coll Cardiol. 2005;46:92-100.

177. Post JC, van Rossum AC, Bronzwaer JG, de Cock CC, Hofman MB, Valk J, Visser CA. Magnetic resonance angiography of anomalous coronary arteries. A new gold standard for delineating the proximal course? Circulation. 1995;92:3163-71.

178. McConnell MV, Ganz P, Selwyn AP, Li W, Edelman RR, Manning WJ. Identification of anomalous coronary arteries and their anatomic course by magnetic resonance coronary angiography. Circulation. 1995;92:3158-62.

179. Bunce NH, Lorenz CH, Keegan J, Lesser J, Reyes EM, Firmin DN, Pennell DJ. Coronary artery anomalies: assessment with freebreathing three-dimensional coronary MR angiography. Radiology. 2003;227:201-8.

180. Gomes AS, Lois JF, Drinkwater DC, Jr., Corday SR. Coronary artery bypass grafts: visualization with MR imaging. Radiology. 1987;162:175-9.

181. White RD, Caputo GR, Mark AS, Modin GW, Higgins CB. Coronary artery bypass graft patency: noninvasive evaluation with MR imaging. Radiology. 1987;164:681-6.

182. Jenkins JP, Love HG, Foster CJ, Isherwood I, Rowlands DJ. Detection of coronary artery bypass graft patency as assessed by magnetic resonance imaging. Br J Radiol. 1988;61:2-4.

183. Langerak SE, Vliegen HW, Jukema JW, Kunz P, Zwinderman AH, Lamb $H J$, van der Wall EE, de Roos A. Value of magnetic resonance imaging for the noninvasive detection of stenosis in coronary artery bypass grafts and recipient coronary arteries. Circulation. 2003;107:1502-8.

184. Clarke GD, Eckels R, Chaney C, Smith D, Dittrich J, Hundley WG, NessAiver M, Li HF, Parkey RW, Peshock RM. Measurement of absolute epicardial coronary artery flow and flow reserve with breathhold cine phase-contrast magnetic resonance imaging. Circulation. 1995;91:2627-34.

185. Hundley WG, Lange RA, Clarke GD, Meshack BM, Payne J, Landau C, McColl R, Sayad DE, Willett DL, Willard JE, Hillis LD, Peshock RM. Assessment of coronary arterial flow and flow reserve in humans with magnetic resonance imaging. Circulation. 1996;93:1502-8.

186. Nagel E, Thouet T, Klein C, Schalla S, Bornstedt A, Schnackenburg B, Hug J, Wellnhofer E, Fleck E. Noninvasive determination of coronary blood flow velocity with cardiovascular magnetic resonance in patients after stent deployment. Circulation. 2003;107:1738-43.
187. Hoogendoorn LI, Pattynama PM, Buis B, van der Geest RJ, van der Wall EE, de Roos A. Noninvasive evaluation of aortocoronary bypass grafts with magnetic resonance flow mapping. Am J Cardiol. 1995;75:845-8.

188. Langerak SE, Kunz P, Vliegen HW, Jukema JW, Zwinderman AH, Steendijk P, Lamb HJ, van der Wall EE, de Roos A. MR flow mapping in coronary artery bypass grafts: a validation study with Doppler flow measurements. Radiology. 2002;222:127-35.

189. Lima JA, Judd RM, Bazille A, Schulman SP, Atalar E, Zerhouni EA. Regional heterogeneity of human myocardial infarcts demonstrated by contrast-enhanced MRI. Potential mechanisms. Circulation. 1995;92:1117-1125.

190. Choi KM, Kim RJ, GubernikoffG, Vargas JD, Parker M, Judd RM. Transmural extent of acute myocardial infarction predicts long-term improvement in contractile function. Circulation. 2001;104:1101-1107.

191. Judd RM, Lugo-Olivieri CH, Arai M, Kondo T, Croisille P, Lima JA, Mohan V, Becker LC, Zerhouni EA. Physiological basis of myocardial contrast enhancement in fast magnetic resonance images of 2-day-old reperfused canine infarcts. Circulation. 1995;92:1902-1910.

192. Kim RJ, Fieno DS, Parrish TB, Harris K, Chen EL, Simonetti O, Bundy J, Finn JP, Klocke FJ, Judd RM. Relationship of MRI delayed contrast enhancement to irreversible injury, infarct age, and contractile function. Circulation. 1999;100:1992-2002.

193. Kim RJ, Chen EL, Lima JA, Judd RM. Myocardial Gd-DTPA kinetics determine MRI contrast enhancement and reflect the extent and severity of myocardial injury after acute reperfused infarction. Circulation. 1996;94:3318-3326.

194. Mahrholdt H, Wagner A, Holly TA, Elliott MD, Bonow RO, Kim RJ, Judd RM. Reproducibility of chronic infarct size measurement by contrast-enhanced magnetic resonance imaging. Circulation. 2002;106:2322-2327.

195. Wu E, Judd RM, Vargas JD, Klocke FJ, Bonow RO, Kim RJ. Visualisation of presence, location, and transmural extent of healed Q-wave and nonQ-wave myocardial infarction. Lancet. 2001;357:21-28.

196. Simonetti OP, Kim RJ, Fieno DS, Hillenbrand HB, Wu E, Bundy JM, Finn JP, Judd RM. An improved MR imaging technique for the visualization of myocardial infarction. Radiology. 2001;218:215-223.

197. Saeed M, Wendland MF, Masui T, Higgins CB. Reperfused myocardial infarctions on T1- and susceptibility-enhanced MRI: evidence for loss of compartmentalization of contrast media. Magn Reson.Med. 1994;31:31-39.

198. Diesbourg LD, Prato FS, Wisenberg G, Drost DJ, Marshall TP, Carroll SE, O'Neill B. Quantification of myocardial blood flow and extracellular volumes using a bolus injection of Gd-DTPA: kinetic modeling in canine ischemic disease. Magn Reson.Med. 1992;23:239-253.

199. Rehwald WG, Fieno DS, Chen EL, Kim RJ, Judd RM. Myocardial magnetic resonance imaging contrast agent concentrations after reversible and irreversible ischemic injury. Circulation. 2002;105:224-229.

200. Rochitte CE, Lima JA, Bluemke DA, Reeder SB, McVeigh ER, Furuta T, Becker LC, Melin JA. Magnitude and time course of microvascular obstruction and tissue injury after acute myocardial infarction. Circulation. 1998;98:1006-1014.

201. Wagner A, Mahrholdt H, Holly TA, Elliott MD, Regenfus M, Parker M, Klocke FJ, Bonow RO, Kim RJ, Judd RM. Contrast-enhanced MRI and routine single photon emission computed tomography (SPECT) perfusion imaging for detection of subendocardial myocardial infarcts: an imaging study. Lancet. 2003;361:374-379.

202. Ricciardi MJ, Wu E, Davidson CJ, Choi KM, Klocke FJ, Bonow RO, Judd RM, Kim RJ. Visualization of discrete microinfarction after percutaneous coronary intervention associated with mild creatine kinase-MB elevation. Circulation. 2001;103:2780-2783.

203. Wu KC, Zerhouni EA, Judd RM, Lugo-Olivieri CH, Barouch LA, Schulman SP, Blumenthal RS, Lima JA. Prognostic significance of 
microvascular obstruction by magnetic resonance imaging in patients with acute myocardial infarction. Circulation. 1998;97:765-772.

204. Azevedo Filho CF, Hadlich M, Petriz JL, Mendonca LA, Moll Filho JN, Rochitte CE. Quantification of left ventricular infarcted mass on cardiac magnetic resonance imaging: comparison between planimetry and the semiquantitative visual scoring method. Arq Bras Cardiol. 2004;83:118-24; 111-7.

205. Wu KC, Kim RJ, Bluemke DA, Rochitte CE, Zerhouni EA, Becker LC, Lima JA. Quantification and time course of microvascular obstruction by contrast-enhanced echocardiography and magnetic resonance imaging following acute myocardial infarction and reperfusion. J.Am. Coll.Cardiol. 1998;32:1756-1764.

206. Braunwald E, Kloner RA. The stunned myocardium: prolonged, postischemic ventricular dysfunction. Circulation. 1982;66:11461149.

207. Kloner RA, Bolli R, Marban E, Reinlib L, Braunwald E. Medical and cellular implications of stunning, hibernation, and preconditioning: an NHLBI workshop. Circulation. 1998;97:1848-1867.

208. Gerber BL, Garot J, Bluemke DA, Wu KC, Lima JA. Accuracy of contrast-enhanced magnetic resonance imaging in predicting improvement of regional myocardial function in patients after acute myocardial infarction. Circulation. 2002;106:1083-1089.

209. Anselmi M, Golia G, Cicoira M, Tinto M, Nitti MT, Trappolin R, Rossi A, Zanolla L, Marino P, Zardini P. Prognostic value of detection of myocardial viability using low-dose dobutamine echocardiography in infarcted patients. Am.J.Cardiol. 1998;81:21G-28G.

210. Picano E, Sicari R, Landi P, Cortigiani L, Bigi R, Coletta C, Galati A, Heyman J, Mattioli R, Previtali M, Mathias W, Jr., Dodi C, Minardi G, Lowenstein J, Seveso G, Pingitore A, Salustri A, Raciti M. Prognostic value of myocardial viability in medically treated patients with global left ventricular dysfunction early after an acute uncomplicated myocardial infarction: a dobutamine stress echocardiographic study. Circulation. 1998;98:1078-1084.

211. Baks T, van Geuns RJ, Biagini E, Wielopolski P, Mollet NR, Cademartiri F, van der Giessen WJ, Krestin GP, Serruys PW, Duncker DJ, de Feyter PJ. Effects of primary angioplasty for acute myocardial infarction on early and late infarct size and left ventricular wall characteristics. J Am Coll Cardiol. 2006;47:40-4.

212. Hombach V, Grebe O, Merkle N, Waldenmaier S, Hoher M, Kochs M, Wohrle J, Kestler HA. Sequelae of acute myocardial infarction regarding cardiac structure and function and their prognostic significance as assessed by magnetic resonance imaging. Eur Heart J. 2005;26:549-57.

213. Bodi V, Sanchis J, Lopez-Lereu MP, Losada A, Nunez J, Pellicer M, Bertomeu V, Chorro FJ, Llacer A. Usefulness of a comprehensive cardiovascular magnetic resonance imaging assessment for predicting recovery of left ventricular wall motion in the setting of myocardial stunning. J Am Coll Cardiol. 2005;46:1747-52.

214. Wellnhofer E, Olariu A, Klein C, Grafe M, Wahl A, Fleck E, Nagel E. Magnetic resonance low-dose dobutamine test is superior to SCAR quantification for the prediction of functional recovery. Circulation. 2004;109:2172-4.

215. Shan K, Constantine G, Sivananthan M, Flamm SD. Role of cardiac magnetic resonance imaging in the assessment of myocardial viability. Circulation. 2004;109:1328-34.

216. Klein C, Nekolla SG, Bengel FM, Momose M, Sammer A, Haas F, Schnackenburg B, Delius W, Mudra H, Wolfram D, Schwaiger M. Assessment of myocardial viability with contrast-enhanced magnetic resonance imaging: comparison with positron emission tomography. Circulation. 2002;105:162-167.

217. Kuhl HP, Beek AM, van der Weerdt AP, Hofman MB, Visser CA, Lammertsma AA, Heussen N, Visser FC, van Rossum AC. Myocardial viability in chronic ischemic heart disease: comparison of contrast-enhanced magnetic resonance imaging with (18)F- fluorodeoxyglucose positron emission tomography. J Am Coll Cardiol. 2003;41:1341-8.

218. Chareonthaitawee P, Gersh BJ, Araoz PA, Gibbons RJ. Revascularization in severe left ventricular dysfunction: the role of viability testing. J Am Coll Cardiol. 2005;46:567-74.

219. Kim RJ, Shah DJ. Fundamental concepts in myocardial viability assessment revisited: when knowing how much is "alive" is not enough. Heart. 2004;90:137-40.

220. Kim RJ, Wu E, Rafael A, Chen EL, Parker MA, Simonetti O, Klocke FJ, Bonow RO, Judd RM. The use of contrast-enhanced magnetic resonance imaging to identify reversible myocardial dysfunction. N.Engl.J.Med. 2000;343:1445-1453.

221. Knuesel PR, Nanz D, Wyss C, Buechi M, Kaufmann PA, von Schulthess GK, Luscher TF, Schwitter J. Characterization of dysfunctional myocardium by positron emission tomography and magnetic resonance: relation to functional outcome after revascularization. Circulation. 2003;108:1095-100.

222. Schvartzman PR, Srichai MB, Grimm RA, Obuchowski NA, Hammer DF, McCarthy PM, Kasper JM, White RD. Nonstress delayedenhancement magnetic resonance imaging of the myocardium predicts improvement of function after revascularization for chronic ischemic heart disease with left ventricular dysfunction. Am Heart J. 2003;146:535-41.

223. Maron BJ. Hypertrophic cardiomyopathy: a systematic review. JAMA. 2002;287:1308-1320.

224. Prasad K, Atherton J, Smith GC, McKenna WJ, Frenneaux MP, Nihoyannopoulos P. Echocardiographic pitfalls in the diagnosis of hypertrophic cardiomyopathy. Heart. 1999;82 Suppl 3:III8-III15.

225. Rickers C, Wilke NM, Jerosch-Herold M, Casey SA, Panse P, Panse N, Weil J, Zenovich AG, Maron BJ. Utility of cardiac magnetic resonance imaging in the diagnosis of hypertrophic cardiomyopathy. Circulation. 2005; 112:855-61.

226. Moon JC, Reed E, Sheppard MN, Elkington AG, Ho SY, Burke M, Petrou $\mathrm{M}$, Pennell DJ. The histologic basis of late gadolinium enhancement cardiovascular magnetic resonance in hypertrophic cardiomyopathy. J.Am.Coll.Cardiol. 2004;43:2260-2264.

227. Moon JC, McKenna WJ, McCrohon JA, Elliott PM, Smith GC, Pennell DJ. Toward clinical risk assessment in hypertrophic cardiomyopathy with gadolinium cardiovascular magnetic resonance. J Am Coll Cardiol. 2003;41:1561-7.

228. Choudhury L, Mahrholdt H, Wagner A, Choi KM, Elliott MD, Klocke FJ, Bonow RO, Judd RM, Kim RJ. Myocardial scarring in asymptomatic or mildly symptomatic patients with hypertrophic cardiomyopathy. J Am Coll Cardiol. 2002;40:2156-64.

229. Weidemann F, Breunig F, Beer M, Sandstede J, Stork S, Voelker W, Ertl G, Knoll A, Wanner C, Strotmann JM. The variation of morphological and functional cardiac manifestation in Fabry disease: potential implications for the time course of the disease. Eur. Heart J. 2005;26:1221-1227.

230. Hudsmith LE, Petersen SE, Francis JM, Robson MD, Watkins $H$, Neubauer S. Hypertrophic cardiomyopathy in Noonan Syndrome closely mimics familial hypertrophic cardiomyopathy due to sarcomeric mutations. Int J Cardiovasc Imaging. 2005:1-3.

231. Roberts R, Sigwart U. Current concepts of the pathogenesis and treatment of hypertrophic cardiomyopathy. Circulation. 2005;112:293-6.

232. Kramer CM, Reichek N, Ferrari VA, Theobald T, Dawson J, Axel L. Regional heterogeneity of function in hypertrophic cardiomyopathy. Circulation. 1994;90:186-194.

233. Mishiro Y, Oki T, luchi A, Tabata T, Yamada H, Abe M, Onose $Y$, Ito S, Nishitani H, Harada M, Taoka Y. Regional left ventricular myocardial contraction abnormalities and asynchrony in patients with hypertrophic cardiomyopathy evaluated by magnetic resonance 
spatial modulation of magnetization myocardial tagging. Jpn.Circ.J. 1999;63:442-446.

234. Young AA, Kramer CM, Ferrari VA, Axel L, Reichek N. Threedimensional left ventricular deformation in hypertrophic cardiomyopathy. Circulation. 1994;90:854-867.

235. Amano Y, Kumita S, Takayama M, Kumazaki T. Comparison of contrast-enhanced MRI with iodine-123 BMIPP for detection of myocardial damage in hypertrophic cardiomyopathy. AJR Am J Roentgenol. 2005;185:312-8.

236. Gaudio C, Pelliccia F, Tanzilli G, Mazzarotto P, Cianfrocca C, Marino B. Magnetic resonance imaging for assessment of apical hypertrophy in hypertrophic cardiomyopathy. Clin.Cardiol. 1992;15:164-168.

237. Moon JC, Fisher NG, McKenna WJ, Pennell DJ. Detection of apical hypertrophic cardiomyopathy by cardiovascular magnetic resonance in patients with non-diagnostic echocardiography. Heart. 2004;90:645-9

238. van Dockum WG, Beek AM, ten Cate FJ, ten Berg JM, Bondarenko O, Gotte MJ, Twisk JW, Hofman MB, Visser CA, van Rossum AC. Early onset and progression of left ventricular remodeling after alcohol septal ablation in hypertrophic obstructive cardiomyopathy. Circulation. 2005;111:2503-2508.

239. Germain P, Roul G, Kastler B, Mossard JM, Bareiss P, Sacrez A. Inter-study variability in left ventricular mass measurement. Comparison between $\mathrm{M}$ mode echography and MRI. Eur. Heart J. 1992;13:1011-1019.

240. Allison JD, Flickinger FW, Wright JC, Falls DG, III, Prisant LM, VonDohlen TW, Frank MJ. Measurement of left ventricular mass in hypertrophic cardiomyopathy using MRI: comparison with echocardiography. Magn Reson.Imaging. 1993;11:329-334.

241. Di Cesare E. MRI of the cardiomyopathies. Eur J Radiol. 2001;38:179-84.

242. Nishimura RA, Holmes DR, Jr. Clinical practice. Hypertrophic obstructive cardiomyopathy. N Eng/ J Med. 2004;350:1320-7.

243. Corrado D, Pelliccia A, Bjornstad HH, Vanhees L, Biffi A, Borjesson M, Panhuyzen-Goedkoop N, Deligiannis A, Solberg E, Dugmore $D$, Mellwig KP, Assanelli D, Delise P, van-Buuren F, Anastasakis A, Heidbuchel H, Hoffmann E, Fagard R, Priori SG, Basso C, Arbustini E, Blomstrom-Lundqvist C, McKenna WJ, Thiene G. Cardiovascular preparticipation screening of young competitive athletes for prevention of sudden death: proposal for a common European protocol. Consensus Statement of the Study Group of Sport Cardiology of the Working Group of Cardiac Rehabilitation and Exercise Physiology and the Working Group of Myocardial and Pericardial Diseases of the European Society of Cardiology. Eur Heart J. 2005;26:516-24.

244. Anastasakis A, Kotsiopoulou C, Rigopoulos A, Theopistou A, Protonotarios N, Panagiotakos D, Mammalis N, Stefanadis C. Similarities in the profile of cardiopulmonary exercise testing between patients with hypertrophic cardiomyopathy and strength athletes. Heart. 2005;91:1477-8.

245. Petersen SE, Selvanayagam JB, Francis JM, Myerson SG, Wiesmann F, Robson MD, Ostman-Smith I, Casadei B, Watkins H, Neubauer S. Differentiation of athlete's heart from pathological forms of cardiac hypertrophy by means of geometric indices derived from cardiovascular magnetic resonance. J Cardiovasc Magn Reson. 2005;7:551-8.

246. Maron BJ. Distinguishing hypertrophic cardiomyopathy from athlete's heart: a clinical problem of increasing magnitude and significance. Heart. 2005;91:1380-2.

247. Croisille P, Revel D. MR imaging of the heart: functional imaging. Eur. Radiol. 2000;10:7-11.

248. Schalla S, Nagel E, Lehmkuhl H, Klein C, Bornstedt A, Schnackenburg $B$, Schneider U, Fleck E. Comparison of magnetic resonance real-time imaging of left ventricular function with conventional magnetic resonance imaging and echocardiography. Am.J.Cardiol. 2001;87:95-99
249. Strohm O, Schulz-Menger J, Pilz B, Osterziel KJ, Dietz R, Friedrich $M G$. Measurement of left ventricular dimensions and function in patients with dilated cardiomyopathy. J.Magn Reson.Imaging. $2001 ; 13: 367-371$

250. Soriano CJ, Ridocci F, Estornell J, Jimenez J, Martinez V, De Velasco $J A$. Noninvasive diagnosis of coronary artery disease in patients with heart failure and systolic dysfunction of uncertain etiology, using late gadolinium-enhanced cardiovascular magnetic resonance. J.Am.Coll. Cardiol. 2005;45:743-748.

251. McCrohon JA, Moon JC, Prasad SK, McKenna WJ, Lorenz CH, Coats AJ, Pennell DJ. Differentiation of heart failure related to dilated cardiomyopathy and coronary artery disease using gadoliniumenhanced cardiovascular magnetic resonance. Circulation. 2003;108:54-59.

252. Mahrholdt H, Wagner A, Judd RM, Sechtem U, Kim RJ. Delayed enhancement cardiovascular magnetic resonance assessment of nonischaemic cardiomyopathies. Eur Heart J. 2005;26:1461-74.

253. Mady C, Cardoso RH, Barretto AC, da Luz PL, Bellotti G, Pileggi F. Survival and predictors of survival in patients with congestive heart failure due to Chagas' cardiomyopathy. Circulation. 1994;90:3098-102.

254. Marin Neto JA, Simoes MV, Sarabanda AV. Chagas' heart disease. Arq Bras Cardiol. 1999;72:247-80.

255. Higuchi Mde L, Benvenuti LA, Martins Reis M, Metzger M. Pathophysiology of the heart in Chagas' disease: current status and new developments. Cardiovasc Res. 2003;60:96-107.

256. Higuchi ML, Fukasawa S, De Brito T, Parzianello LC, Bellotti G, Ramires JA. Different microcirculatory and interstitial matrix patterns in idiopathic dilated cardiomyopathy and Chagas' disease: a three dimensional confocal microscopy study. Heart. 1999;82:279-85.

257. Mady C, lanni BM, Arteaga E, Montes GS, Caldini EG, Andrade G, Giorgi MC, Saldiva PH. Relation between interstitial myocardial collagen and the degree of clinical impairment in Chagas' disease. Am J Cardiol. 1999;84:354-6, A9.

258. Rochitte CE, Oliveira PF, Andrade JM, lanni BM, Parga JR, Avila LF, Kalil-Filho R, Mady C, Meneghetti JC, Lima JA, Ramires JA. Myocardial delayed enhancement by magnetic resonance imaging in patients with Chagas' disease: a marker of disease severity. J Am Coll Cardiol. 2005;46:1553-8.

259. Basso C, Thiene G, Corrado D, Angelini A, Nava A, Valente M. Arrhythmogenic right ventricular cardiomyopathy. Dysplasia, dystrophy, or myocarditis? Circulation. 1996;94:983-991.

260. McKenna WJ, Thiene G, Nava A, Fontaliran F, Blomstrom-Lundqvist C Fontaine G, Camerini F. Diagnosis of arrhythmogenic right ventricular dysplasia/cardiomyopathy. Task Force of the Working Group Myocardial and Pericardial Disease of the European Society of Cardiology and of the Scientific Council on Cardiomyopathies of the International Society and Federation of Cardiology. Br. Heart J. 1994;71:215-218.

261. Kayser HW, van der Wall EE, Sivananthan MU, Plein S, Bloomer TN, de Roos A. Diagnosis of arrhythmogenic right ventricular dysplasia: a review. Radiographics. 2002;22:639-48; discussion 649-50.

262. Maron BJ, Roberts WC, McAllister HA, Rosing DR, Epstein SE. Sudden death in young athletes. Circulation. 1980;62:218-229.

263. Thiene G, Nava A, Corrado D, Rossi L, Pennelli N. Right ventricular cardiomyopathy and sudden death in young people. N.Engl.J.Med. 1988;318:129-133.

264. Dalal D, Nasir K, Bomma C, Prakasa K, Tandri H, Piccini J, Roguin A, Tichnell C, James C, Russell SD, Judge DP, Abraham T, Spevak PJ, Bluemke DA, Calkins H. Arrhythmogenic right ventricular dysplasia: a United States experience. Circulation. 2005;112:3823-32.

265. Marcus F, Towbin JA, Zareba W, Moss A, Calkins H, Brown M, Gear K. Arrhythmogenic right ventricular dysplasia/cardiomyopathy (ARVD/C): a multidisciplinary study: design and protocol. Circulation. 2003;107:2975-8. 
266. Alfakih K, Reid S, Jones T, Sivananthan M. Assessment of ventricular function and mass by cardiac magnetic resonance imaging. Eur Radiol. 2004; 14:1813-22.

267. Blake LM, Scheinman MM, Higgins CB. MR features of arrhythmogenic right ventricular dysplasia. AJR Am.J. Roentgenol. 1994;162:809-812.

268. Keller DI, Osswald S, Bremerich J, Bongartz G, Cron TA, Hilti $\mathrm{P}$, Pfisterer ME, Buser PT. Arrhythmogenic right ventricular cardiomyopathy: diagnostic and prognostic value of the cardiac MRI in relation to arrhythmia-free survival. Int.J.Cardiovasc.Imaging. 2003; 19:537-543.

269. Castillo E, Tandri H, Rodriguez ER, Nasir K, Rutberg J, Calkins H, Lima JA, Bluemke DA. Arrhythmogenic right ventricular dysplasia: ex vivo and in vivo fat detection with black-blood MR imaging. Radiology. 2004;232:38-48.

270. Burke AP, Farb A, Tashko G, Virmani R. Arrhythmogenic right ventricular cardiomyopathy and fatty replacement of the right ventricular myocardium: are they different diseases? Circulation. 1998;97:1571-1580.

271. Fontaliran F, Fontaine G, Fillette F, Aouate P, Chomette G, Grosgogeat Y. [Nosologic frontiers of arrhythmogenic dysplasia. Quantitative variations of normal adipose tissue of the right heart ventricle]. Arch. Mal Coeur Vaiss. 1991;84:33-38.

272. Sievers B, Addo M, Franken U, Trappe HJ. Right ventricular wall motion abnormalities found in healthy subjects by cardiovascular magnetic resonance imaging and characterized with a new segmental model. J Cardiovasc Magn Reson. 2004;6:601-8.

273. Tandri H, Saranathan M, Rodriguez ER, Martinez C, Bomma C, Nasir K, Rosen B, Lima JA, Calkins H, Bluemke DA. Noninvasive detection of myocardial fibrosis in arrhythmogenic right ventricular cardiomyopathy using delayed-enhancement magnetic resonance imaging. J.Am.Coll. Cardiol. 2005;45:98-103.

274. Tandri H, Friedrich MG, Calkins H, Bluemke DA. MRI of arrhythmogenic right ventricular cardiomyopathy/dysplasia. J Cardiovasc Magn Reson. 2004;6:557-63.

275. Bomma C, Rutberg J, Tandri H, Nasir K, Roguin A, Tichnell C, Rodriguez R, James C, Kasper E, Spevak P, Bluemke DA, Calkins $\mathrm{H}$. Misdiagnosis of arrhythmogenic right ventricular dysplasia/ cardiomyopathy. J Cardiovasc Electrophysiol. 2004;15:300-6.

276. Little DR. Hemochromatosis: diagnosis and management. Am. Fam. Physician. 1996;53:2623-2.

277. Olivieri NF, Nathan DG, MacMillan JH, Wayne AS, Liu PP, McGee A, Martin M, Koren G, Cohen AR. Survival in medically treated patients with homozygous beta-thalassemia. N.Engl.J.Med. 1994;331:574-578.

278. Anderson LJ, Holden S, Davis B, Prescott E, Charrier CC, Bunce NH, Firmin DN, Wonke B, Porter J, Walker JM, Pennell DJ. Cardiovascular T2-star (T2*) magnetic resonance for the early diagnosis of myocardial iron overload. Eur. Heart J. 2001;22:2171-2179.

279. Westwood MA, Anderson LJ, Firmin DN, Gatehouse PD, Lorenz CH, Wonke B, Pennell DJ. Interscanner reproducibility of cardiovascular magnetic resonance T2* measurements of tissue iron in thalassemia. J.Magn Reson.Imaging. 2003;18:616-620.

280. Westwood MA, Firmin DN, Gildo M, Renzo G, Stathis G, Markissia K, Vasili B, Pennell DJ. Intercentre reproducibility of magnetic resonance T2* measurements of myocardial iron in thalassaemia. Int J Cardiovasc Imaging. 2005;21:531-8.

281. Westwood M, Anderson LJ, Firmin DN, Gatehouse PD, Charrier CC, Wonke B, Pennell DJ. A single breath-hold multiecho T2* cardiovascular magnetic resonance technique for diagnosis of myocardial iron overload. J.Magn Reson.Imaging. 2003;18:33-39.

282. Anderson LJ, Westwood MA, Holden S, Davis B, Prescott E, Wonke $\mathrm{B}$, Porter JB, Walker JM, Pennell DJ. Myocardial iron clearance during reversal of siderotic cardiomyopathy with intravenous desferrioxamine: a prospective study using $\mathrm{T} 2{ }^{*}$ cardiovascular magnetic resonance. Br.J.Haematol. 2004; 127:348-355.

283. Anderson LJ, Wonke B, Prescott E, Holden S, Walker JM, Pennell DJ. Comparison of effects of oral deferiprone and subcutaneous desferrioxamine on myocardial iron concentrations and ventricular function in beta-thalassaemia. Lancet. 2002;360:516-520.

284. Jensen PD, Jensen FT, Christensen T, Eiskjaer H, Baandrup U, Nielsen $\mathrm{JL}$. Evaluation of myocardial iron by magnetic resonance imaging during iron chelation therapy with deferrioxamine: indication of close relation between myocardial iron content and chelatable iron pool. Blood. 2003;101:4632-4639.

285. Pennell DJ, Berdoukas V, Karagiorga M, Ladis V, Piga A, Aessopos A, Gotsis ED, Tanner MA, Smith GC, Westwood MA, Wonke B, Galanello R. Randomized controlled trial of deferiprone or deferoxamine in beta-thalassemia major patients with asymptomatic myocardial siderosis. Blood. 2005.

286. Bluemke DA, Liddell RP. Can MR imaging provide a noninvasive "biopsy" of the heart to measure iron levels? Radiology. 2005;234:647-648.

287. Kushwaha SS, Fallon JT, Fuster V. Restrictive cardiomyopathy. N.Eng/. J.Med. 1997;336:267-276.

288. Bishop GG, Bergin JD, Kramer CM. Hypereosinophilic syndrome and restrictive cardiomyopathy due to apical thrombi. Circulation. 2001;104:E3-E4.

289. Giorgi B, Mollet NR, Dymarkowski S, Rademakers FE, Bogaert J. Clinically suspected constrictive pericarditis: MR imaging assessment of ventricular septal motion and configuration in patients and healthy subjects. Radiology. 2003;228:417-24.

290. Masui T, Finck S, Higgins CB. Constrictive pericarditis and restrictive cardiomyopathy: evaluation with MR imaging. Radiology. 1992;182:369-373.

291. Fattori R, Rocchi G, Celletti F, Bertaccini P, Rapezzi C, Gavelli G. Contribution of magnetic resonance imaging in the differential diagnosis of cardiac amyloidosis and symmetric hypertrophic cardiomyopathy. Am. Heart J. 1998;136:824-830.

292. Brindeiro FD, Cavalcanti C. [Value of Doppler echocardiography in the diagnosis and management of endomyocardial fibrosis]. Arq Bras. Cardiol. 1996;67:279-284.

293. Puigbo JJ, Acquatella H, Schiller NB, Tortoledo F, Combellas I, Casal $\mathrm{H}$, Giordano H, Hirschhaut E. Two-Dimensional Echocardiographic Findings in Endomyocardial Fibrosis. Circulation. 1981;64:48.

294. Sechtem U, Higgins CB, Sommerhoff BA, Lipton MJ, Huycke EC. Magnetic resonance imaging of restrictive cardiomyopathy. Am. J.Cardiol. 1987;59:480-482.

295. Friedrich MG, Strohm O, Schulz-Menger J, Marciniak H, Luft FC, Dietz R. Contrast media-enhanced magnetic resonance imaging visualizes myocardial changes in the course of viral myocarditis. Circulation. 1998;97:1802-9.

296. Wagner A, Schulz-Menger J, Dietz R, Friedrich MG. Long-term followup of patients paragraph sign with acute myocarditis by magnetic paragraph sign resonance imaging. MAGMA. 2003;16:17-20.

297. Laissy JP, Messin B, Varenne O, lung B, Karila-Cohen D, SchoumanClaeys E, Steg PG. MRI of acute myocarditis: a comprehensive approach based on various imaging sequences. Chest. 2002;122:1638-48.

298. Mahrholdt H, Goedecke C, Wagner A, Meinhardt G, Athanasiadis A, Vogelsberg H, Fritz P, Klingel K, Kandolf R, Sechtem U. Cardiovascular magnetic resonance assessment of human myocarditis: a comparison to histology and molecular pathology. Circulation. 2004;109:1250-1258.

299. Laissy JP, Hyafil F, Feldman LJ, Juliard JM, Schouman-Claeys E, Steg PG, Faraggi M. Differentiating acute myocardial infarction from 
myocarditis: diagnostic value of early- and delayed-perfusion cardiac MR imaging. Radiology. 2005;237:75-82.

300. Abdel-Aty H, Boye P, Zagrosek A, Wassmuth R, Kumar A, Messroghli D, Bock P, Dietz R, Friedrich MG, Schulz-Menger J. Diagnostic performance of cardiovascular magnetic resonance in patients with suspected acute myocarditis: comparison of different approaches. $J$ Am Coll Cardiol. 2005;45:1815-22.

301. Liu PP, Yan AT. Cardiovascular magnetic resonance for the diagnosis of acute myocarditis: prospects for detecting myocardial inflammation. J Am Coll Cardiol. 2005;45:1823-5.

302. Magnani JW, Dec GW. Myocarditis: current trends in diagnosis and treatment. Circulation. 2006;113:876-90.

303. Pujadas S, Bordes R, Bayes-Genis A. Ventricular noncompaction cardiomyopathy: CMR and pathology findings. Heart. 2005;91:582.

304. Weiford BC, Subbarao VD, Mulhern KM. Noncompaction of the ventricular myocardium. Circulation. 2004;109:2965-71.

305. Conraads V, Paelinck B, Vorlat A, Goethals M, Jacobs W, Vrints C. Isolated non-compaction of the left ventricle: a rare indication for transplantation. J. Heart Lung Transplant. 2001;20:904-907.

306. Varghese A, Fisher NG, Pennell DJ. Late recognition of left ventricular non-compaction by cardiovascular magnetic resonance. Heart. 2005;91:282.

307. Petersen SE, Selvanayagam JB, Wiesmann F, Robson MD, Francis $\mathrm{JM}$, Anderson RH, Watkins H, Neubauer S. Left ventricular noncompaction: insights from cardiovascular magnetic resonance imaging. J Am Coll Cardiol. 2005;46:101-5.

308. Soler R, Rodriguez E, Monserrat L, Alvarez N. MRI of subendocardial perfusion deficits in isolated left ventricular noncompaction. J Comput Assist Tomogr. 2002;26:373-5.

309. Smedema JP, Snoep G, van Kroonenburgh MP, van Geuns RJ, Dassen WR, Gorgels AP, Crijns HJ. Evaluation of the accuracy of gadoliniumenhanced cardiovascular magnetic resonance in the diagnosis of cardiac sarcoidosis. J.Am.Coll.Cardiol. 2005;45:1683-1690.

310. Stauder NI, Bader B, Fenchel M, Kramer U, Kuhlkamp V, Miller S. Images in cardiovascular medicine. Follow-up of cardiac sarcoidosis by magnetic resonance imaging. Circulation. 2005;111:e158-e160.

311. Shimada T, Shimada K, Sakane T, Ochiai K, Tsukihashi H, Fukui M, Inoue S, Katoh H, Murakami Y, Ishibashi Y, Maruyama R. Diagnosis of cardiac sarcoidosis and evaluation of the effects of steroid therapy by gadolinium-DTPA-enhanced magnetic resonance imaging. Am.J.Med. 2001;110:520-527.

312. Serra JJ, Monte GU, Mello ES, Coral GP, Avila LF, Parga JR, Ramires $J A$, Rochitte CE. Images in cardiovascular medicine. Cardiac sarcoidosis evaluated by delayed-enhanced magnetic resonance imaging. Circulation. 2003;107:e188-e189.

313. Danias PG. Gadolinium-enhanced cardiac magnetic resonance imaging: expanding the spectrum of clinical applications. Am.J.Med. 2001;110:591-592.

314. Vignaux O, Dhote R, Duboc D, Blanche P, Dusser D, Weber S, Legmann $P$. Clinical significance of myocardial magnetic resonance abnormalities in patients with sarcoidosis: a 1-year follow-up study. Chest. 2002;122:1895-1901.

315. Pearson GD, Veille JC, Rahimtoola S, Hsia J, Oakley CM, Hosenpud JD, Ansari A, Baughman KL. Peripartum cardiomyopathy: National Heart, Lung, and Blood Institute and Office of Rare Diseases (National Institutes of Health) workshop recommendations and review. JAMA. 2000;283:1183-1188.

316. Demakis JG, Rahimtoola SH, Sutton GC, Meadows WR, Szanto PB, Tobin JR, Gunnar RM. Natural course of peripartum cardiomyopathy. Circulation. 1971;44:1053-1061.
317. Aso H, Takeda K, Ito T, Shiraishi T, Matsumura K, Nakagawa T. Assessment of myocardial fibrosis in cardiomyopathic hamsters with gadolinium-DTPA enhanced magnetic resonance imaging. Invest Radiol. 1998;33:22-32.

318. Bellenger NG, Marcus NJ, Rajappan K, Yacoub M, Banner NR, Pennell DJ. Comparison of techniques for the measurement of left ventricular function following cardiac transplantation. J.Cardiovasc. Magn Reson. 2002;4:255-263.

319. Revel D, Chapelon C, Mathieu D, Cochet P, Ninet J, Chuzel M, Champsaur G, Dureau G, Amiel M, Helenon O, . Magnetic resonance imaging of human orthotopic heart transplantation: correlation with endomyocardial biopsy. J. Heart Transplant. 1989;8:139-146.

320. Marie PY, Angioi M, Carteaux JP, Escanye JM, Mattei S, Tzvetanov K, Claudon O, Hassan N, Danchin N, Karcher G, Bertrand A, Walker $\mathrm{PM}$, Villemot JP. Detection and prediction of acute heart transplant rejection with the myocardial T2 determination provided by a blackblood magnetic resonance imaging sequence. J.Am.Coll.Cardiol. 2001;37:825-831.

321. Marie PY, Carteaux JP, Angioi M, Marwan NS, Tzvetanov K, Escanye JM, David N, Mattei S, Danchin N, Karcher G, Bertrand A, Villemot JP. Detection and prediction of acute heart transplant rejection: preliminary results on the clinical use of a "black blood" magnetic resonance imaging sequence. Transplant.Proc. 1998;30:1933-1935.

322. Neubauer S. Cardiac magnetic resonance spectroscopy. Curr.Cardiol. Rep. 2003;5:75-82.

323. Le Floch M, Ramee MP, LeLong B, Leray G, Kerbaol M, de Certaines JD. Proton magnetic resonance spectroscopy of blood plasma in heart transplant recipients treated with cyclosporine: an early prognosis test of long-term graft tolerance. J. Heart Lung Transplant. 1997; 16:381-386.

324. Moulton MJ, Creswell LL, Ungacta FF, Downing SW, Szabo BA, Pasque MK. Magnetic resonance imaging provides evidence for remodeling of the right ventricle after single-lung transplantation for pulmonary hypertension. Circulation. 1996;94:II312-II319.

325. Lauerma K, Harjula A, Jarvinen V, Kupari M, Keto P. Assessment of right and left atrial function in patients with transplanted hearts with the use of magnetic resonance imaging. J. Heart Lung Transplant. 1996;15:360-367.

326. Mohiaddin RH, Bogren HG, Lazim F, Keegan J, Gatehouse PD, Barbir $\mathrm{M}$, Firmin DN, Yacoub MH. Magnetic resonance coronary angiography in heart transplant recipients. Coron. Artery Dis. 1996;7:591-597.

327. Kurland RJ, West J, Kelley S, Shoop JD, Harris R, Carr EA, Jr., Bergsland J, Wright J, Carroll M. Magnetic resonance imaging to detect heart transplant rejection: sensitivity and specificity. Transplant.Proc. 1989;21:2537-2543.

328. Schwitter J, De Marco T, Globits S, Sakuma H, Klinski C, Chatterjee K, Parmley WW, Higgins CB. Influence of felodipine on left ventricular hypertrophy and systolic function in orthotopic heart transplant recipients: possible interaction with cyclosporine medication. J. Heart Lung Transplant. 1999;18:1003-1013.

329. Globits S, De Marco T, Schwitter J, Sakuma H, O'Sullivan M, Rifkin C, Keith F, Chatterjee K, Parmley WW, Higgins CB. Assessment of early left ventricular remodeling in orthotopic heart transplant recipients with cine magnetic resonance imaging: potential mechanisms. J. Heart Lung Transplant. 1997;16:504-510.

330. Rienmuller R, Groll R, Lipton MJ. CT and MR imaging of pericardial disease. Radiol Clin North Am. 2004;42:587-601, vi.

331. Smith WH, Beacock DJ, Goddard AJ, Bloomer TN, Ridgway JP, Sivananthan UM. Magnetic resonance evaluation of the pericardium. Br J Radiol. 2001;74:384-92.

332. Axel L. Assessment of pericardial disease by magnetic resonance and computed tomography. J Magn Reson Imaging. 2004;19:816-26. 
333. Francone M, Dymarkowski S, Kalantzi M, Rademakers FE, Bogaert $\mathrm{J}$. Assessment of ventricular coupling with real-time cine MRI and its value to differentiate constrictive pericarditis from restrictive cardiomyopathy. Eur Radiol. 2005:1-8.

334. Frank H, Globits S. Magnetic resonance imaging evaluation of myocardial and pericardial disease. J Magn Reson Imaging. 1999;10:617-26.

335. Sagrista-Sauleda J, Angel J, Sanchez A, Permanyer-Miralda G, Soler-Soler J. Effusive-constrictive pericarditis. N Eng/ J Med. 2004;350:469-75.

336. Troughton RW, Asher CR, Klein AL. Pericarditis. Lancet. 2004;363:717-27

337. Wang ZJ, Reddy GP, Gotway MB, Yeh BM, Hetts SW, Higgins CB. CT and MR imaging of pericardial disease. Radiographics. 2003;23 Spec No:S167-80.

338. Faridah $Y$, Julsrud PR. Congenital absence of pericardium revisited. Int J Cardiovasc Imaging. 2002;18:67-73.

339. Hoffmann U, Globits S, Schima W, Loewe C, Puig S, Oberhuber G, Frank $\mathrm{H}$. Usefulness of magnetic resonance imaging of cardiac and paracardiac masses. Am J Cardiol. 2003;92:890-5.

340. Hoffmann U, Globits S, Frank H. Cardiac and paracardiac masses. Current opinion on diagnostic evaluation by magnetic resonance imaging. Eur Heart J. 1998; 19:553-63.

341. Araoz PA, Mulvagh SL, Tazelaar HD, Julsrud PR, Breen JF. CT and MR imaging of benign primary cardiac neoplasms with echocardiographic correlation. Radiographics. 2000;20:1303-19.

342. Grebenc ML, Rosado de Christenson ML, Burke AP, Green CE, Galvin JR. Primary cardiac and pericardial neoplasms: radiologic-pathologic correlation. Radiographics. 2000;20:1073-103; quiz 1110-1, 1112.

343. Aziz YF, Julsrud PR. Can cardiac magnetic resonance imaging reliably differentiate between benign and neoplastic fat? Int J Cardiovasc Imaging. 2002;18:227-30.

344. Barkhausen J, Hunold P, Eggebrecht H, Schuler WO, Sabin GV, Erbel $\mathrm{R}$, Debatin JF. Detection and characterization of intracardiac thrombi on MR imaging. AJR Am J Roentgenol. 2002;179:1539-44.

345. Wagner S, Auffermann W, Buser P, Lim TH, Kircher B, Pflugfelder $P$, Higgins CB. Diagnostic accuracy and estimation of the severity of valvular regurgitation from the signal void on cine magnetic resonance images. Am Heart J. 1989;118:760-7.

346. Didier D, Ratib O, Lerch R, Friedli B. Detection and quantification of valvular heart disease with dynamic cardiac MR imaging. Radiographics. 2000;20:1279-99; discussion 1299-301.

347. Krombach GA, Kuhl H, Bucker A, Mahnken AH, Spuntrup E, Lipke C, Schroder J, Gunther RW. Cine MR imaging of heart valve dysfunction with segmented true fast imaging with steady state free precession. $J$ Magn Reson Imaging. 2004;19:59-67.

348. Djavidani B, Debl K, Lenhart M, Seitz J, Paetzel C, Schmid FX, Nitz WR, Feuerbach S, Riegger G, Luchner A. Planimetry of mitral valve stenosis by magnetic resonance imaging. J Am Coll Cardiol. 2005;45:2048-53.

349. Kupfahl C, Honold M, Meinhardt G, Vogelsberg H, Wagner A, Mahrholdt $H$, Sechtem U. Evaluation of aortic stenosis by cardiovascular magnetic resonance imaging: comparison with established routine clinical techniques. Heart. 2004;90:893-901.

350. John AS, Dill T, Brandt RR, Rau M, Ricken W, Bachmann G, Hamm $\mathrm{CW}$. Magnetic resonance to assess the aortic valve area in aortic stenosis: how does it compare to current diagnostic standards? J Am Coll Cardiol. 2003;42:519-26.

351. Caruthers SD, Lin SJ, Brown P, Watkins MP, Williams TA, Lehr KA, Wickline SA. Practical value of cardiac magnetic resonance imaging for clinical quantification of aortic valve stenosis: comparison with echocardiography. Circulation. 2003;108:2236-43.
352. Heidenreich PA, Steffens J, Fujita N, O'Sullivan M, Caputo GR, Foster E, Higgins CB. Evaluation of mitral stenosis with velocity-encoded cinemagnetic resonance imaging. Am J Cardiol. 1995;75:365-9.

353. Sechtem U, Pflugfelder PW, Cassidy MM, White RD, Cheitlin MD, Schiller NB, Higgins CB. Mitral or aortic regurgitation: quantification of regurgitant volumes with cine MR imaging. Radiology. 1988;167:425-30.

354. Hundley WG, Li HF, Willard JE, Landau C, Lange RA, Meshack BM, Hillis LD, Peshock RM. Magnetic resonance imaging assessment of the severity of mitral regurgitation. Comparison with invasive techniques. Circulation. 1995;92:1151-8.

355. Kozerke S, Hasenkam JM, Nygaard H, Paulsen PK, Pedersen EM, Boesiger P. Heart motion-adapted MR velocity mapping of blood velocity distribution downstream of aortic valve prostheses: initial experience. Radiology. 2001;218:548-55.

356. Neubauer S, Krahe T, Schindler R, Horn M, Hillenbrand H, Entzeroth $\mathrm{C}$, Mader H, Kromer EP, Riegger GA, Lackner K, et al. 31P magnetic resonance spectroscopy in dilated cardiomyopathy and coronary artery disease. Altered cardiac high-energy phosphate metabolism in heart failure. Circulation. 1992;86:1810-8.

357. de Roos A, Doornbos J, Rebergen S, van Rugge P, Pattynama P, van der Wall EE. Cardiovascular applications of magnetic resonance imaging and phosphorus-31 spectroscopy. Eur J Radiol. 1992;14:97-103.

358. Hardy CJ, Weiss RG, Bottomley PA, Gerstenblith G. Altered myocardial high-energy phosphate metabolites in patients with dilated cardiomyopathy. Am Heart J. 1991;122:795-801.

359. Neubauer S, Horn M, Cramer M, Harre K, Newell JB, Peters W, Pabst T, Ertl G, Hahn D, Ingwall JS, Kochsiek K. Myocardial phosphocreatineto-ATP ratio is a predictor of mortality in patients with dilated cardiomyopathy. Circulation. 1997;96:2190-6.

360. Weiss RG, Bottomley PA, Hardy CJ, Gerstenblith G. Regional myocardial metabolism of high-energy phosphates during isometric exercise in patients with coronary artery disease. $N$ Eng/ J Med. 1990;323:1593-600.

361. Yabe T, Mitsunami K, Inubushi T, Kinoshita M. Quantitative measurements of cardiac phosphorus metabolites in coronary artery disease by $31 \mathrm{P}$ magnetic resonance spectroscopy. Circulation. 1995;92:15-23.

362. Kalil-Filho R, de Albuquerque CP, Weiss RG, Mocelim A, Bellotti G, Cerri G, Pileggi F. Normal high energy phosphate ratios in "stunned" human myocardium. J Am Coll Cardiol. 1997;30:1228-32.

363. Buchthal SD, den Hollander JA, Merz CN, Rogers WJ, Pepine CJ, Reichek N, Sharaf BL, Reis S, Kelsey SF, Pohost GM. Abnormal myocardial phosphorus-31 nuclear magnetic resonance spectroscopy in women with chest pain but normal coronary angiograms. N Eng/ J Med. 2000;342:829-35.

364. Bottomley PA, Weiss RG. Non-invasive magnetic-resonance detection of creatine depletion in non-viable infarcted myocardium. Lancet. 1998;351:714-8.

365. Reeves RC, Evanochko WT, Canby RC, McMillin JB, Pohost GM. Demonstration of increased myocardial lipid with postischemic dysfunction ("myocardial stunning") by proton nuclear magnetic resonance spectroscopy. J Am Coll Cardiol. 1989;13:739-44.

366. Kim RJ, Lima JA, Chen EL, Reeder SB, Klocke FJ, Zerhouni EA, Judd RM. Fast $23 \mathrm{Na}$ magnetic resonance imaging of acute reperfused myocardial infarction. Potential to assess myocardial viability. Circulation. 1997;95:1877-85.

367. Rochitte CE, Kim RJ, Hillenbrand HB, Chen EL, Lima JA. Microvascular integrity and the time course of myocardial sodium accumulation after acute infarction. Circ Res. 2000;87:648-55.

368. Fieno DS, Kim RJ, Rehwald WG, Judd RM. Physiological basis for potassium (39K) magnetic resonance imaging of the heart. Circ Res. 1999;84:913-20. 
369. Araujo DV, Ferraz MB. [Economic impact of chronic ischemic cardiopathy treatment in Brazil. The challenge of new cardiovascular technology inclusion]. Arq Bras Cardiol. 2005;85:1-2.

370. Banta D. The development of health technology assessment. Health Policy. 2003;63:121-32.

371. Becker CR, Knez A. Past, present, and future perspective of cardiac computed tomography. J Magn Reson Imaging. 2004;19:676-85.

372. Mollet NR, Cademartiri F, de Feyter PJ. Non-invasive multislice CT coronary imaging. Heart. 2005;91:401-7.

373. Schoenhagen P, Halliburton SS, Stillman AE, Kuzmiak SA, Nissen SE, Tuzcu EM, White RD. Noninvasive imaging of coronary arteries: current and future role of multi-detector row CT. Radiology. 2004;232:7-17.

374. Pannu HK, Flohr TG, Corl FM, Fishman EK. Current concepts in multidetector row CT evaluation of the coronary arteries: principles, techniques, and anatomy. Radiographics. 2003;23 Spec No:S111-25.

375. Nieman K, van Geuns RJ, Wielopolski P, Pattynama PM, de Feyter PJ. Noninvasive coronary imaging in the new millennium: a comparison of computed tomography and magnetic resonance techniques. Rev Cardiovasc Med. 2002;3:77-84.

376. Kopp AF, Ohnesorge B, Becker C, Schroder S, Heuschmid M, Kuttner A, Kuzo R, Claussen CD. Reproducibility and accuracy of coronary calcium measurements with multi-detector row versus electron-beam CT. Radiology. 2002;225:113-9.

377. Achenbach S, Moshage W, Ropers D, Nossen J, Daniel WG. Value of electron-beam computed tomography for the noninvasive detection of high-grade coronary-artery stenoses and occlusions. N Eng/ J Med. 1998;339:1964-71.

378. Flohr TG, Schaller S, Stierstorfer K, Bruder H, Ohnesorge BM, Schoepf UJ. Multi-detector row CT systems and image-reconstruction techniques. Radiology. 2005;235:756-73

379. Schoepf UJ, Becker CR, Ohnesorge BM, Yucel EK. CT of coronary artery disease. Radiology. 2004;232:18-37.

380. Flohr TG, McCollough CH, Bruder H, Petersilka M, Gruber K, Suss C, Grasruck M, Stierstorfer K, Krauss B, Raupach R, Primak AN, Kuttner A, Achenbach S, Becker C, Kopp A, Ohnesorge BM. First performance evaluation of a dual-source CT (DSCT) system. Eur Radiol. 2006;16:256-68

381. Schroeder S, Kopp AF, Kuettner A, Burgstahler C, Herdeg C, Heuschmid M, Baumbach A, Claussen CD, Karsch KR, Seipel L. Influence of heart rate on vessel visibility in noninvasive coronary angiography using new multislice computed tomography: experience in 94 patients. Clin Imaging. 2002;26:106-11.

382. Choi HS, Choi BW, Choe KO, Choi D, Yoo KJ, Kim MI, Kim J. Pitfalls, artifacts, and remedies in multi- detector row CT coronary angiography. Radiographics. 2004;24:787-800.

383. Rubin GD. Data explosion: the challenge of multidetector-row CT. Eur J Radiol. 2000;36:74-80

384. Cody DD. AAPM/RSNA physics tutorial for residents: topics in CT. Image processing in CT. Radiographics. 2002;22:1255-68.

385. Hunold P, Vogt FM, Schmermund A, Debatin JF, Kerkhoff G, Budde T, Erbel R, Ewen K, Barkhausen J. Radiation exposure during cardiac CT: effective doses at multi-detector row CT and electron-beam CT. Radiology. 2003;226:145-52.

386. McNitt-Gray MF. AAPM/RSNA Physics Tutorial for Residents: Topics in CT. Radiation dose in CT. Radiographics. 2002;22:1541-53.

387. Morin RL, Gerber TC, McCollough CH. Radiation dose in computed tomography of the heart. Circulation. 2003;107:917-22.

388. Bae KT, Hong C, Whiting BR. Radiation dose in multidetector row computed tomography cardiac imaging. J Magn Reson Imaging. 2004;19:859-63.
389. Higgins CB, de Roos A. MRI and CT of the cardiovascular system. 2nd ed. Philadelphia: Lippincott Williams \& Wilkins; 2006.

390. Crean A, Dutka D, Coulden R. Cardiac imaging using nuclear medicine and positron emission tomography. Radiol Clin North Am. 2004;42:619-34, vii.

391. Katritsis D, Efstathopoulos E, Betsou S, Korovesis S, Faulkner K, Panayiotakis G, Webb-Peploe MM. Radiation exposure of patients and coronary arteries in the stent era: A prospective study. Catheter Cardiovasc Interv. 2000;51:259-64.

392. Hausleiter J, Meyer T, Hadamitzky M, Huber E, Zankl M, Martinoff S, Kastrati A, Schomig A. Radiation dose estimates from cardiac multislice computed tomography in daily practice: impact of different scanning protocols on effective dose estimates. Circulation. 2006; 113:1305-10.

393. Huda W, Scalzetti EM, Roskopf M. Effective doses to patients undergoing thoracic computed tomography examinations. Med Phys. 2000;27:838-44.

394. Hausleiter J, Meyer T, Hadamitzky M, Huber E, Zankl M, Martinoff S, Kastrati A, Schomig A. Radiation Dose Estimates From Cardiac Multislice Computed Tomography in Daily Practice. Impact of Different Scanning Protocols on Effective Dose Estimates. Circulation. 2006.

395. Thomsen HS. Guidelines for contrast media from the European Society of Urogenital Radiology. AJR Am J Roentgenol. 2003;181:1463-71.

396. Morcos SK, Thomsen HS. Adverse reactions to iodinated contrast media. Eur Radiol. 2001;11:1267-75.

397. Webb JA, Stacul F, Thomsen HS, Morcos SK. Late adverse reactions to intravascular iodinated contrast media. Eur Radiol. 2003;13:181-4

398. Stacul F, Cova M. Contrast media induced nephrotoxicity: problems in clinical practice. Radiol Med (Torino). 2003;105:36-41.

399. American College of Radiology. Manual on contrast media v. (Acessado em 14/03/2006 - http://www.acr.org/s_acr/sec. asp?CID $=2131 \& D I D=16687)$.

400. Morcos SK, Thomsen HS, Webb JA. Prevention of generalized reactions to contrast media: a consensus report and guidelines. Eur Radiol. 2001;11:1720-8.

401. Barrett BJ, Parfrey PS. Clinical practice. Preventing nephropathy induced by contrast medium. N Eng/ J Med. 2006;354:379-86.

402. Nasir K, Budoff MJ, Post WS, Fishman EK, Mahesh M, Lima JA, Blumenthal RS. Electron beam CT versus helical CT scans for assessing coronary calcification: current utility and future directions. Am. Heart J. 2003;146:969-977

403. Agatston AS, Janowitz WR, Hildner FJ, Zusmer NR, Viamonte M, Jr. Detrano R. Quantification of coronary artery calcium using ultrafast computed tomography. J.Am.Coll.Cardiol. 1990;15:827-832.

404. Becker CR. Estimation of cardiac event risk by MDCT. Eur.Radiol. 2005;15 Suppl 2:B17-B22.

405. Santos RD, Meneghelo RS, Chacra AP, Martinez TL, Ramires JA, Carvalho JA. Detection of subclinical atherosclerosis by electron beam tomography in females with heterozygous familial hypercholesterolaemia. Heart. 2004;90:92-94.

406. Meneghelo RS, Santos RD, Almeida B, Hidal J, Martinez T, Moron R, Ramires JA, Nasri F. Distribution of coronary artery calcium scores determined by ultrafast computed tomography in 2.253 asymptomatic white men. Arq Bras.Cardiol. 2003;81 Suppl 7:27-36.

407. Clouse ME. How useful is computed tomography for screening for coronary artery disease? Noninvasive screening for coronary artery disease with computed tomography is useful. Circulation. 2006;113:125-46; discussion 125-46.

408. Chen J, Krumholz HM. How useful is computed tomography for screening for coronary artery disease? Screening for coronary artery 
disease with electron-beam computed tomography is not useful. Circulation. 2006;113:125-46; discussion 125-46.

409. Greenland P, LaBree L, Azen SP, Doherty TM, Detrano RC. Coronary artery calcium score combined with Framingham score for risk prediction in asymptomatic individuals. JAMA. 2004;291:210-215.

410. Shaw LJ, Raggi P, Schisterman E, Berman DS, Callister TQ. Prognostic value of cardiac risk factors and coronary artery calcium screening for all-cause mortality. Radiology. 2003;228:826-833.

411. Pletcher MJ, Tice JA, Pignone M, McCulloch C, Callister TQ, Browner WS. What does my patient's coronary artery calcium score mean? Combining information from the coronary artery calcium score with information from conventional risk factors to estimate coronary heart disease risk. BMC.Med. 2004;2:31.

412. Kondos GT, Hoff JA, Sevrukov A, Daviglus ML, Garside DB, Devries SS, Chomka EV, Liu K. Electron-beam tomography coronary artery calcium and cardiac events: a 37-month follow-up of 5635 initially asymptomatic low- to intermediate-risk adults. Circulation. 2003; 107:2571-2576.

413. Pletcher MJ, Tice JA, Pignone M, Browner WS. Using the coronary artery calcium score to predict coronary heart disease events: a systematic review and meta-analysis. Arch.Intern.Med. 2004;164:1285-1292.

414. Raggi P, Shaw LJ, Berman DS, Callister TQ. Prognostic value of coronary artery calcium screening in subjects with and without diabetes. J.Am.Coll.Cardiol. 2004;43:1663-1669.

415. Arad Y, Spadaro LA, Roth M, Newstein D, Guerci AD. Treatment of asymptomatic adults with elevated coronary calcium scores with atorvastatin, vitamin C, and vitamin E: the St. Francis Heart Study randomized clinical trial. J Am Coll Cardiol. 2005;46:166-72.

416. Nasir K, Michos ED, Blumenthal RS, Raggi P. Detection of highrisk young adults and women by coronary calcium and National Cholesterol Education Program Panel III guidelines. J Am Coll Cardiol. 2005;46:1931-6.

417. Nasir K, Santos RD, Roguin A, Carvalho JA, Meneghello R, Blumenthal RS. Relationship of subclinical coronary atherosclerosis and National Cholesterol Education Panel guidelines in asymptomatic Brazilian men. Int J Cardiol. 2006;108:68-75.

418. Kalia NK, Miller LG, Nasir K, Blumenthal RS, Agrawal N, Budoff MJ. Visualizing coronary calcium is associated with improvements in adherence to statin therapy. Atherosclerosis. 2006;185:394-9.

419. Khera A, de Lemos JA, Peshock RM, Lo HS, Stanek HG, Murphy SA, Wians FH, Jr., Grundy SM, McGuire DK. Relationship between C-reactive protein and subclinical atherosclerosis: the Dallas Heart Study. Circulation. 2006;113:38-43.

420. Budoff MJ, Diamond GA, Raggi P, Arad Y, Guerci AD, Callister TQ, Berman D. Continuous probabilistic prediction of angiographically significant coronary artery disease using electron beam tomography. Circulation. 2002;105:1791-1796.

421. Schmermund A, Achenbach S, Budde T, Buziashvili Y, Forster A, Friedrich G, Henein M, Kerkhoff G, Knollmann F, Kukharchuk V, Lahiri A, Leischik R, Moshage W, Schartl M, Siffert W, Steinhagen-Thiessen E, Sinitsyn V, Vogt A, Wiedeking B, Erbel R. Effect of intensive versus standard lipid-lowering treatment with atorvastatin on the progression of calcified coronary atherosclerosis over 12 months: a multicenter, randomized, double-blind trial. Circulation. 2006;113:427-37.

422. Taylor AJ, Arora NS, Feuerstein I, Bindeman J, Perron T, Cao F, O'Malley P G. Relation between coronary artery calcium and incident chest pain in a community-dwelling screening population. Am J Cardiol. 2005;96:61-3.

423. Raggi P, Callister TQ, Cooil B, He ZX, Lippolis NJ, Russo DJ, Zelinger A, Mahmarian JJ. Identification of patients at increased risk of first unheralded acute myocardial infarction by electron-beam computed tomography. Circulation. 2000;101:850-855.
424. Sechtem U, Vohringer M. The clinical role of ‘non-invasive' coronary angiography by multidetector spiral computed tomography: yet to be defined. Eur Heart J. 2005;26:1942-4.

425. Christian TF. Anatomy of an emerging diagnostic test: computed tomographic coronary angiography. Circulation. 2005;112:2222-5.

426. Schroeder S, Bax JJ. Multi-slice spiral computed tomography: useful for non-invasive coronary angiography? Int J Cardiovasc Imaging. 2004;20:67-9.

427. Achenbach S. Detection of coronary stenoses by multidetector computed tomography: it's all about resolution. J Am Coll Cardiol. 2004;43:840-1.

428. Garcia MJ. Noninvasive coronary angiography: hype or new paradigm? Jama. 2005;293:2531-3.

429. Donnelly PM, Higginson JD, Hanley PD. Multidetector CT coronary angiography: have we found the holy grail of non-invasive coronary imaging? Heart. 2005;91:1385-8.

430. Hoffmann U, Butler J. MDCT-based coronary angiography: A Rosetta stone for understanding coronary disease? Eur J Radiol. 2006;57:329-30.

431. Kopp AF, Schroeder S, Kuettner A, Baumbach A, Georg C, Kuzo R, Heuschmid M, Ohnesorge B, Karsch KR, Claussen CD. Noninvasive coronary angiography with high resolution multidetectorrow computed tomography. Results in 102 patients. Eur Heart J. 2002;23:1714-25

432. Ropers D, Baum U, Pohle K, Anders K, Ulzheimer S, Ohnesorge B, Schlundt C, Bautz W, Daniel WG, Achenbach S. Detection of coronary artery stenoses with thin-slice multi-detector row spiral computed tomography and multiplanar reconstruction. Circulation. 2003;107:664-6.

433. Hoffmann MH, Shi H, Schmitz BL, Schmid FT, Lieberknecht M, Schulze R, Ludwig B, Kroschel U, Jahnke N, Haerer W, Brambs $\mathrm{HJ}$, Aschoff AJ. Noninvasive coronary angiography with multislice computed tomography. Jama. 2005;293:2471-8.

434. Hoffmann U, Moselewski F, Cury RC, Ferencik M, Jang IK, Diaz LJ, Abbara S, Brady TJ, Achenbach S. Predictive value of 16-slice multidetector spiral computed tomography to detect significant obstructive coronary artery disease in patients at high risk for coronary artery disease: patient-versus segment-based analysis. Circulation. 2004;110:2638-43.

435. Nieman K, Cademartiri F, Lemos PA, Raaijmakers R, Pattynama PM, de Feyter PJ. Reliable noninvasive coronary angiography with fast submillimeter multislice spiral computed tomography. Circulation. 2002;106:2051-4.

436. Kuettner A, Beck T, Drosch T, Kettering K, Heuschmid M, Burgstahler C, Claussen CD, Kopp AF, Schroeder S. Diagnostic accuracy of noninvasive coronary imaging using 16-detector slice spiral computed tomography with $188 \mathrm{~ms}$ temporal resolution. J Am Coll Cardiol. 2005;45:123-7.

437. Kuettner A, Beck T, Drosch T, Kettering K, Heuschmid M, Burgstahler C, Claussen CD, Kopp AF, Schroeder S. Image quality and diagnostic accuracy of non-invasive coronary imaging with 16 detector slice spiral computed tomography with 188 ms temporal resolution. Heart. 2005;91:938-41.

438. Heuschmid M, Kuettner A, Schroeder S, Trabold T, Feyer A, Seemann MD, Kuzo R, Claussen CD, Kopp AF. ECG-gated 16-MDCT of the coronary arteries: assessment of image quality and accuracy in detecting stenoses. AJR Am J Roentgenol. 2005;184:1413-9.

439. Achenbach S, Ropers D, Pohle FK, Raaz D, von Erffa J, Yilmaz A, Muschiol G, Daniel WG. Detection of coronary artery stenoses using multi-detector CT with $16 \times 0.75$ collimation and 375 ms rotation. Eur Heart J. 2005;26:1978-86.

440. Mollet NR, Cademartiri F, Krestin GP, McFadden EP, Arampatzis CA, Serruys PW, de Feyter PJ. Improved diagnostic accuracy with 16-row 
multi-slice computed tomography coronary angiography. J Am Coll Cardiol. 2005;45:128-32.

441. Mollet NR, Cademartiri F, Nieman K, Saia F, Lemos PA, McFadden EP, Pattynama PM, Serruys PW, Krestin GP, de Feyter PJ. Multislice spiral computed tomography coronary angiography in patients with stable angina pectoris. J Am Coll Cardiol. 2004;43:2265-70.

442. Kuettner A, Trabold T, Schroeder S, Feyer A, Beck T, Brueckner A, Heuschmid M, Burgstahler C, Kopp AF, Claussen CD. Noninvasive detection of coronary lesions using 16-detector multislice spiral computed tomography technology: initial clinical results. J Am Coll Cardiol. 2004;44:1230-7.

443. Morgan-Hughes GJ, Roobottom CA, Owens PE, Marshall AJ. Highly accurate coronary angiography with submillimetre, 16 slice computed tomography. Heart. 2005;91:308-13.

444. Cury RC, Ferencik M, Achenbach S, Pomerantsev E, Nieman K, Moselewski F, Abbara S, Jang IK, Brady TJ, Hoffmann U. Accuracy of 16-slice multi-detector CT to quantify the degree of coronary artery stenosis: Assessment of cross-sectional and longitudinal vessel reconstructions. Eur J Radiol. 2006;57:345-50.

445. Martuscelli E, Romagnoli A, D’Eliseo A, Razzini C, Tomassini M, Sperandio M, Simonetti G, Romeo F. Accuracy of thin-slice computed tomography in the detection of coronary stenoses. Eur Heart $J$. 2004;25:1043-8.

446. Mollet NR, Cademartiri F, van Mieghem CA, Runza G, McFadden EP, Baks T, Serruys PW, Krestin GP, de Feyter PJ. High-resolution spiral computed tomography coronary angiography in patients referred for diagnostic conventional coronary angiography. Circulation. 2005; 112:2318-23.

447. Leber AW, Knez A, von Ziegler F, Becker A, Nikolaou K, Paul S, Wintersperger B, Reiser M, Becker CR, Steinbeck G, Boekstegers P. Quantification of obstructive and nonobstructive coronary lesions by 64-slice computed tomography: a comparative study with quantitative coronary angiography and intravascular ultrasound. J Am Coll Cardiol. 2005;46:147-54.

448. Ropers D, Rixe J, Anders K, Kuttner A, Baum U, Bautz W, Daniel WG, Achenbach S. Usefulness of multidetector row spiral computed tomography with 64- x 0.6-mm collimation and 330-ms rotation for the noninvasive detection of significant coronary artery stenoses. Am J Cardiol. 2006;97:343-8.

449. Raff GL, Gallagher MJ, O'Neill WW, Goldstein JA. Diagnostic accuracy of noninvasive coronary angiography using 64-slice spiral computed tomography. J Am Coll Cardiol. 2005;46:552-7.

450. Ferencik M, Moselewski F, Ropers D, Hoffmann U, Baum U, Anders K, Pomerantsev EV, Abbara S, Brady TJ, Achenbach S. Quantitative parameters of image quality in multidetector spiral computed tomographic coronary imaging with submillimeter collimation. Am J Cardiol. 2003;92:1257-62.

451. Cury RC, Pomerantsev EV, Ferencik M, Hoffmann U, Nieman K, Moselewski F, Abbara S, Jang IK, Brady TJ, Achenbach S. Comparison of the degree of coronary stenoses by multidetector computed tomography versus by quantitative coronary angiography. Am J Cardiol. 2005;96:784-7.

452. Moselewski F, Ropers D, Pohle K, Hoffmann U, Ferencik M, Chan RC, Cury RC, Abbara S, Jang IK, Brady TJ, Daniel WG, Achenbach S. Comparison of measurement of cross-sectional coronary atherosclerotic plaque and vessel areas by 16 -slice multidetector computed tomography versus intravascular ultrasound. Am J Cardiol. 2004;94:1294-7.

453. Burgstahler C, Beck T, Kuettner A, Reimann A, Kopp AF, Heuschmid $M$, Claussen CD, Schroeder S. Image quality and diagnostic accuracy of 16-slice multidetector spiral computed tomography for the detection of coronary artery disease in elderly patients. J Comput Assist Tomogr. 2005;29:734-8.

454. Gaspar T, Halon DA, Lewis BS, Adawi S, Schliamser JE, Rubinshtein $\mathrm{R}$, Flugelman MY, Peled N. Diagnosis of coronary in-stent restenosis with multidetector row spiral computed tomography. J Am Coll Cardiol. 2005;46:1573-9.

455. Schuijf JD, Bax JJ, Jukema JW, Lamb HJ, Warda HM, Vliegen HW, de Roos A, van der Wall EE. Feasibility of assessment of coronary stent patency using 16-slice computed tomography. Am J Cardiol. 2004;94:427-30.

456. Cademartiri F, Mollet N, Lemos PA, Pugliese F, Baks T, McFadden EP, Krestin GP, de Feyter PJ. Usefulness of multislice computed tomographic coronary angiography to assess in-stent restenosis. Am J Cardiol. 2005;96:799-802.

457. Gilard M, Cornily JC, Rioufol G, Finet G, Pennec PY, Mansourati J, Blanc JJ, Boschat J. Noninvasive assessment of left main coronary stent patency with 16-slice computed tomography. Am J Cardiol. 2005;95:110-2.

458. Gilard M, Cornily JC, Pennec PY, Le Gal G, Nonent M, Mansourati J, Blanc JJ, Boschat J. Assessment of coronary artery stents by 16 slice computed tomography. Heart. 2006;92:58-61.

459. Khan MF, Herzog C, Landenberger K, Maataoui A, Martens S, Ackermann $\mathrm{H}$, Moritz A, Vogl TJ. Visualisation of non-invasive coronary bypass imaging: 4-row vs. 16-row multidetector computed tomography. Eur Radiol. 2005;15:118-26.

460. Frazier AA, Qureshi F, Read KM, Gilkeson RC, Poston RS, White CS. Coronary artery bypass grafts: assessment with multidetector CT in the early and late postoperative settings. Radiographics. 2005;25:881-96.

461. Burgstahler C, Kuettner A, Kopp AF, Herdeg C, Martensen J, Claussen $C D$, Schroeder S. Non-invasive evaluation of coronary artery bypass grafts using multi-slice computed tomography: initial clinical experience. Int J Cardiol. 2003;90:275-80.

462. Burgstahler C, Beck T, Kuettner A, Drosch T, Kopp AF, Heuschmid M, Claussen CD, Schroeder S. Non-invasive evaluation of coronary artery bypass grafts using 16-row multi-slice computed tomography with 188 ms temporal resolution. Int J Cardiol. 2006;106:244-9.

463. Anders K, Baum U, Schmid M, Ropers D, Schmid A, Pohle K, Daniel WG, Bautz W, Achenbach S. Coronary artery bypass graft (CABG) patency: Assessment with high-resolution submillimeter 16-slice multidetector-row computed tomography (MDCT) versus coronary angiography. Eur J Radiol. 2006;57:336-44.

464. White CS, Kuo D, Kelemen M, Jain V, Musk A, Zaidi E, Read K, Sliker $C$, Prasad R. Chest pain evaluation in the emergency department: can MDCT provide a comprehensive evaluation? AJR Am J Roentgenol. 2005; 185:533-40.

465. Schroeder S, Kuettner A, Beck T, Kopp AF, Herdeg C, Heuschmid M, Burgstahler C, Seipel L, Claussen CD. Usefulness of noninvasive MSCT coronary angiography as first-line imaging technique in patients with chest pain: initial clinical experience. Int J Cardiol. 2005;102:469-75.

466. Ghersin E, Litmanovich D, Dragu R, Rispler S, Lessick J, Ofer A, Brook OR, Gruberg L, Beyar R, Engel A. 16-MDCT coronary angiography versus invasive coronary angiography in acute chest pain syndrome: a blinded prospective study. AJR Am J Roentgenol. 2006;186:177-84.

467. White C, Read K, Kuo D. Assessment of chest pain in the emergency room: What is the role of multidetector CT? Eur J Radiol. 2006;57:368-72.

468. Gaspar T, Halon DA, Peled N. Advantages of multidetector computed tomography angiography in the evaluation of patients with chest pain. Coron Artery Dis. 2006;17:107-13.

469. Hoffmann A, Pena A, Abbara S. MDCT in early triage of patients with acute chest pain - meeting abstract, SSG08-06. In: Proceedings of the RSNA 2005; 2005.

470. Savino G, Herzog C, Costello P, Schoepf UJ. 64 slice cardiovascular CT in the emergency department: concepts and first experiences. Radiol Med (Torino). 2006;111:481-96.

471. Cademartiri F, Mollet N, Nieman K, Szili-Torok T, de Feyter PJ. Images in cardiovascular medicine. Right coronary artery arising from the 
left circumflex demonstrated with multislice computed tomography. Circulation. 2004;109:e185-6.

472. Horisaki T, Yamashita T, Yokoyama H, Urasawa K, Kitabatake A. Three-dimensional reconstruction of computed tomographic images of anomalous origin of the left main coronary artery from the pulmonary trunk in an adult. Am J Cardiol. 2003;92:898-9.

473. Reant P, Brunot S, Lafitte S, Serri K, Leroux L, Corneloup O, Iriart $X$, Coste P, Dos Santos P, Roudaut R, Laurent F. Predictive Value of Noninvasive Coronary Angiography With Multidetector Computed Tomography to Detect Significant Coronary Stenosis Before Valve Surgery. Am J Cardiol. 2006;97:1506-1510.

474. Kanamaru H, Sato Y, Takayama T, Ayusawa M, Karasawa K, Sumitomo N, Harada K. Assessment of coronary artery abnormalities by multislice spiral computed tomography in adolescents and young adults with Kawasaki disease. Am J Cardiol. 2005;95:522-5.

475. Schroeder S, Kopp AF, Baumbach A, Meisner C, Kuettner A, Georg C, Ohnesorge B, Herdeg C, Claussen CD, Karsch KR. Noninvasive detection and evaluation of atherosclerotic coronary plaques with multislice computed tomography. J Am Coll Cardiol. 2001;37:1430-5.

476. Achenbach S, Moselewski F, Ropers D, Ferencik M, Hoffmann U, MacNeill B, Pohle K, Baum U, Anders K, Jang IK, Daniel WG, Brady TJ. Detection of calcified and noncalcified coronary atherosclerotic plaque by contrast-enhanced, submillimeter multidetector spiral computed tomography: a segment-based comparison with intravascular ultrasound. Circulation. 2004;109:14-7.

477. Leber AW, Knez A, Becker A, Becker C, von Ziegler F, Nikolaou K, Rist C, Reiser M, White C, Steinbeck G, Boekstegers P. Accuracy of multidetector spiral computed tomography in identifying and differentiating the composition of coronary atherosclerotic plaques: a comparative study with intracoronary ultrasound. J Am Coll Cardiol. 2004;43:1241-7.

478. Achenbach S, Ropers D, Hoffmann U, MacNeill B, Baum U, Pohle K, Brady TJ, Pomerantsev E, Ludwig J, Flachskampf FA, Wicky S, Jang IK, Daniel WG. Assessment of coronary remodeling in stenotic and nonstenotic coronary atherosclerotic lesions by multidetector spiral computed tomography. J Am Coll Cardiol. 2004;43:842-7.
479. Gotway MB, Dawn SK. Thoracic aorta imaging with multisclice CT. Radiol Clin North Am. 2003;41:521-43.

480. Lawler LP, Fishman EK. Multidetector row computed tomography of the aorta and peripheral arteries. Cardiol Clin. 2003;21:607-29.

481. Gottschalk A, Stein PD, Goodman LR, Sostman HD. Overview of Prospective Investigation of Pulmonary Embolism Diagnosis II. Semin Nucl Med. 2002;32:173-82.

482. Siegel MD. Multidetector-row computed tomography in suspected pulmonary embolism. N Eng/ J Med. 2005;353:630-1; author reply 630-1.

483. Takahashi K, Stanford W. Multidetector CT of the thoracic aorta. Int J Cardiovasc Imaging. 2005;21:141-53.

484. Perrier A, Roy PM, Sanchez O, Le Gal G, Meyer G, Gourdier AL, Furber A, Revel MP, Howarth N, Davido A, Bounameaux H. Multidetector-row computed tomography in suspected pulmonary embolism. N Eng/ J Med. 2005;352:1760-8.

485. Jongbloed MR, Dirksen MS, Bax JJ, Boersma E, Geleijns K, Lamb HJ, van der Wall EE, de Roos A, Schalij MJ. Atrial fibrillation: multi-detector row CT of pulmonary vein anatomy prior to radiofrequency catheter ablation--initial experience. Radiology. 2005;234:702-9.

486. Centonze M, Del Greco M, Nollo G, Ravelli F, Marini M, Della Sala SW, Dalla Palma F. The role of multidetector CT in the evaluation of the left atrium and pulmonary veins anatomy before and after radio-frequency catheter ablation for atrial fibrillation. Preliminary results and work in progress. Technical note. Radiol Med (Torino). 2005;110:52-60.

487. Koelemay MJ, Nederkoorn PJ, Reitsma JB, Majoie CB. Systematic review of computed tomographic angiography for assessment of carotid artery disease. Stroke. 2004;35:2306-12.

488. Cademartiri F, Raaijmakers RH, Kuiper JW, van Dijk LC, Pattynama PM, Krestin GP. Multi-detector row CT angiography in patients with abdominal angina. Radiographics. 2004;24:969-84.

489. Weise WJ, Jaffrey JB. Review: CT angiography and magnetic resonance imaging are the best less-invasive tests for renal artery stenosis. ACP J Club. 2002;136:69. 